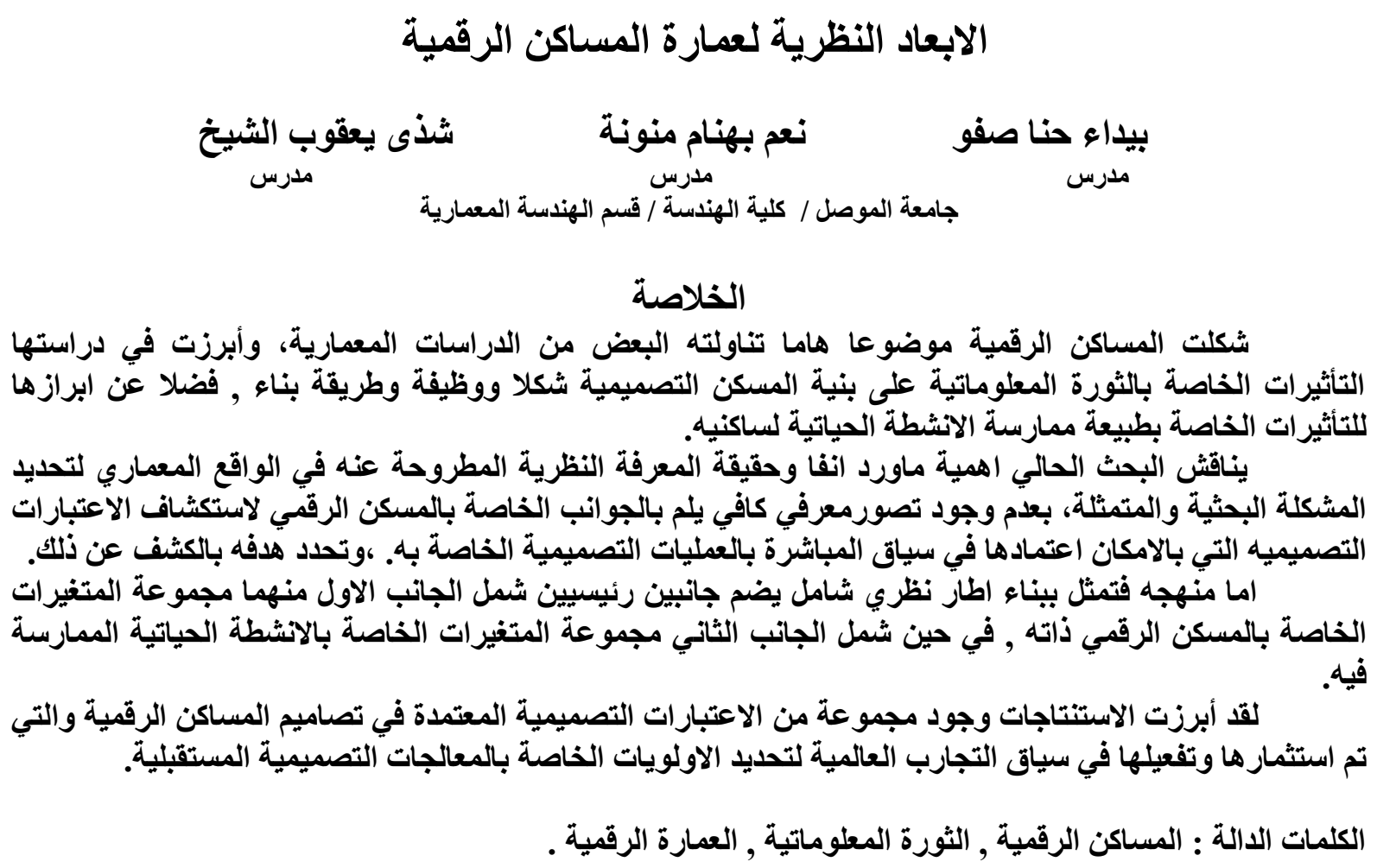

\title{
Theoretical Dimensions Of Digital Houses Architecture
}

\author{
Bayda H. Saffo Niam B. Manona Shatha Y. El - Sheikh \\ Lecturer \\ Lecturer \\ Lecturer
}

College of Engineering / dept. of Architecture

\begin{abstract}
Digital houses have formed an important subject, examined by several architectural studies, which have declared the special effects of the information technology revolution on houses design, especially,its form,function and construction, as well as , special effects on the human activities being practiced in.

This paper has discussed the importance of this subject and its theoretical knowledge, in order to determine the research problem, represented by the ambiguous knowledge in the different aspects of digital houses design, in order to explore design considerations in its design, thus its objective has determined by revealing this and its approach has presented by building up a theoretical framework includes two main aspects, the first includes variables concerning the digital house design, whereas the second, includes variables concerning human activities.

Conclusions have shown different design considerations which have been employed in digital houses designs of the international experiences, as well as determining the priorities of future design treatments .
\end{abstract}

Keywords: digital houses, information technology revolution, digital Architecture

$$
\text { قبل: 19-3-2012 }
$$

أستلم: 19-6-2011 


\section{1}

ركزت بعض الادبيات المعمارية على دراسة اثر التطورات الكبيرة في انظمة الحاسب الالي وتقاتقبة انظمة

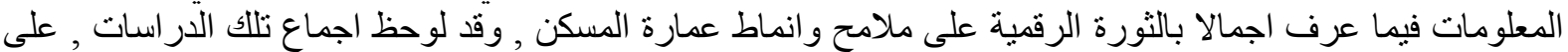

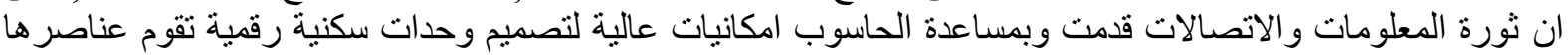

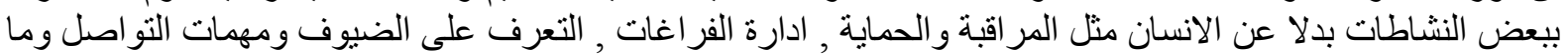
الى ذلك.

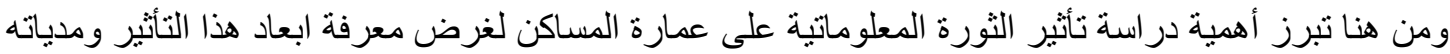

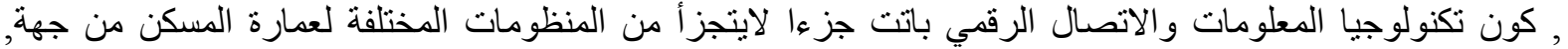

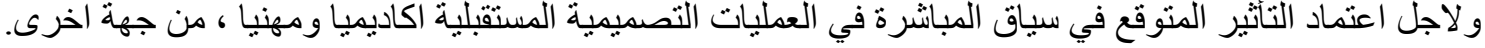

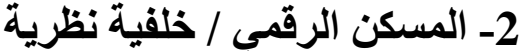

عُرفت العمارة الرقية وفية وفقاً للمعماري (Negroponty) , و والتي ينضوي المسكن الرقمي تحت لو ائها, "بأنها

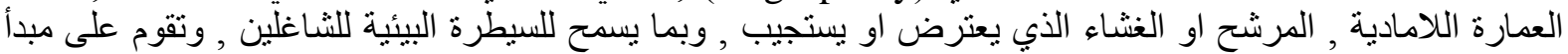

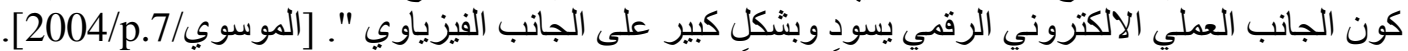

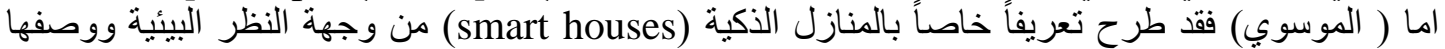

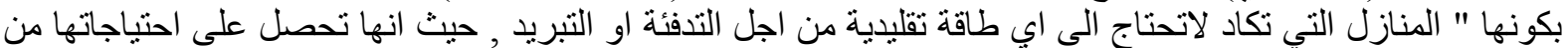
الطاقة ومن ضوء الثمس ومن الارض ومن سكانها وتُشهل اعمال ساكنيها ومنطلبات حياتهم اليومية وحتى في غيابهم".

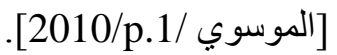

في حين مثل المسكن الرقمي بحسب ( حسن) بانه" المسكن المجهز بطريقة تقنية اكتسب بها القدرة على التفكير

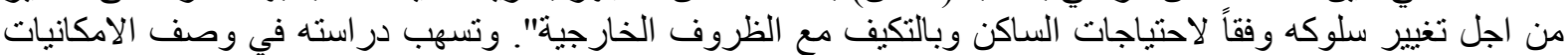

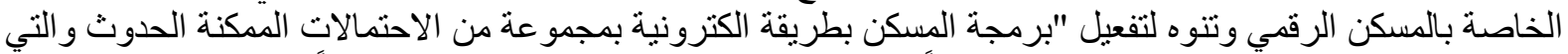

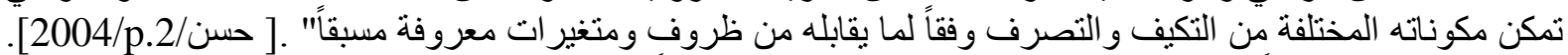

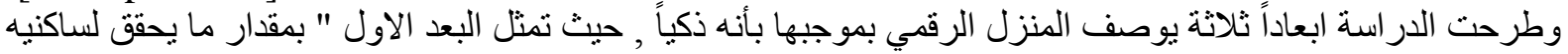

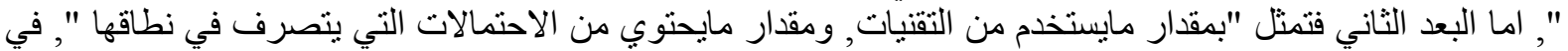
حين تمثل البعد الثالث "باتساع المجال العمر اني الذي يعمل في نطاقه وتعامله مع المكونات الآنات الاخت من من مباني وشبكات

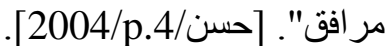
اما بالنسبة لدر اسة (Yeang) فقد وصفت المنزل الرقمي الذكي في ضوء وظة وظائفه التي يقوم بها و التي تشمل "

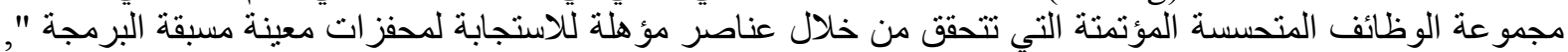

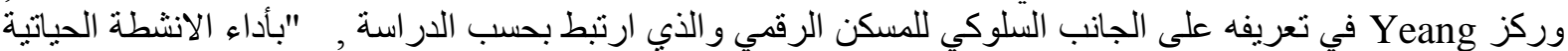

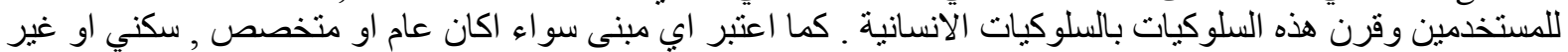

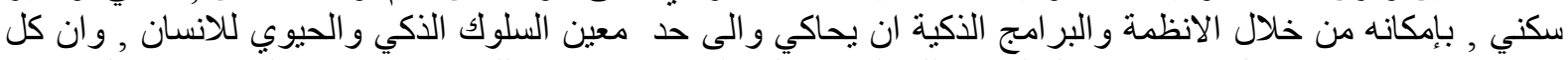

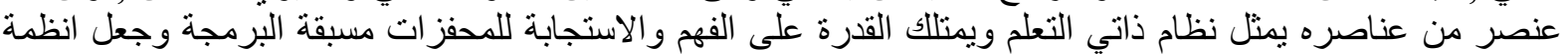

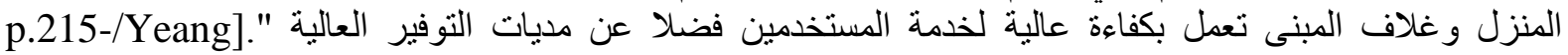

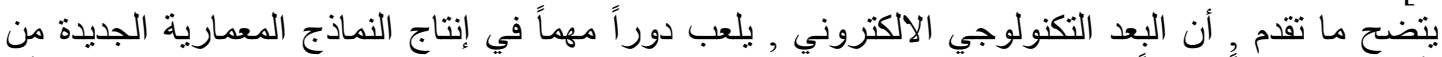

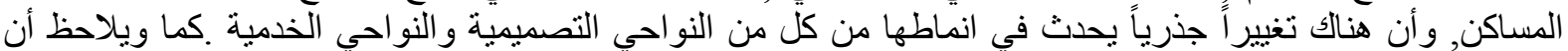

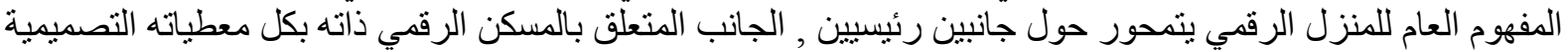

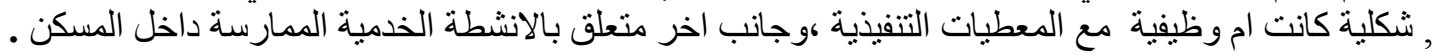

\section{3_المساكن الرقمية في الواقع المعماري}

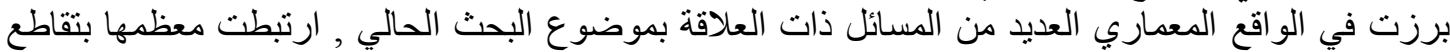
و اختلاف وجهات النظر المتعلقة بأبعاد المنزل الرقمي التصميمية منها و التنفيذية فضلا عن التباين في كيفية ادارة الانشطة الحياتية داخله .

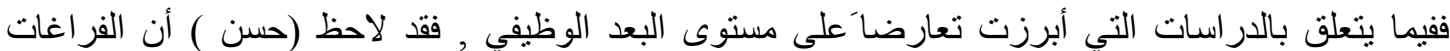

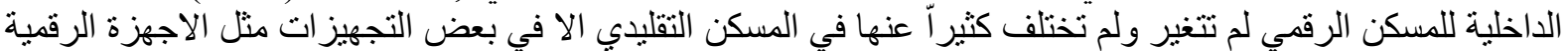

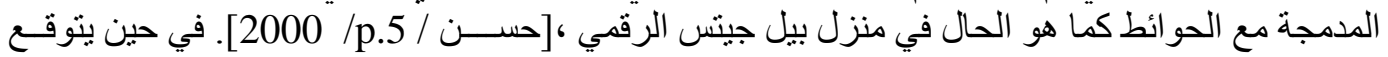




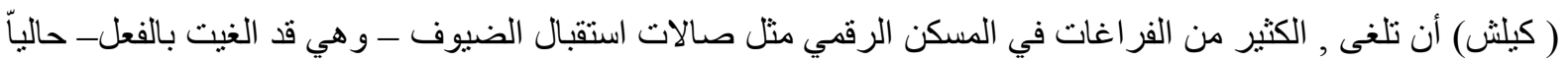

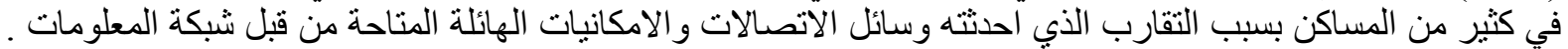

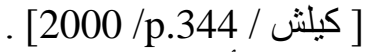

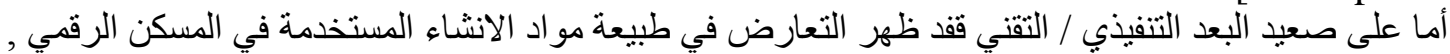

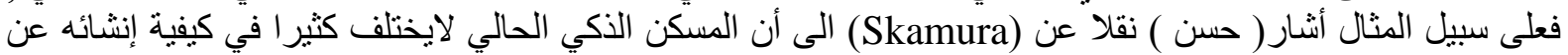

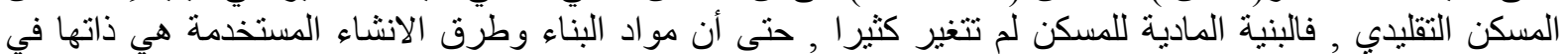

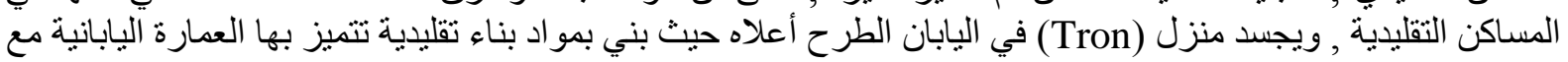

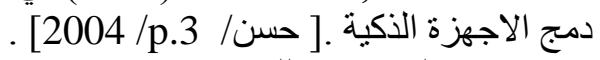
وبالضد من ذللك يؤكد (Riewoldt) على أن انتشار المباني الرقمية بمفهومها الثشامل للتحكم في جميع الانشطة

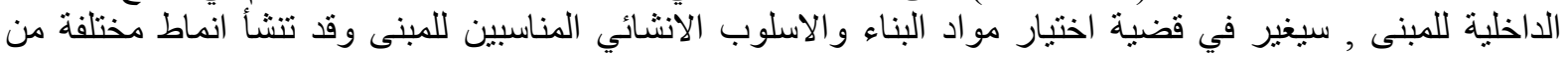

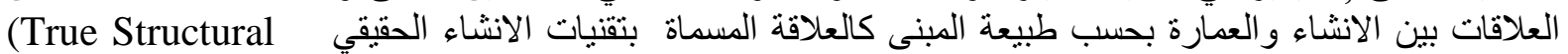
في المنشآت العملاقة والعلاقة المسماة بالانشاء الرمزي ( High-Tech)

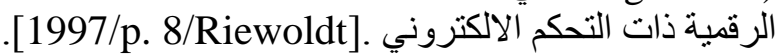

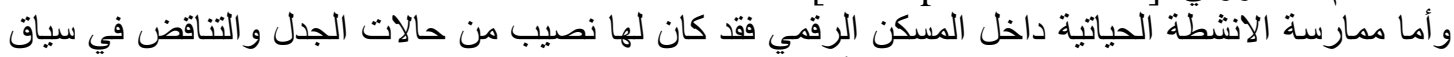

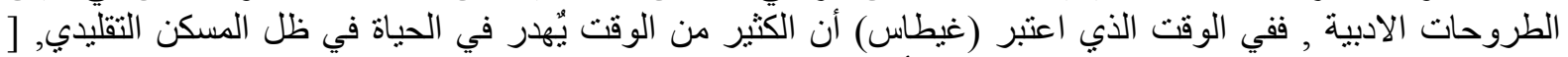

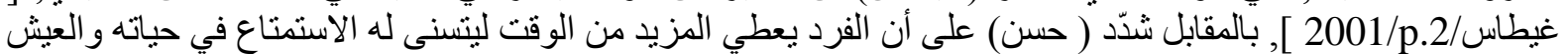

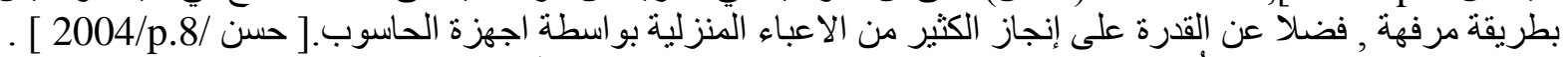

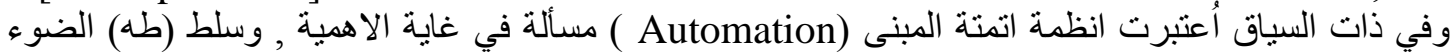

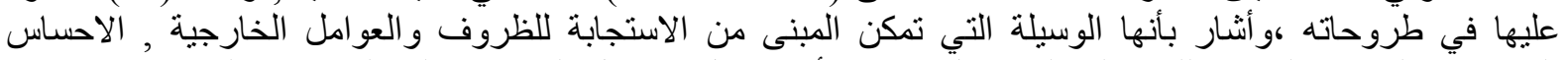

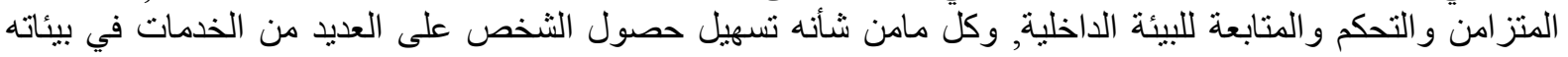

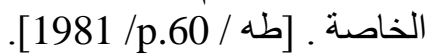

وبالضد من ذللك , لاحظ ( جيتس) أن الاتمتة , على الرغم من ميز اتها الكثيرة من الناحية التقنية وتسهيل الحياة

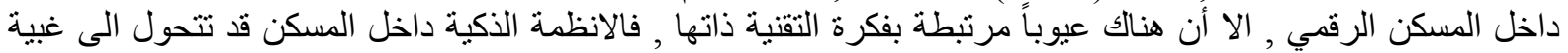

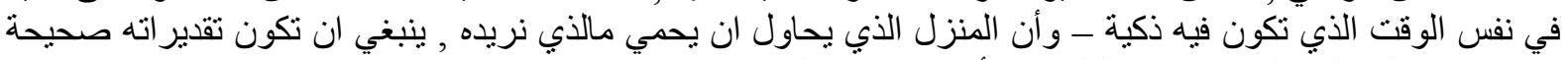

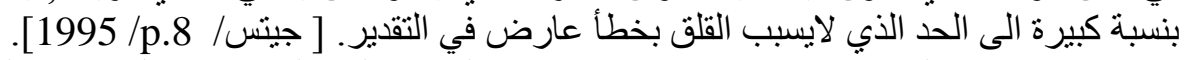

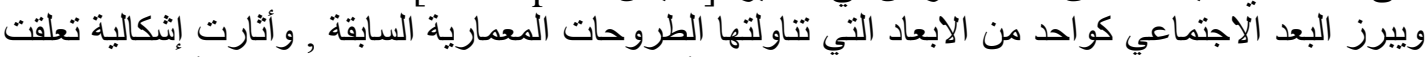

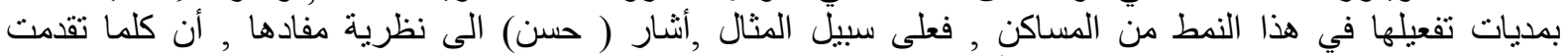

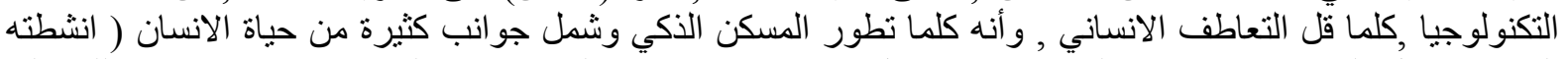

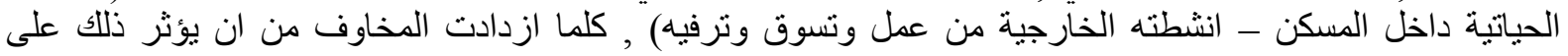

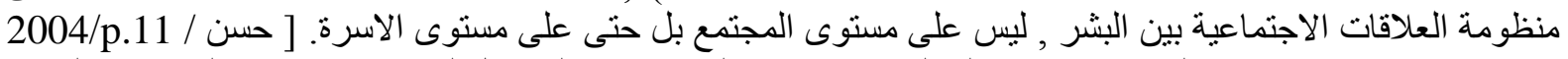

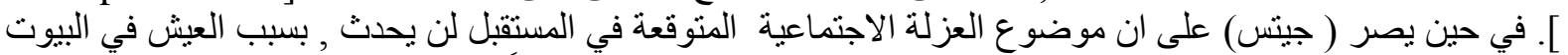

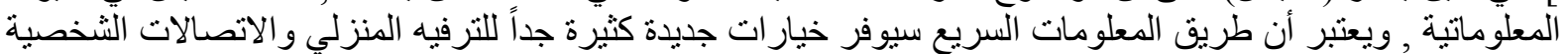

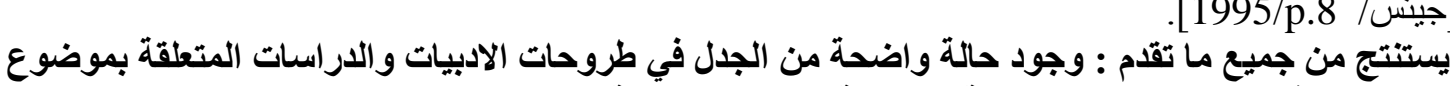

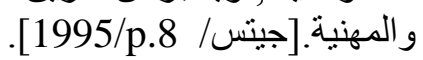

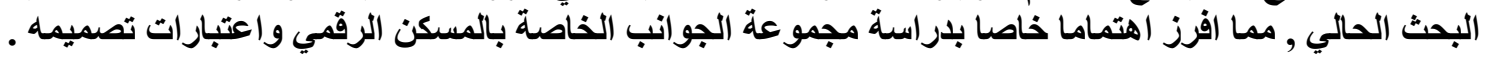

4- المشكلة البحثية / المعرفة العلمية السابقة بالموضوع

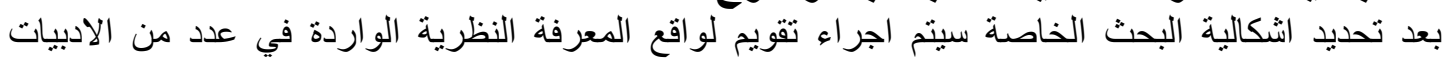

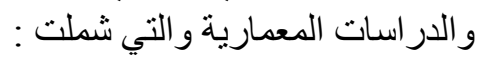

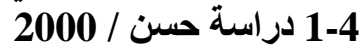

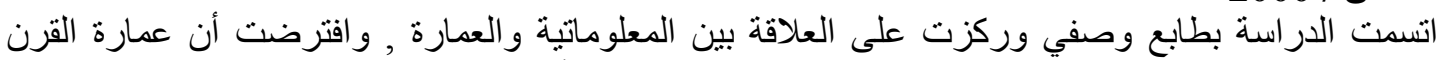

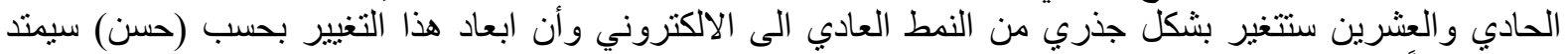

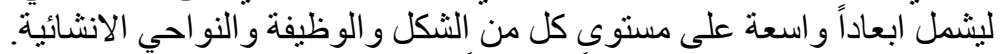

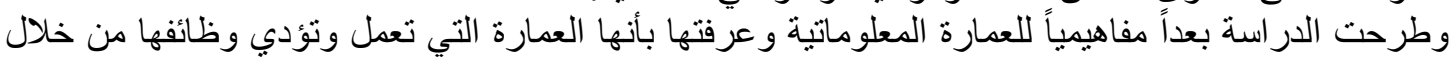

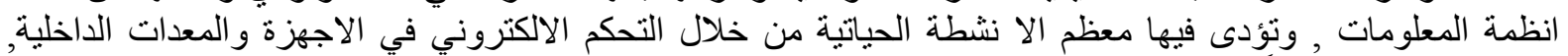

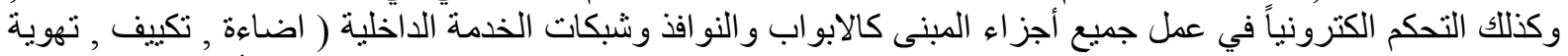

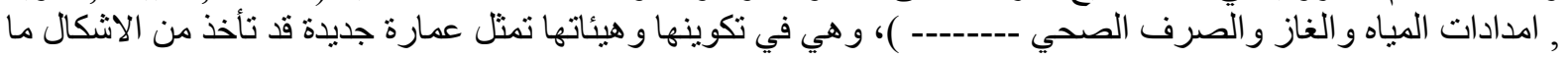


لم يُعهد من قبل وقد تحتوي على وظائف متعددة تحت سقف واحد او تُلغى منها بعض الوظائف كالفر اغات المتعارف عليها

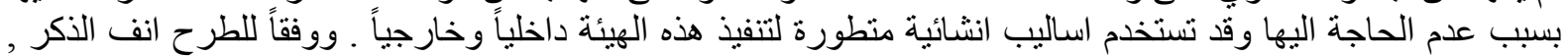

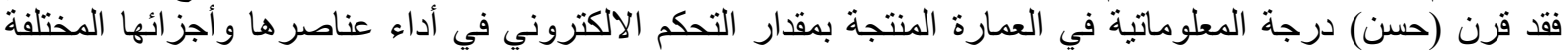
وكذلك بعدد الانشطة الحياتية المؤداة داخلها بطرية العيقة الكترونة النية.

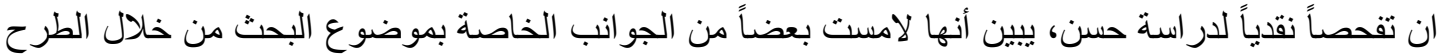

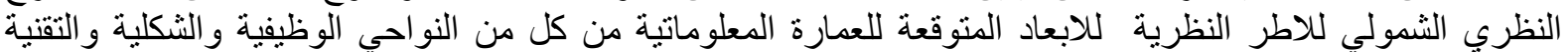

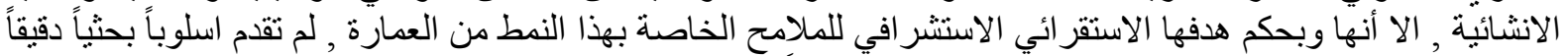

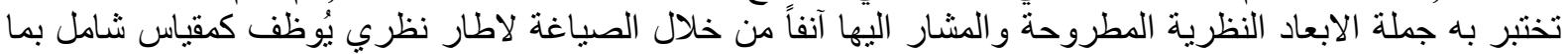

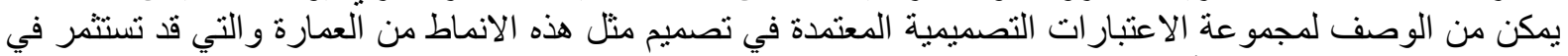

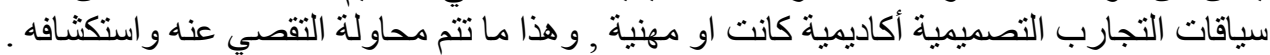

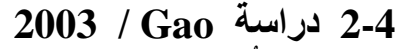

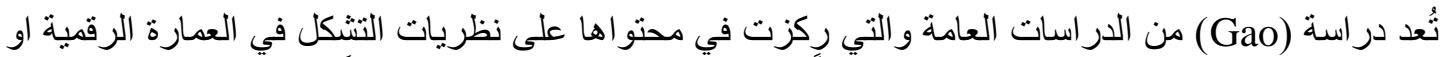

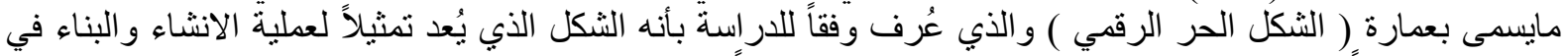

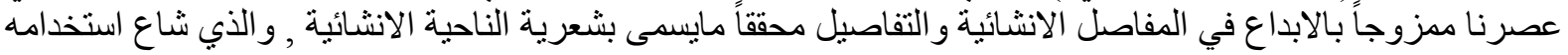

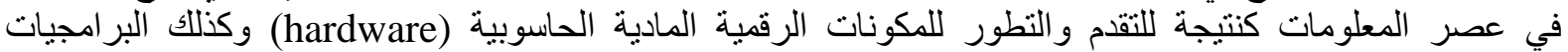

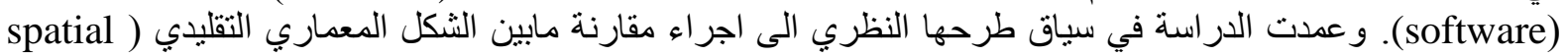

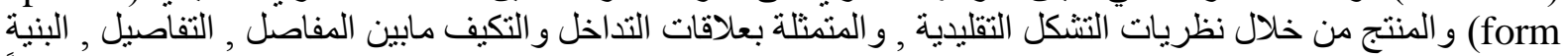

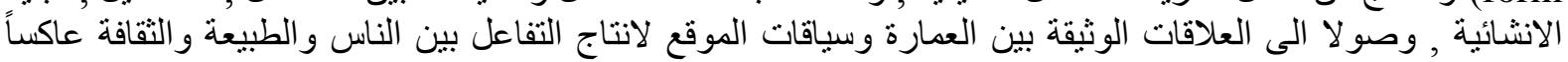

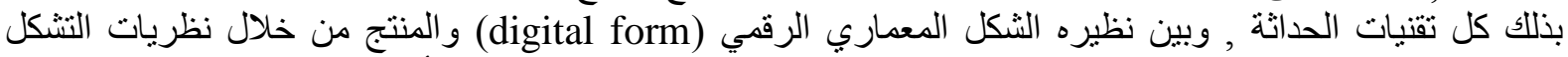

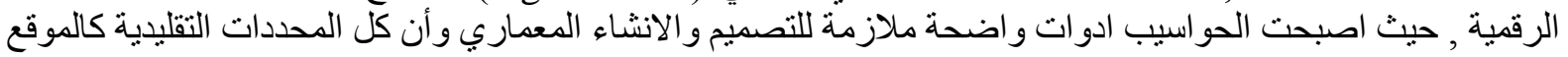

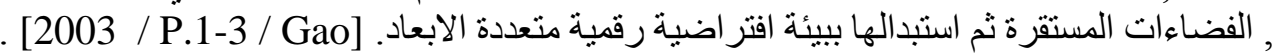

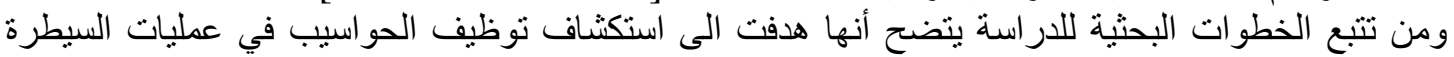

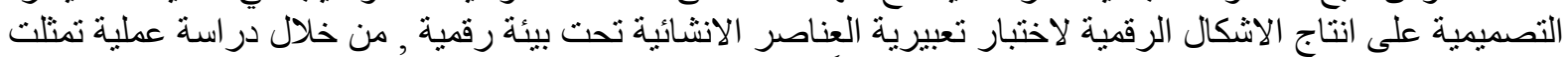

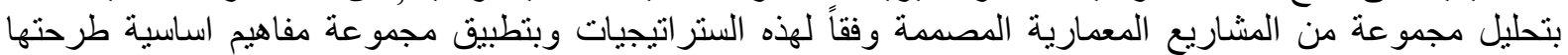

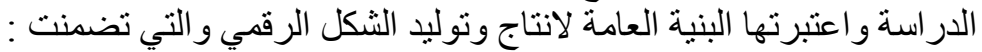

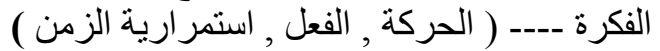

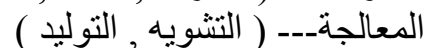

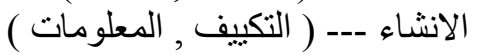

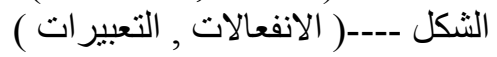
الفضاء ---( التحسس , التفاعل الفضائي )

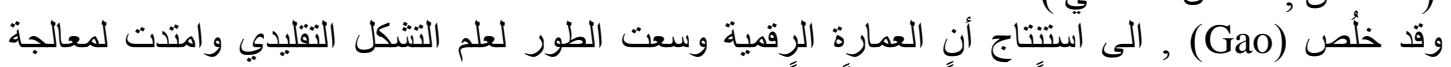

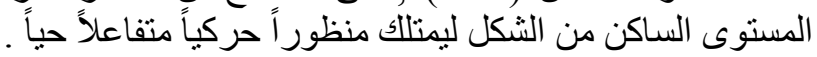

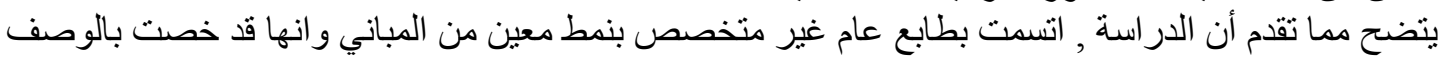

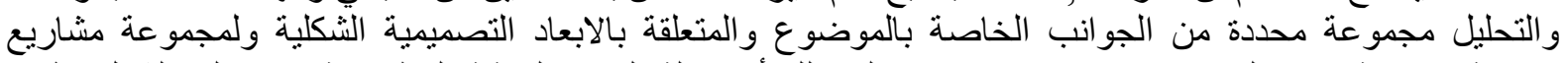

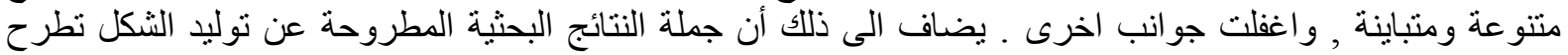
استفسار ات عن امكانية اعتمادها وتعميمها على جميع انماط المباني بما في ذلك مباني السكن , و هذا مايركز عليه البحتي البحث

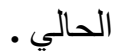

3-4 2004 / 3راسة حسن

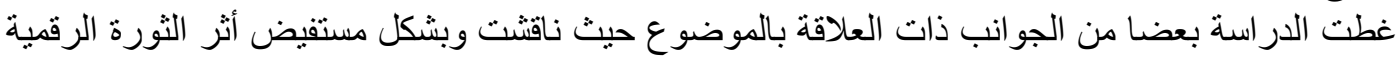

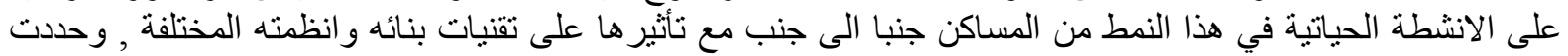

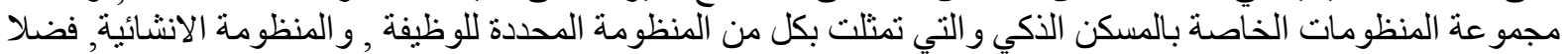

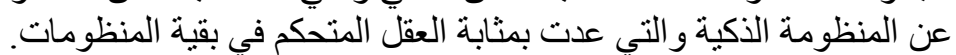

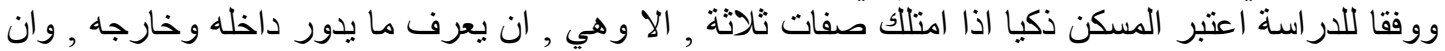

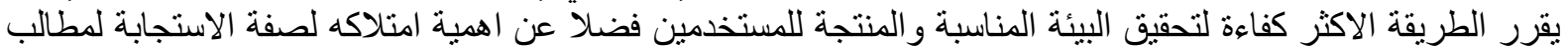

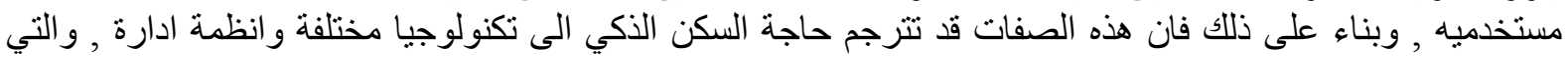
شملت كلا من نظام الاتمتة , لاستجابة المسكن للظروف و العو امل الخارجيةٌ (مناخ , حريق , امن) الاحساس المنز امن - 
تخزين المعلومات لمعرفة اداء المبنى ,كما شملت نظام اتمتة المبنى مع الاتصالات المتقدمة لتحقيق الاتصالات السريعة

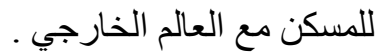

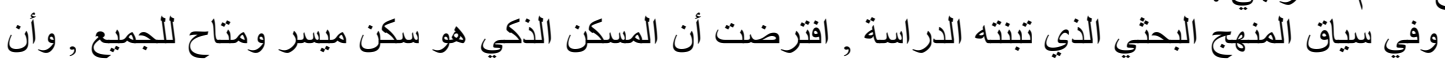

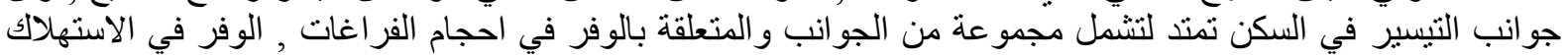

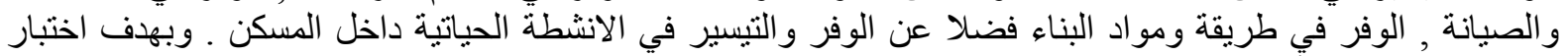

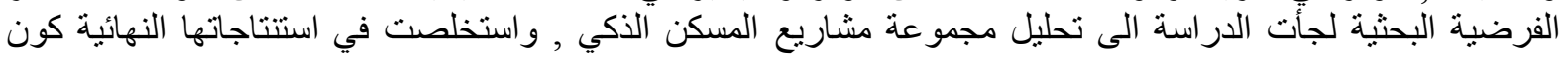

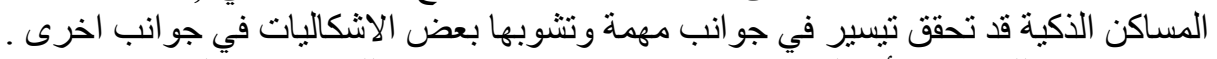

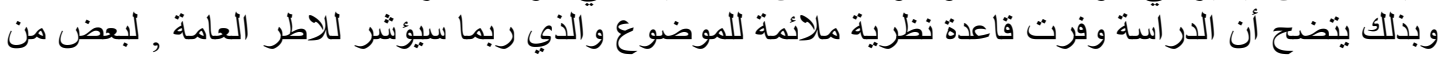

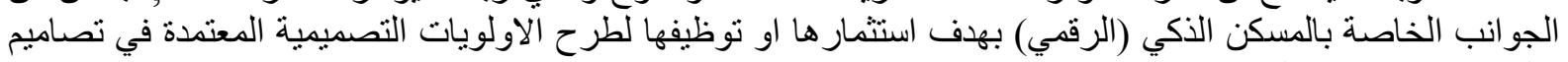

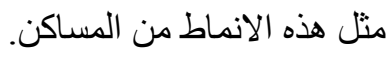

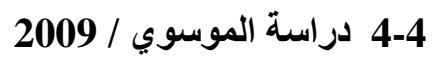

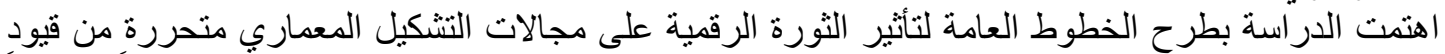

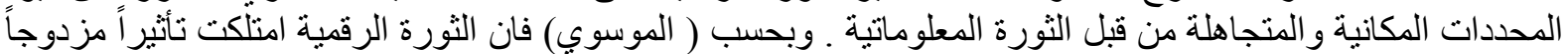

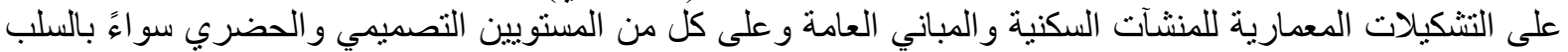

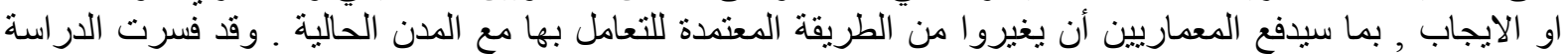

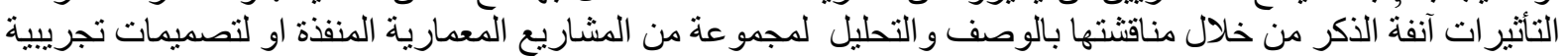

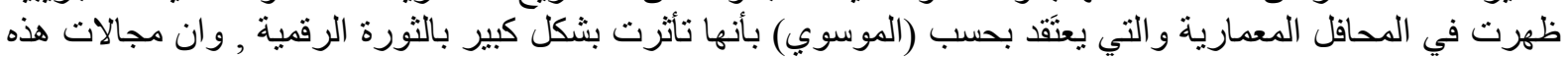

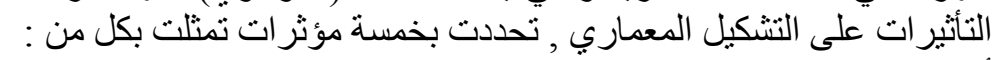

Architectural design elements

Digital architecture with digital elements

Functional requirements

User

Cyberspaces

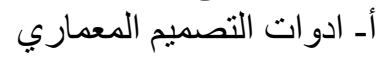

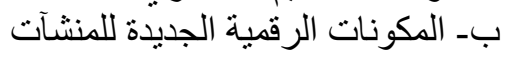
ج- المتطلبات و التحو لات الوظية الجئية

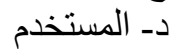
هـ الفر اغات غير المادية

ان قراءة عامة للار اسة تظهر بأنها تبين وتبرز أهمية الموضوع و أنها هيأت اساساً نظرياً يُستند عليه البحث

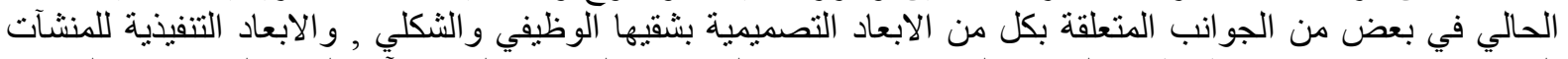

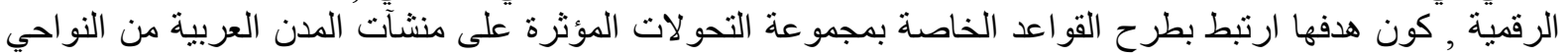

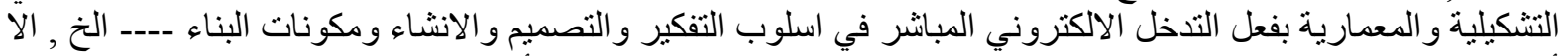

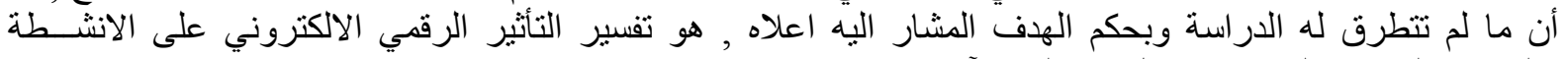

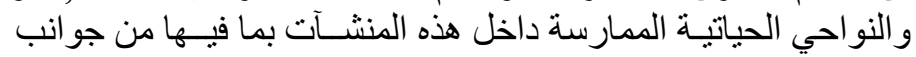

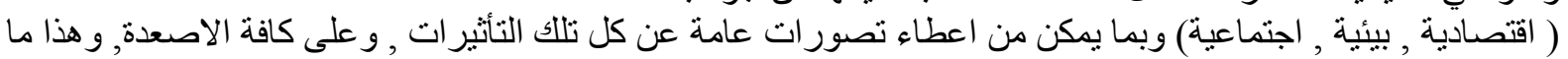

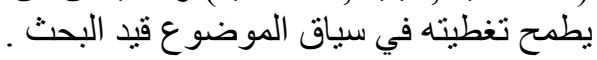

\section{9 /Architectural Design Magazine 5-4 دراسة}

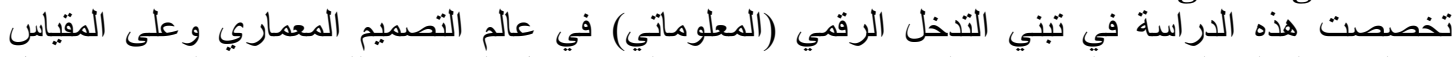

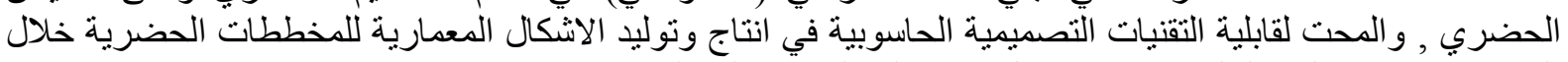

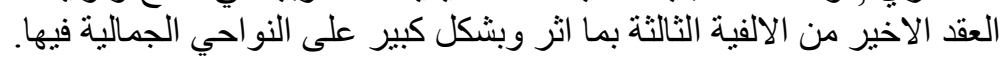

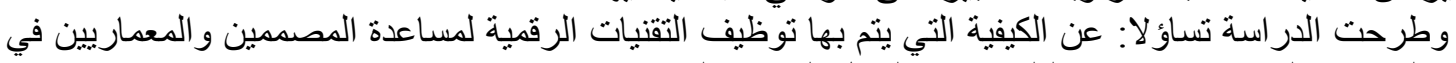

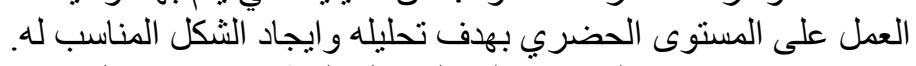

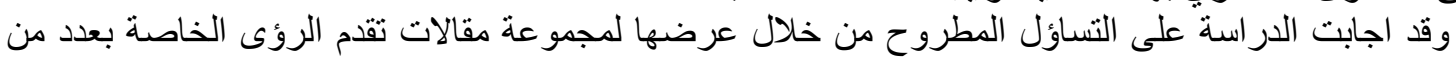

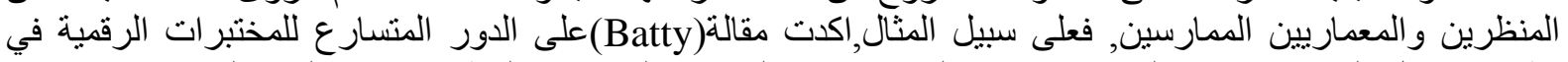

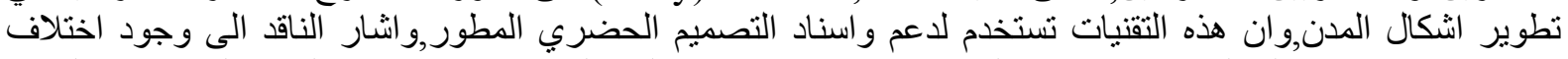

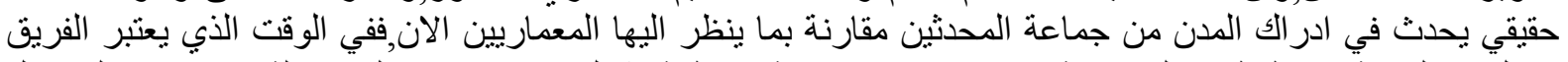

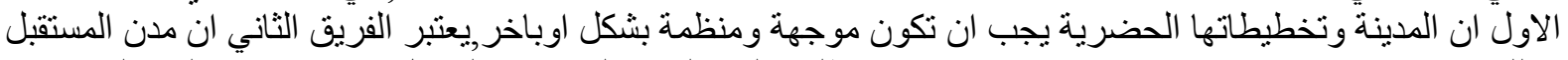

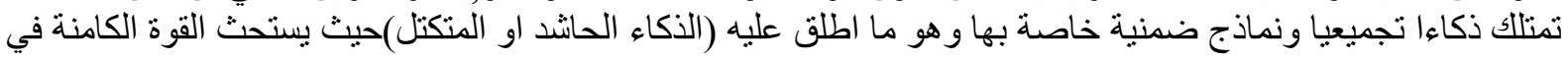


التصاميم الحضرية ويحاكي توظيف المفهوم الخاص بالساق الجذري , لفهم افضل العلاقات بين النسيج الفيزياوي

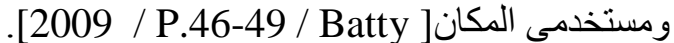

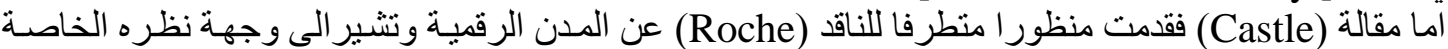

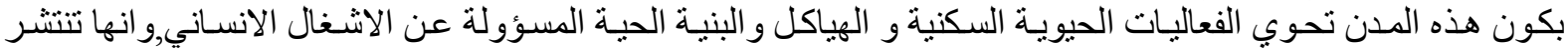

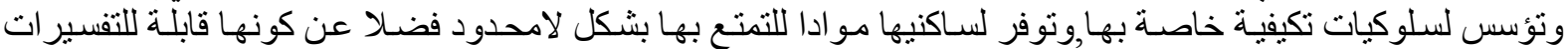

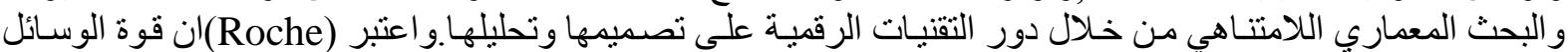

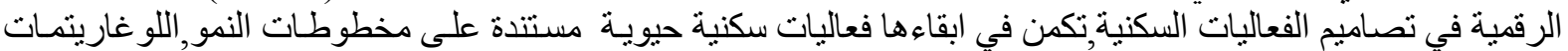

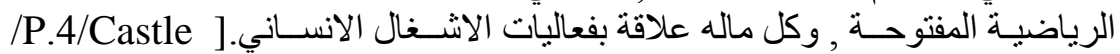
.[2009 / P.40-46/ Roche ],[2009

واخيرا وضح (Derebes) في مقالته (Experiment in Associative) كيف ان فئ المختبرات البحثية

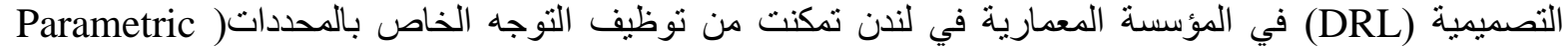
(Approach

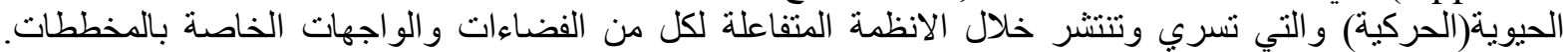
.[2009/ p.25/Verebes]

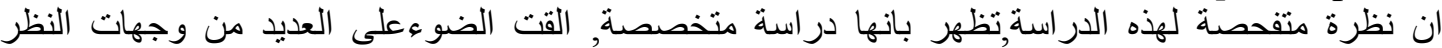

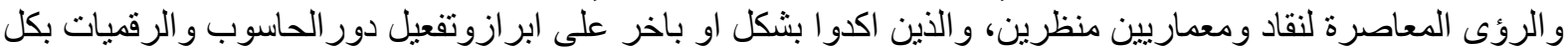

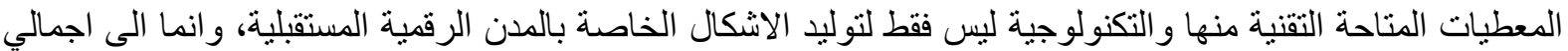

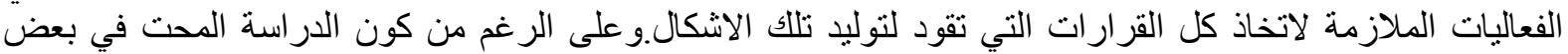

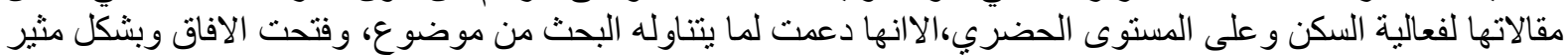

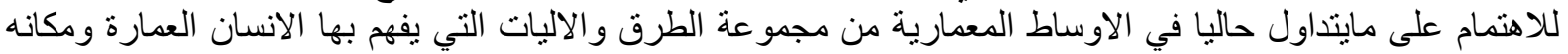

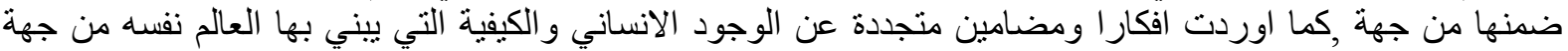
ثانبة.

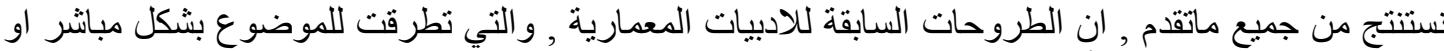

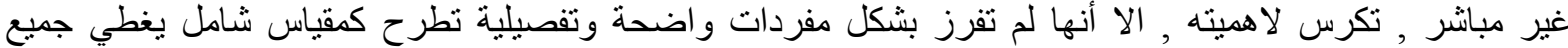

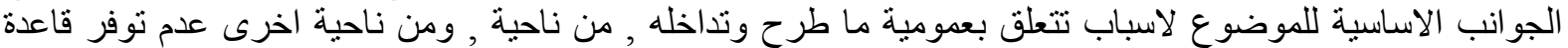

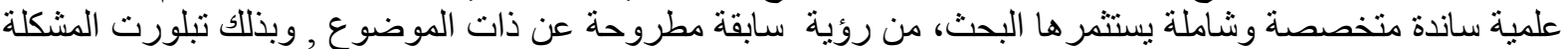

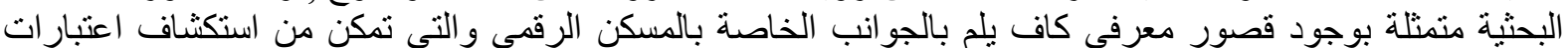

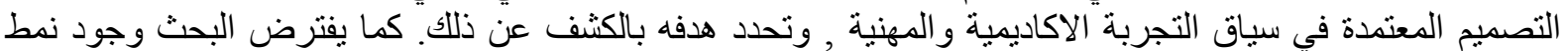

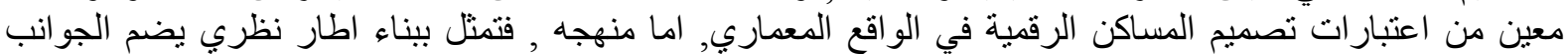

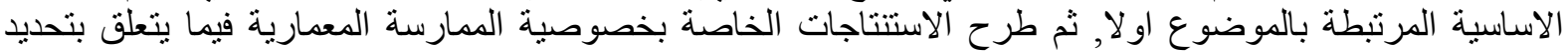
الاعتبار ات التصميمية المعتمدة في تصاميم المساكن الرقمية ، ثانيا.

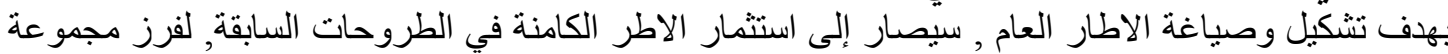

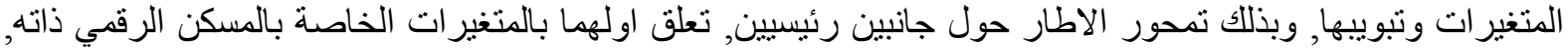

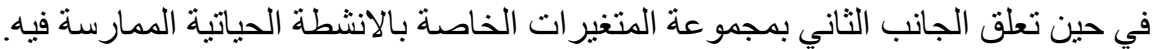

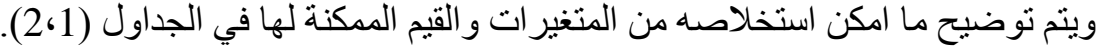

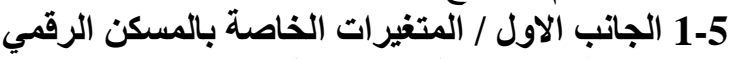

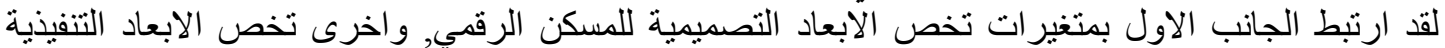
(التقنية) المرتبطة به.

1-1-5 الابعاد التصميمية : وبدور ها تمثلت بمتغير ات شكلية, ومتغير ات وظيفية.

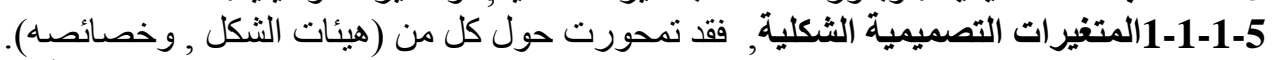

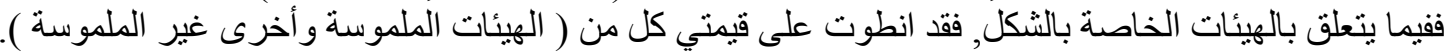

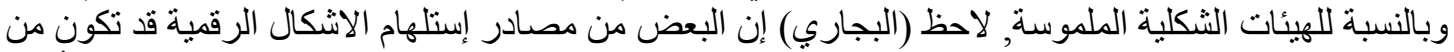

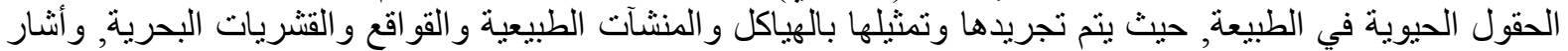

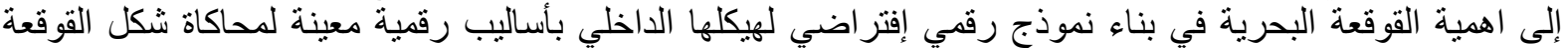
واعتماد النموذج الناتج في العرض البصري لتوليد النكل [البجاري/2007/p.57] ويعرض (Verebes) شكلا رقميا 


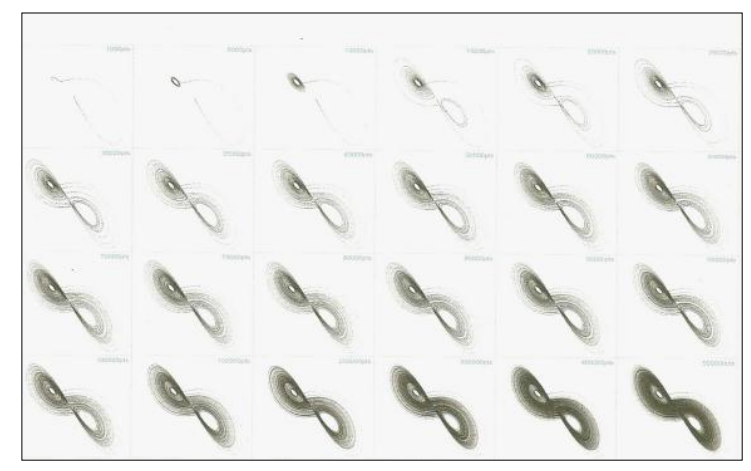

(شكل 1) هيئات طبيعية لتوليد الثكل الرقمي [2009/p.28/Verebes]

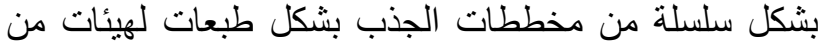

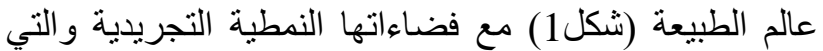

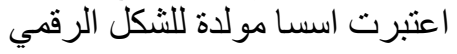

[2009/p.28/Verebes]

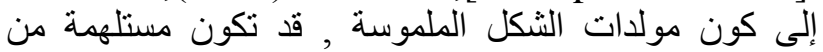

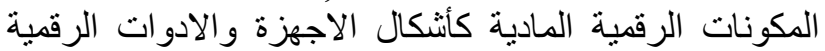

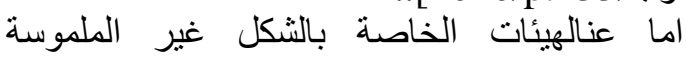

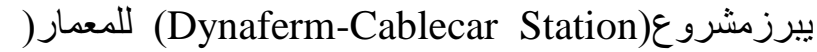

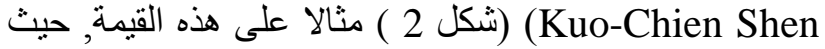

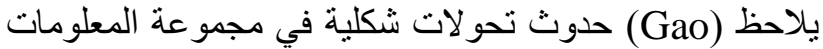

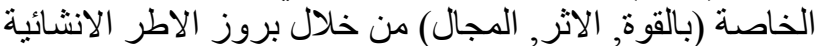

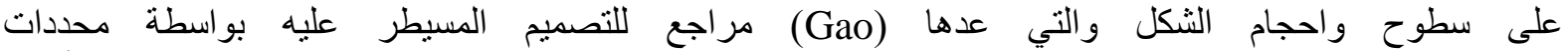

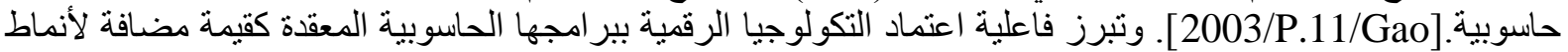

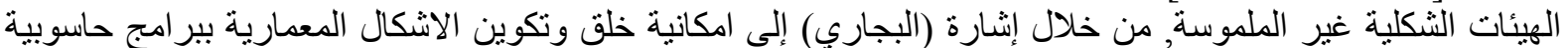

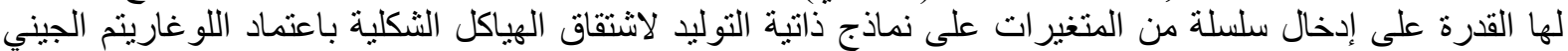

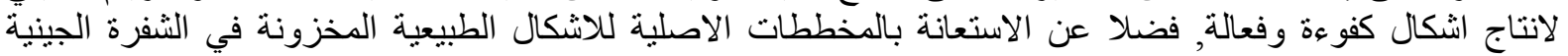

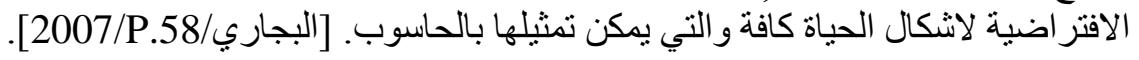

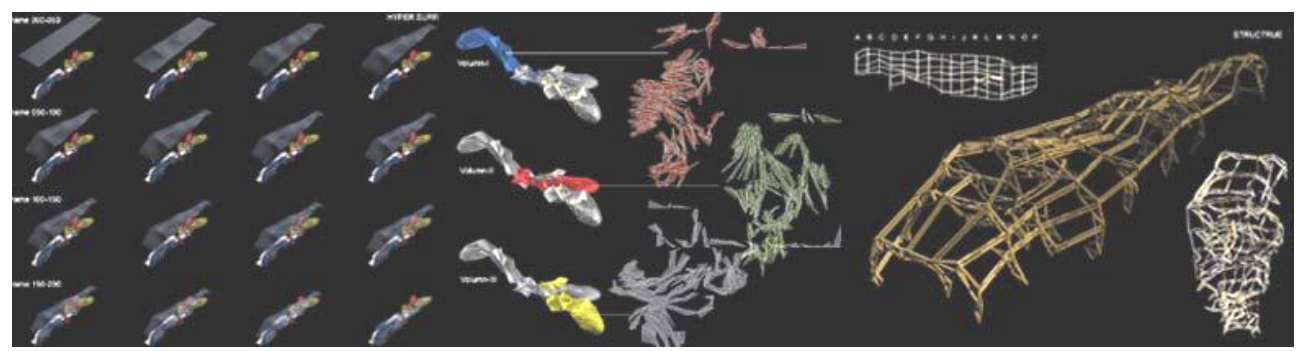

Kuo-Chien Shen للمعمارDynaferm-Cablecar Station شكل 2 ) مشروع (2003/P ) [2003/P.11/Gao]

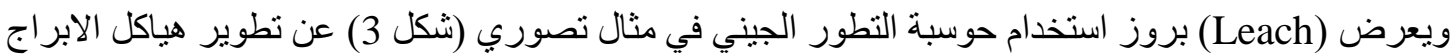

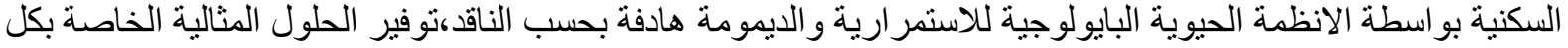

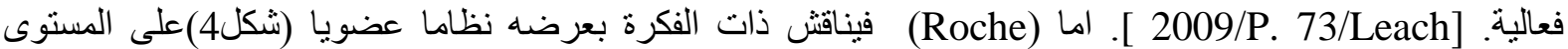

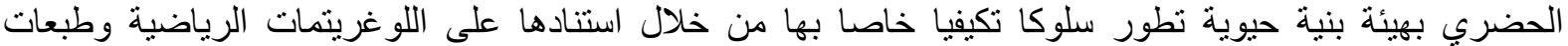
النموو التو الد مستجيبة بذللك للاشغال الانساني. [2009/P. 46/Roche].

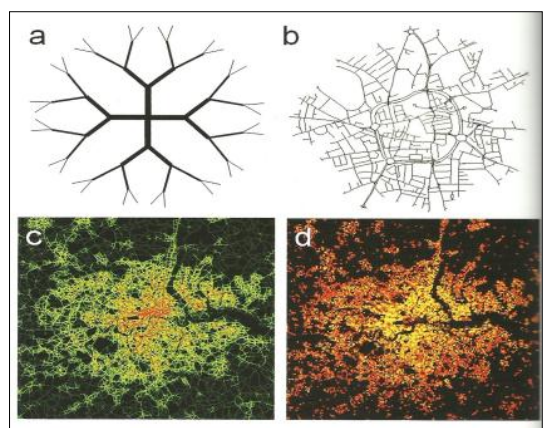

(شكل 4) توظيف طبعات النمو و التو الد الد

لاشتقاق الثكل الرقمي[تصفي]

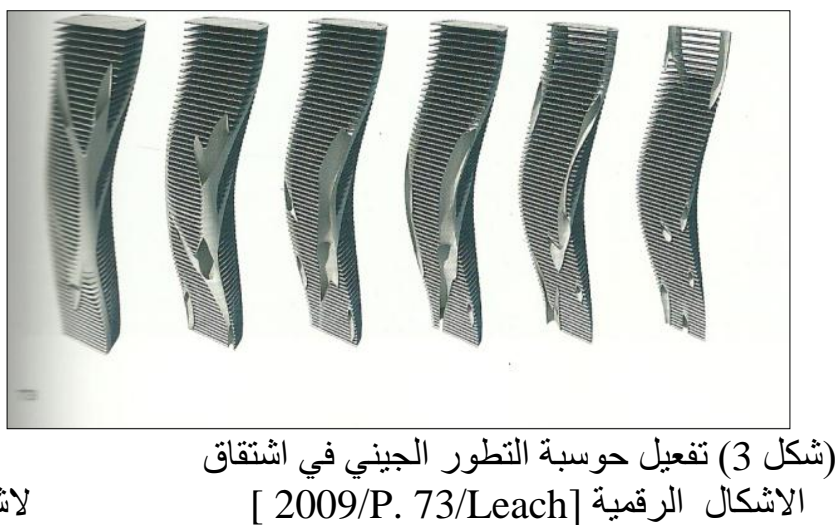

الاشكال الرقمية [2009/P. 73/Leach] 


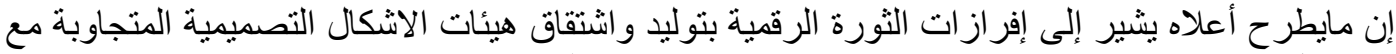

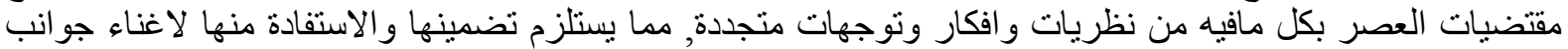
رئيسية تخص موضوع البحث.

اما الخصائص الخاصة بالشكل, فقد تضمنت قيمتين ثانويتين تمثلتا بكل من التحو لات الثكات الثلية وصفات الثكل.

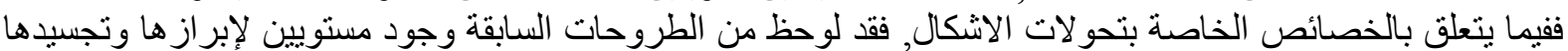

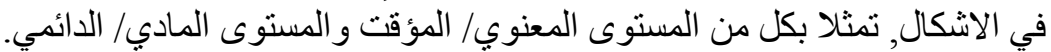

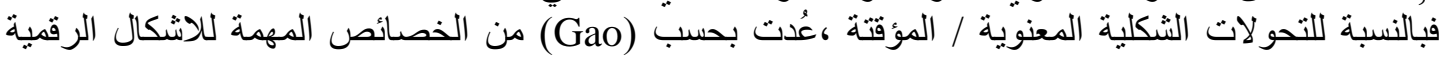

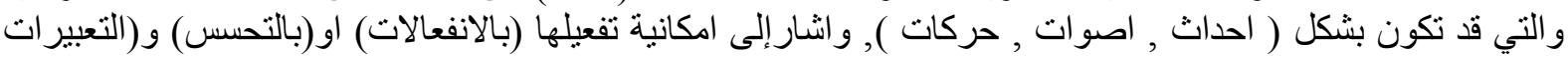

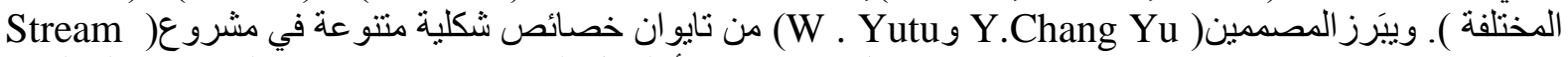

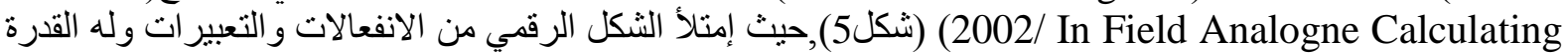

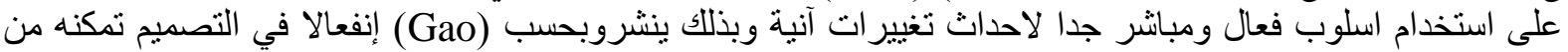
التعبير عن نفسه فالمشروع يحاول خلق نموذج لحركة انسباب او تدفق جزئي في تصميم الثنكل , وبالتالي التعبير عن فئن

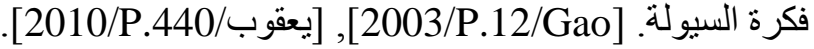

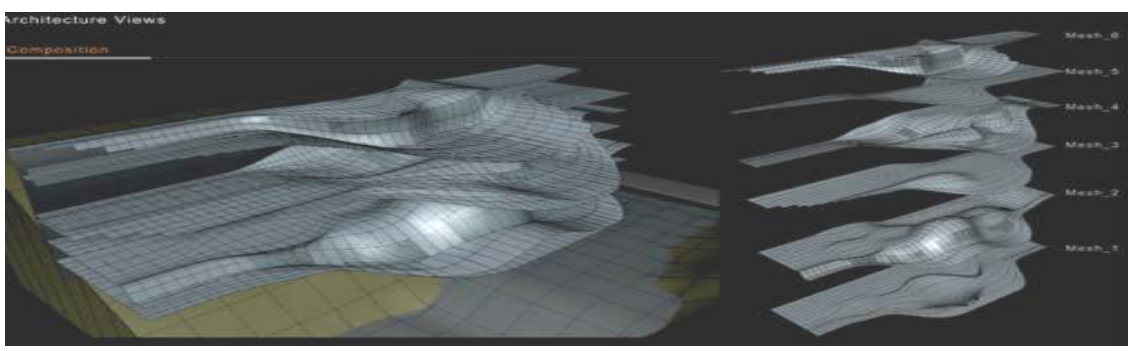

Stream In Field Analogne Calculatin شكل 5 ) مشروع) [2003/P.12/Gao]

كما ويقترح (Verebes) مثالا عده (مثاليا) بهيئة اشكال متلاحمة,متضامة ( شكل 6) و والمستندة على قاعدة

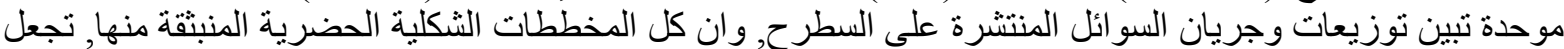

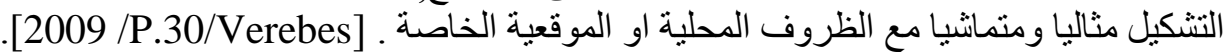

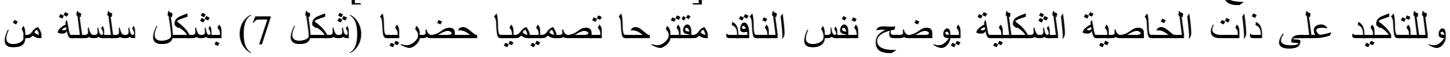

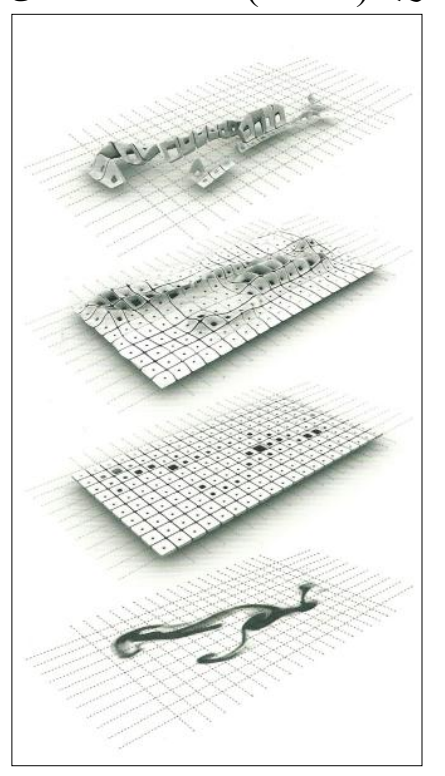

(شكل 7) مخططات رقمية منبنقة من محاكاة السائل [2009/P.26/Verebes]

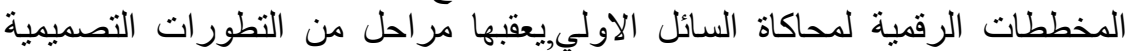

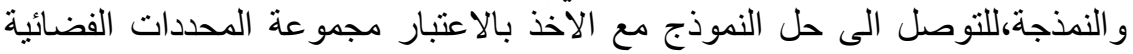
الانشائية و الحركية. [2009/P.26/Verebes/

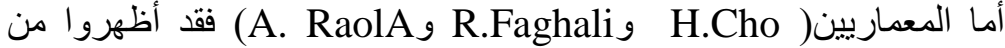

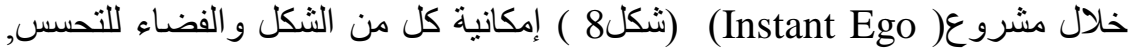

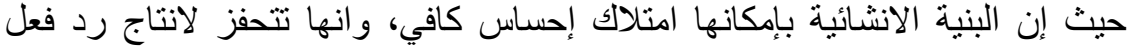

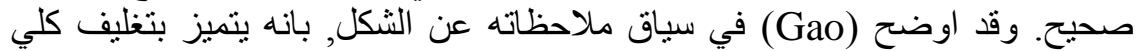

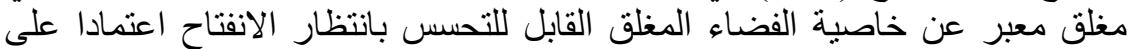

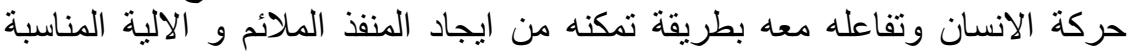

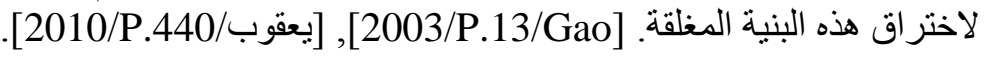

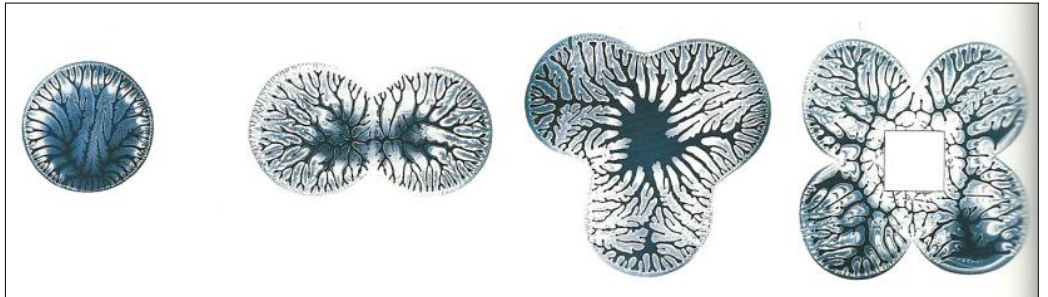

(شكل 6) مخططات شكلية منبثقة من نوزيع وجريان السو ائل المنتشرة على [2009/ P.30/Verebes] 


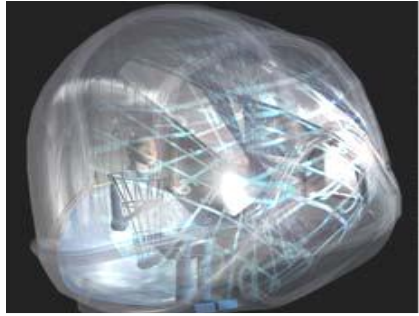

Instant Ego مشروع 8) مشرع) [2003/P.13/Gao]

وتدرج ذات الدراسة مشروعا تصميميا للمعماريين Decoi 2001/ HYPO- SURFAC) (AEGISE الا وهو مشرو دات

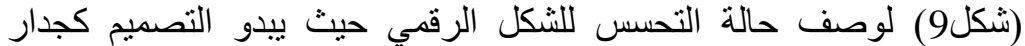
حساس بإمكانه ان بعكس معلومات عن البيئة المحيطة لتغيير تعبيرية السطوح. ]2003/P.13/Gao]

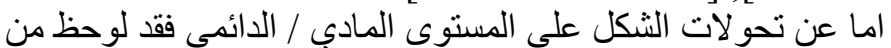

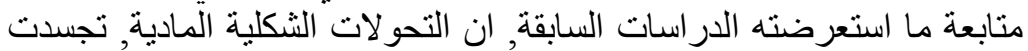

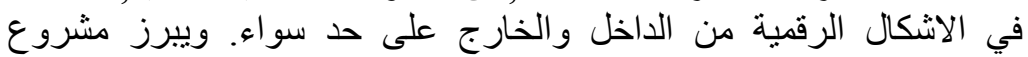

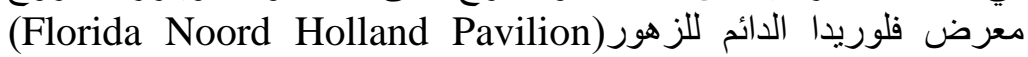

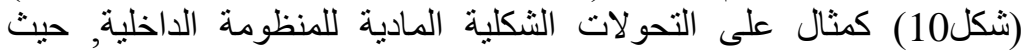

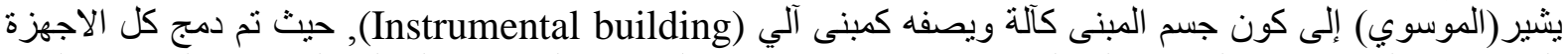

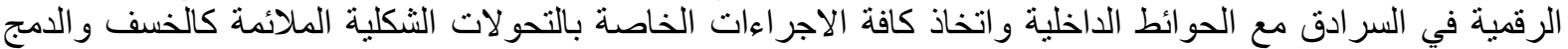

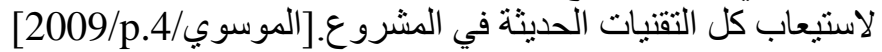

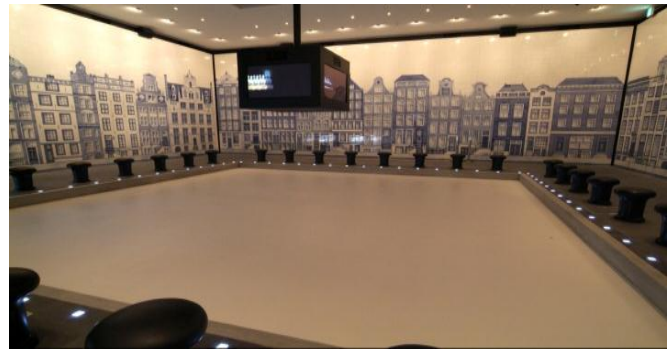

( شكل10) الجناح الهولندي الدائم في فلوريد

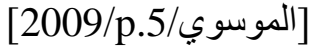

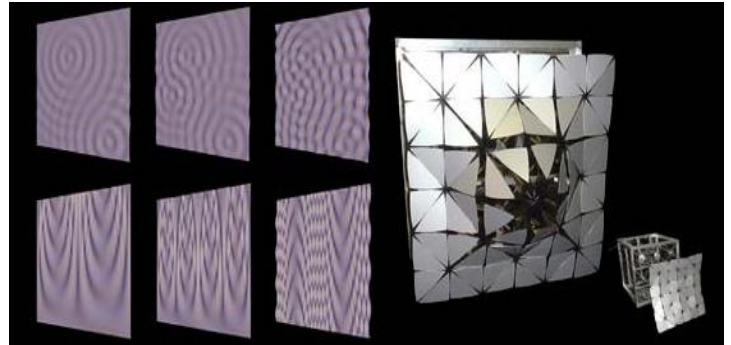

AEGIS HYPO- SURFAC شكل9) مشروع) [2003/P.11/Gao]

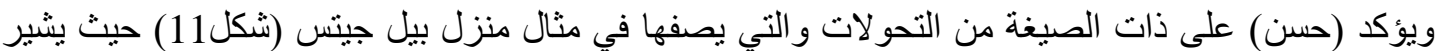

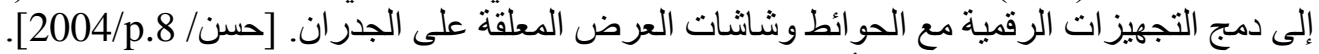

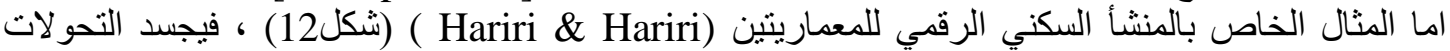

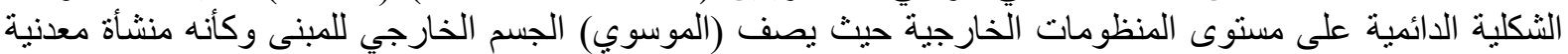

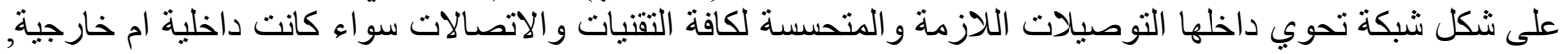
كما إن الهيكل المعدني مغلف بشاثنات من زجاج الكرستال السائل لاستعمالات متعددة ومتنو عة. [الموسوي/2009/p.5].

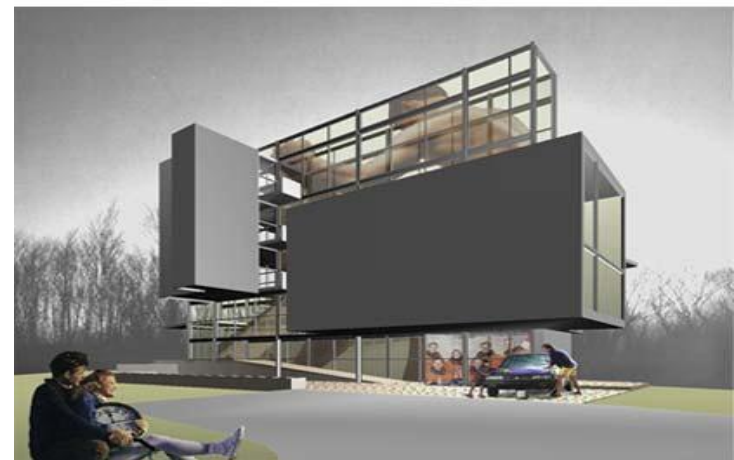

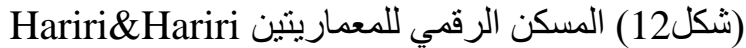

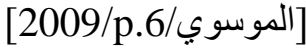

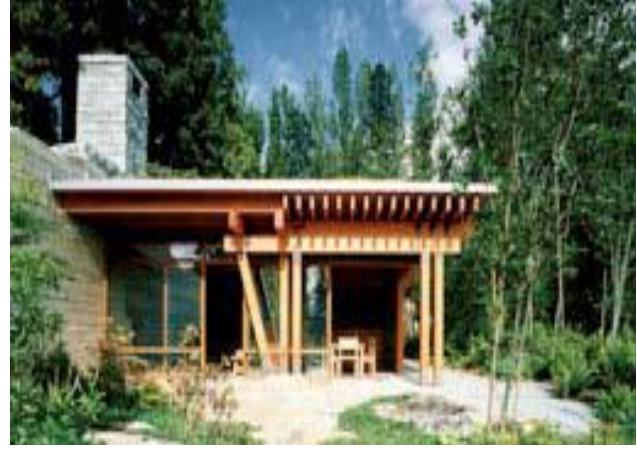

$$
\begin{aligned}
& \text { (شكل 11) منزل بيل جيتس الرقمي } \\
& \text { [2004/p. 9سن آ }
\end{aligned}
$$

وبالنسبة لصفات الاشكال كواحدة من القيم الثانوية الخاصة بخصائصها, فقد أظهرت الدراسات السابقة بروزها على مستوى كل من العناصر و العلاقات الثكلية. 
ففيما يتعلق بصفات الاشكال على مستوى العناصر فقد لاحظ (الموسوي) بأن الاعتمـاد على عناصـر التكنولوجيا

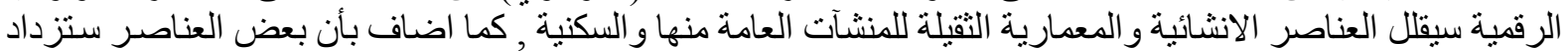

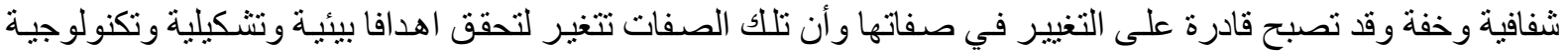

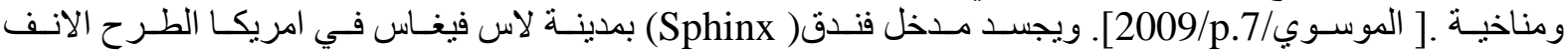

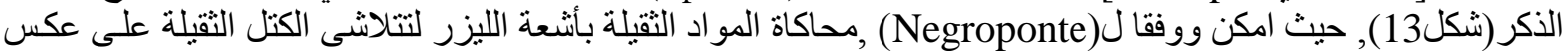

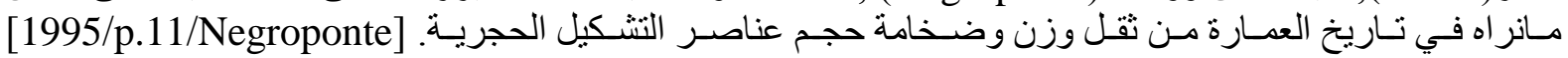

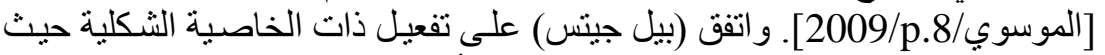

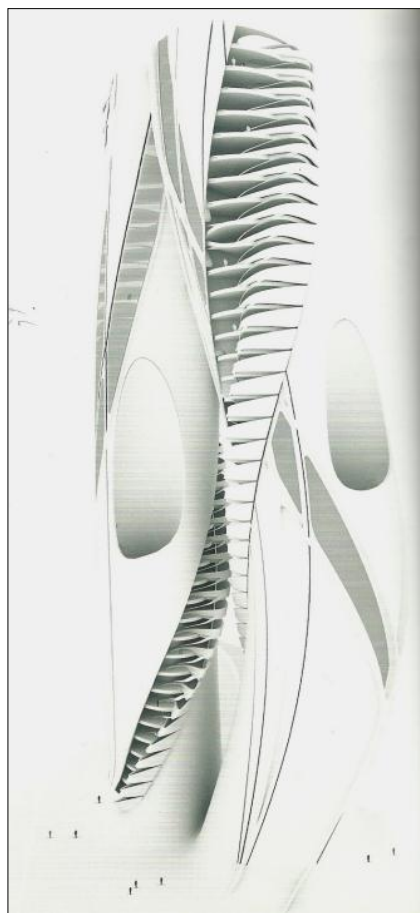

(شكل 15) برج رقمي يبين

بعض الصفات الخاصة

بالاشكال الرقية

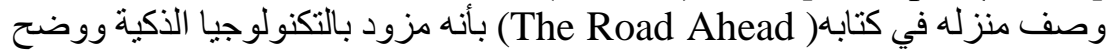

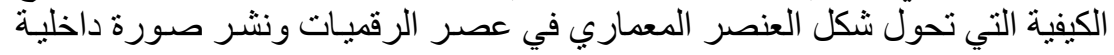

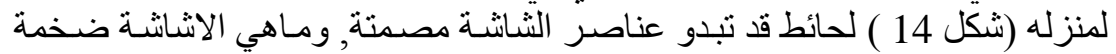

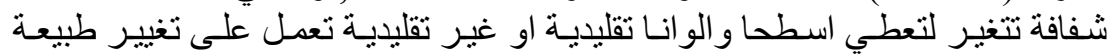

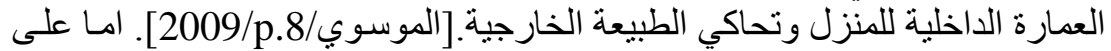
المقياس الحضري فقد وضح) (Verebes) في مثنال لبرج مرتفع بعض من الصنات الصفات الخاصة باشكالها الرقمية( شكل15 )كالاغلفة التي تبدو صلدة متناقضـة مـع الجدران

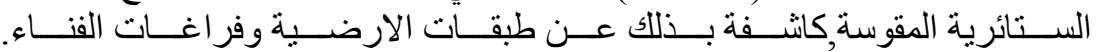

.[2009 P.26/Verebes]

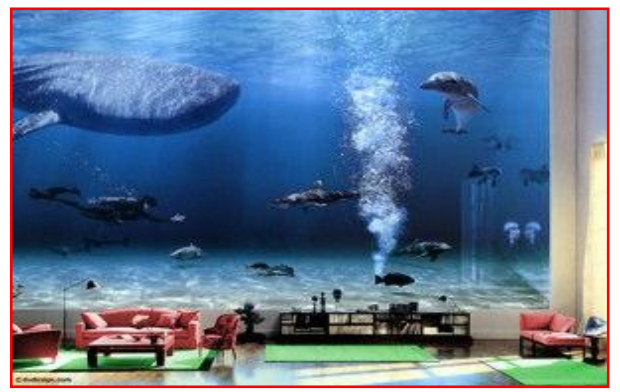

(شكل14) فضاء الاستقبال الخاص بمنزل

بيل جيتس الرقمي [الموسوي/2009/P.8

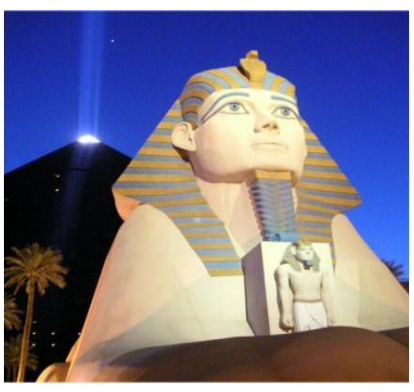

Sphinx شكل13) مدخل فندق

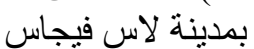

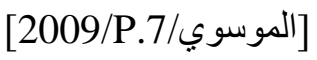

[2009/ P.26/Verebes]

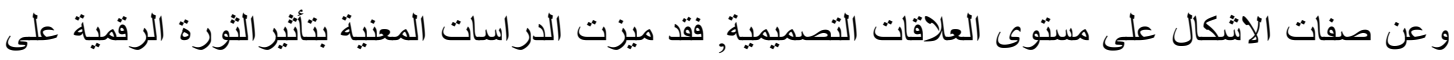

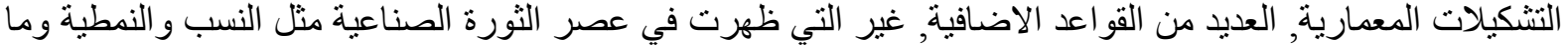

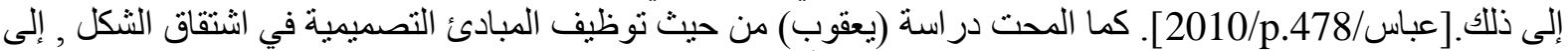

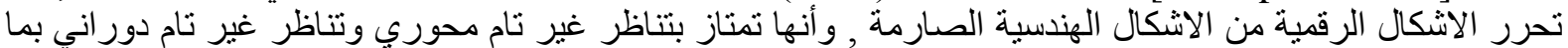

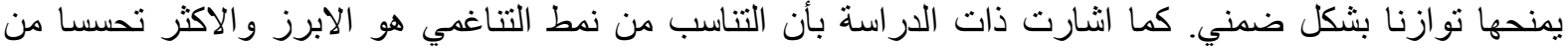

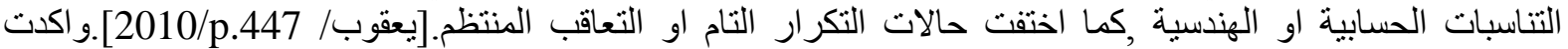

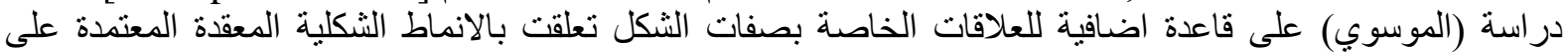

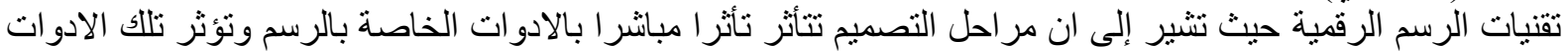

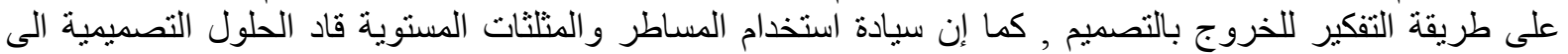

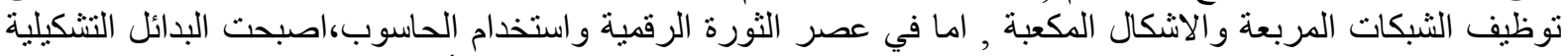

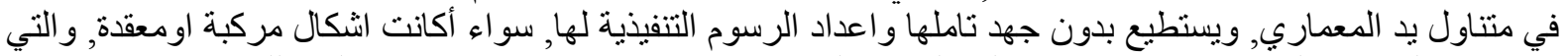

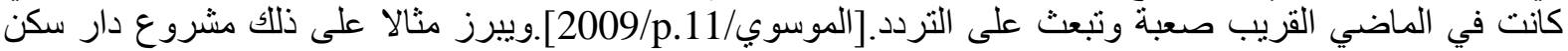

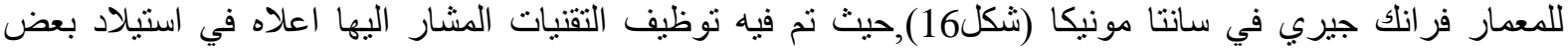
الاضافات الخاصة بشكل المنزل.[العلي/ 1997/p.74].اما (Verebes) فيوضح مثالا لبرج (شكل 14 ) مطور تصميميا 
بتوظيف التدخل الرقمي و الذي يدل على القابليات التقنية المتقدمة و المنمكنة من توضيح الانظمة الفضائية لتصميم البرج

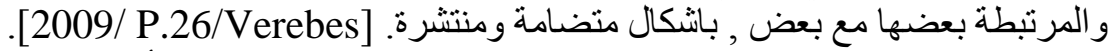

وييرز في عصر الثورة الرقمية التعدد والتنوع في التشكيل كأحد صفات الثكل (Sass Customization)

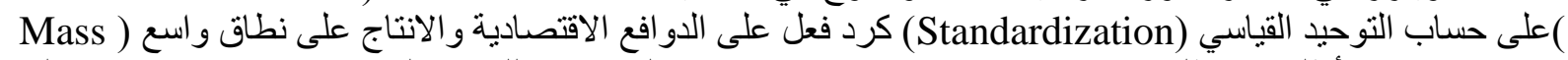

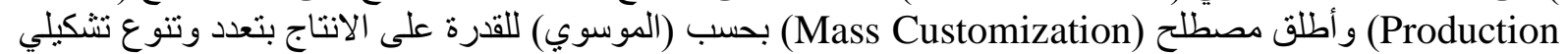

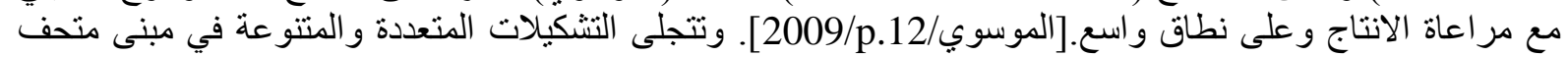

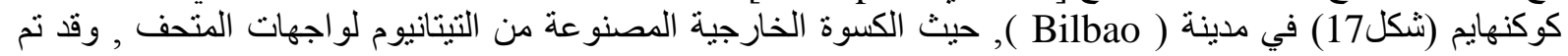

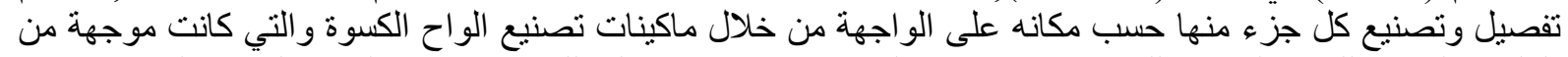

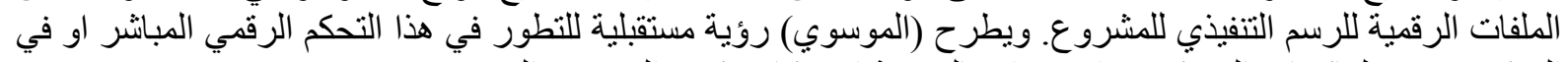

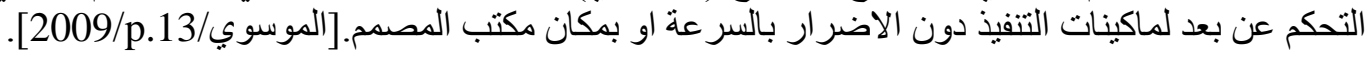

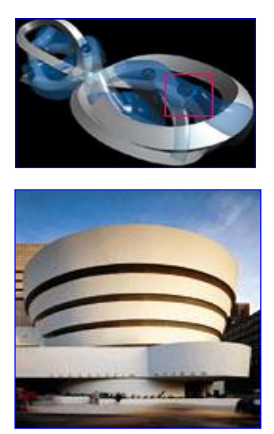

(شكل17) متحف كوكنهايم الافتر اضي

$$
\begin{aligned}
& \text { [الموسوى/2009/P. 4] } \\
& 1 \text { الد }
\end{aligned}
$$
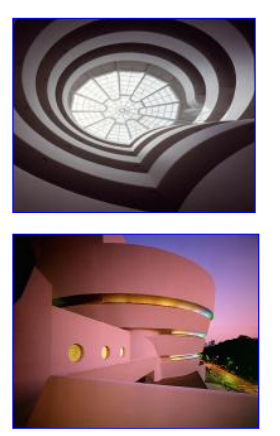

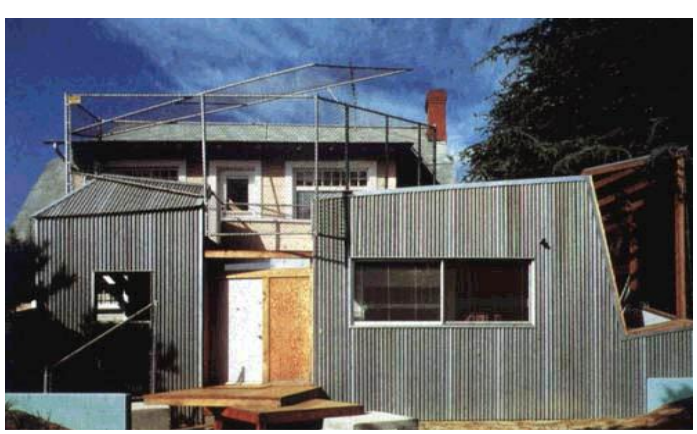

(شكل16) مشروع دار سكن للمعمار فر انك جيري

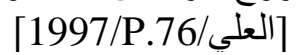

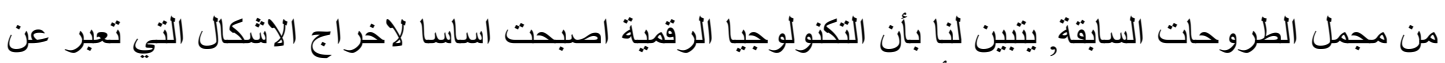

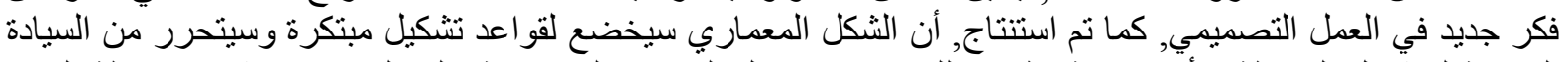

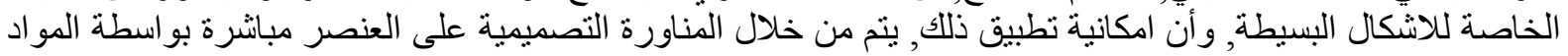

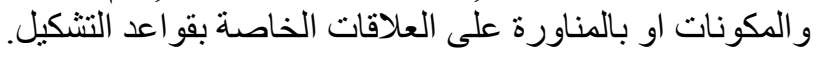

2-1-1-5 المتفير ات التصميمية الوظيفية، فقد تمحورت حول كل من ( مادية الفضاء, مألوفيته, تو اصليته, تعددية وظائفه,

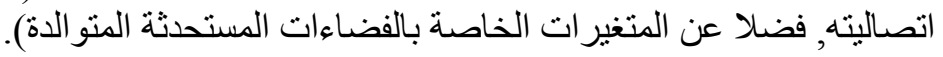

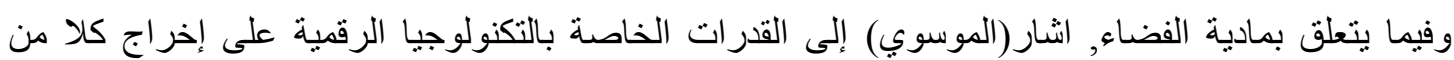

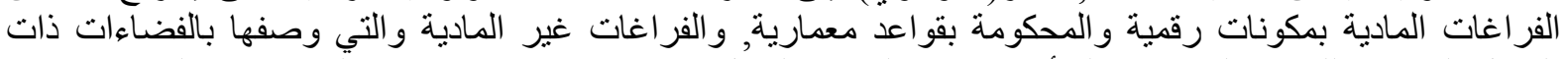

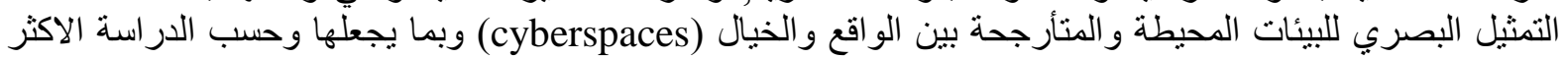

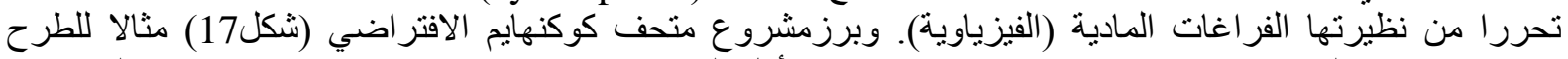

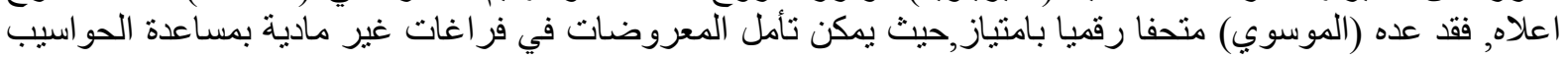

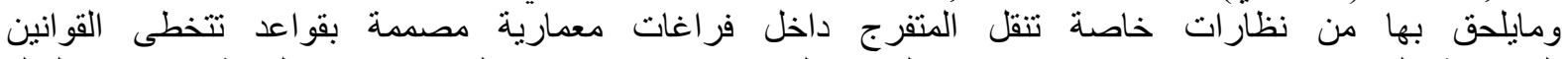

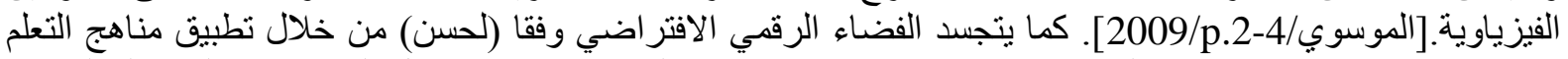

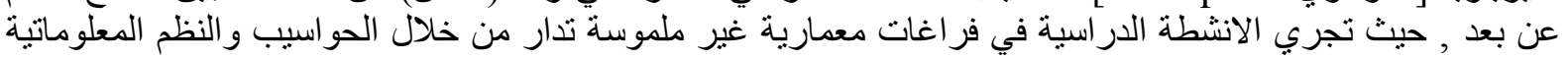

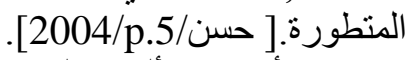

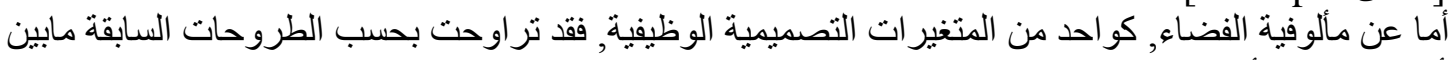

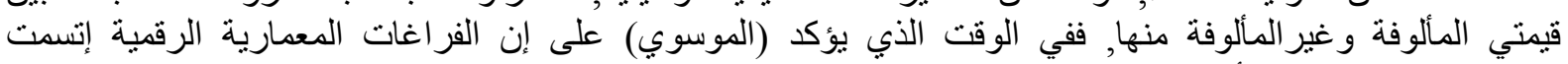

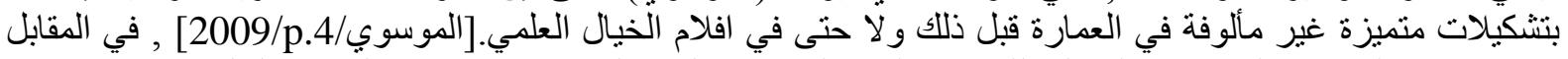

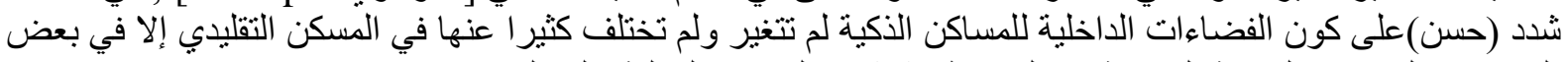

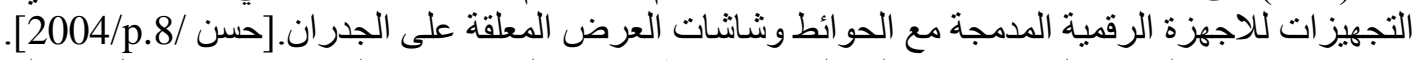

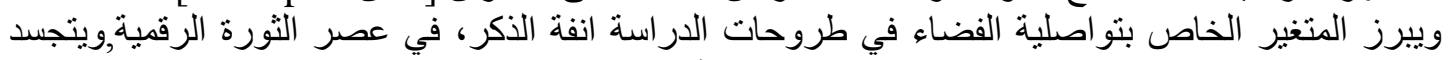

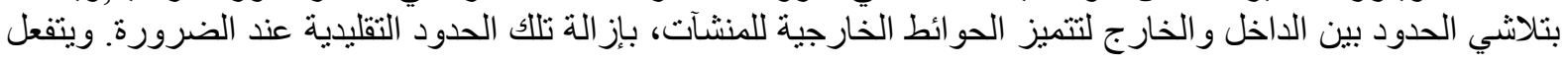




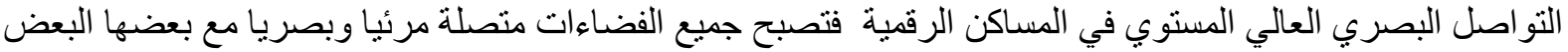

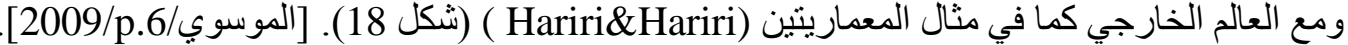

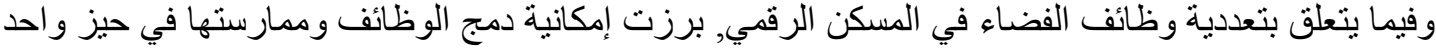

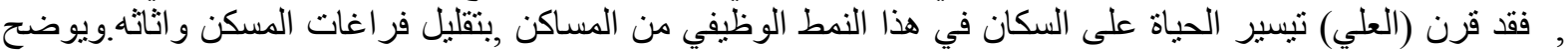

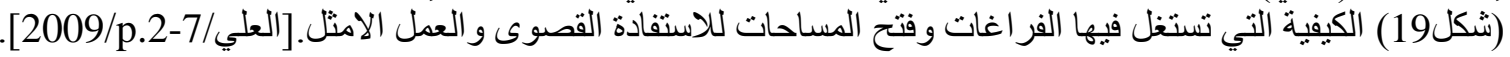

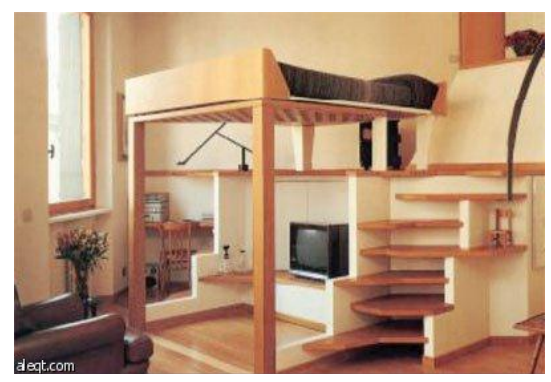

(شكل19) فضاءات مدمجة الوظائف

$$
\text { [2009/p.2/العلئi] }
$$

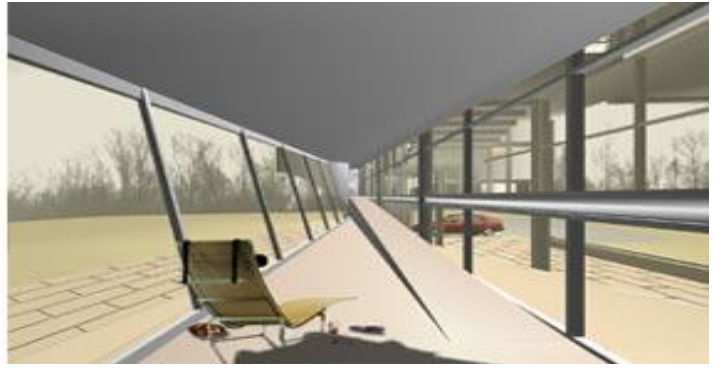

Hariri\&Hariri شكل18) المسكن الرقمي للمعماريتين

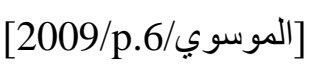

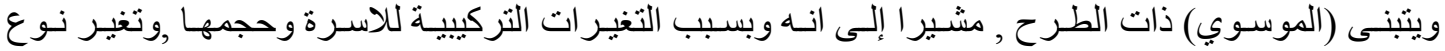

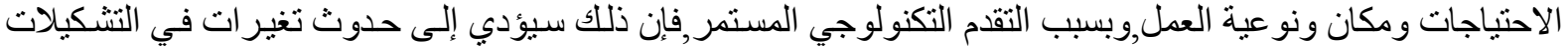

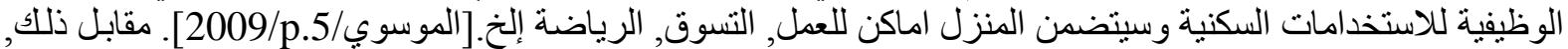

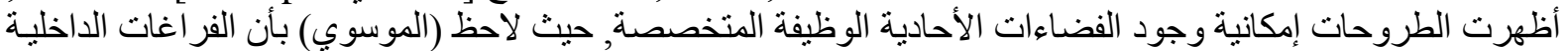

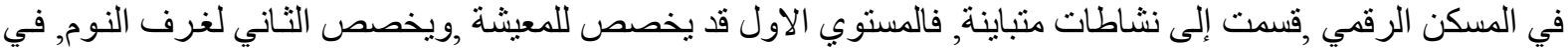

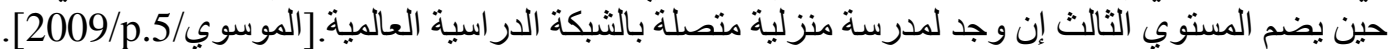

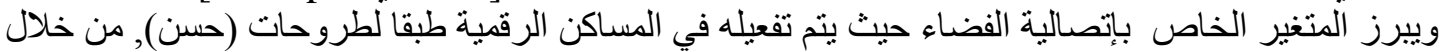

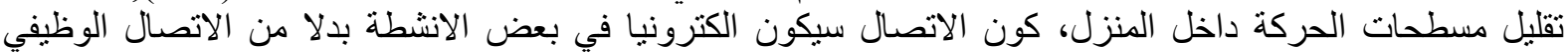

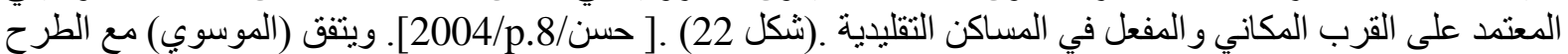

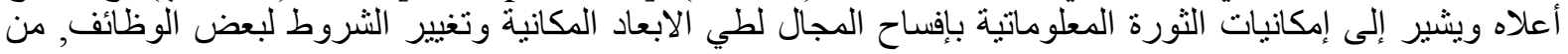

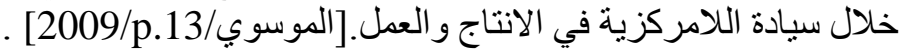

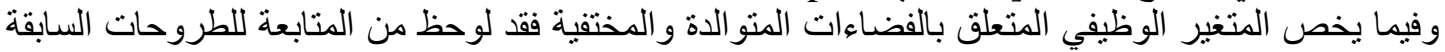

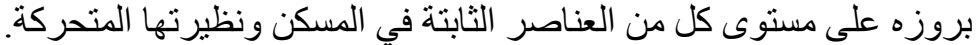

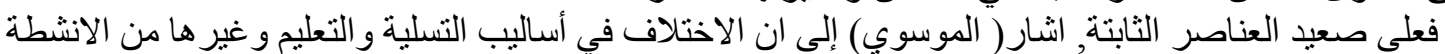

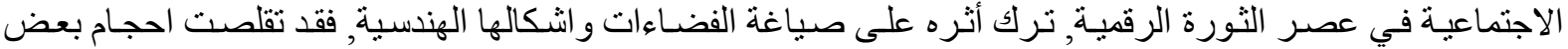

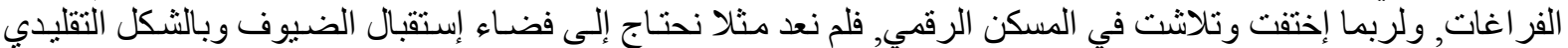

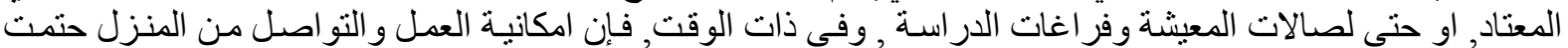

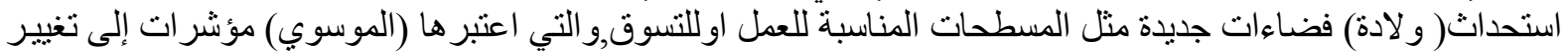

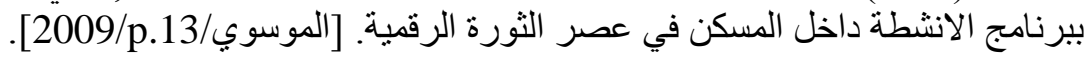

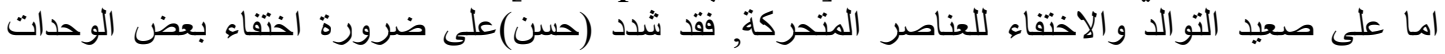

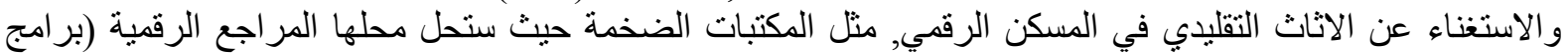

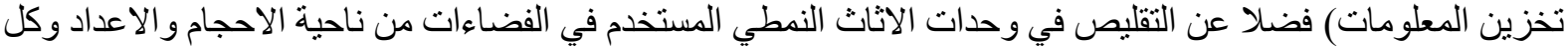

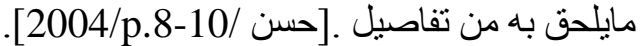

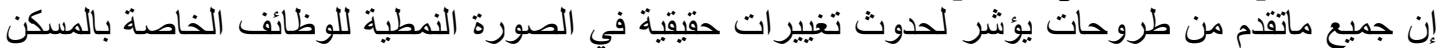

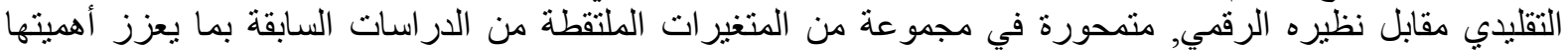
وامكانية اعتمادها في الاطار العام للموضوع. 
2-1-5 الابعاد التنفيذية ( التقتية ): وبدور ها تمثلت بكل من مواد التنفيذ وآلياته.

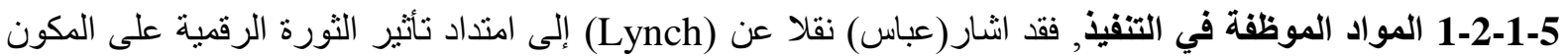

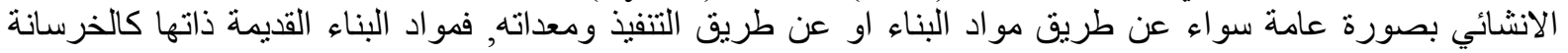

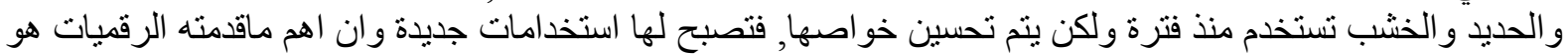

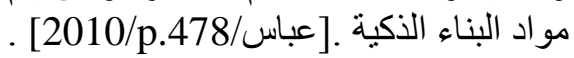
وقد ادرجت الطروحات السابقة نماذج عديدة للمواد انفة الذكر, فعلى سبيل المثال اشتار (حلاوة) إلى اعتبار

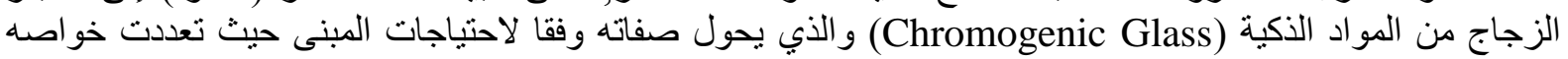

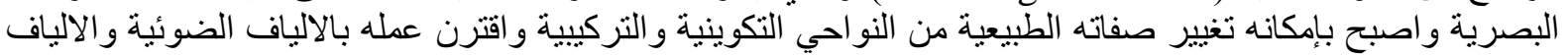

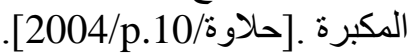
ويطرح ( الموسوي) مثالا على نوظيف الزجاج في الواجهات الذكية للمنزل التجريبي للضيافة (البيت الفائق ) ,

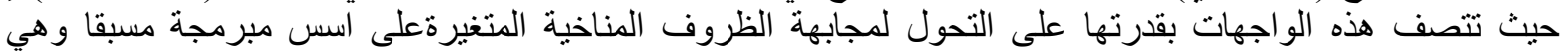

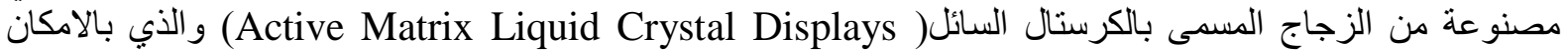

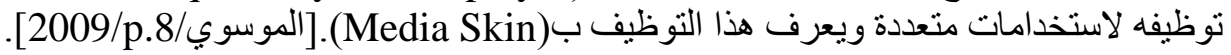

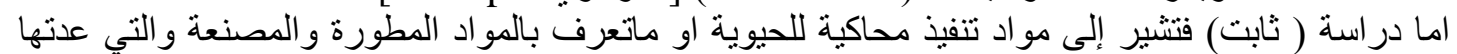

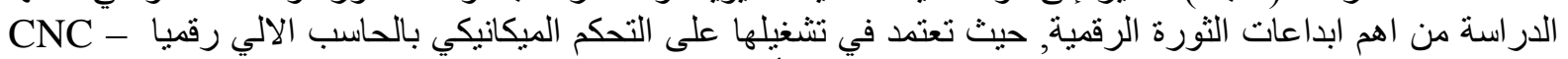
(Computer - Numerical Control Maching)

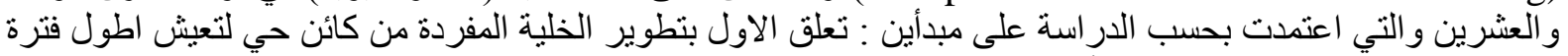

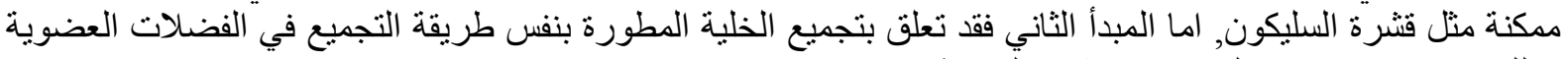

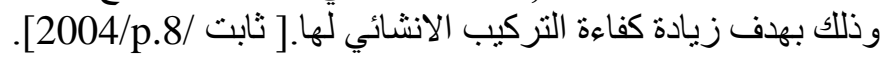

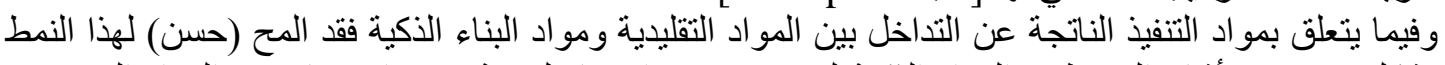

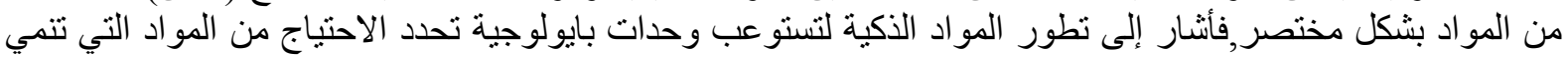

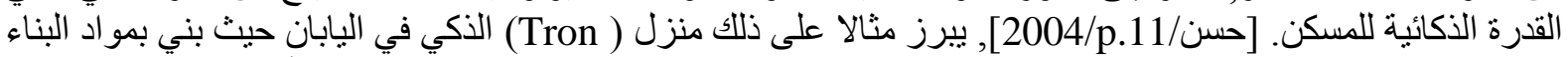

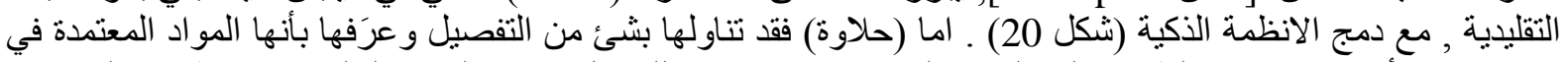

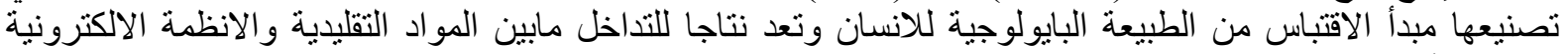

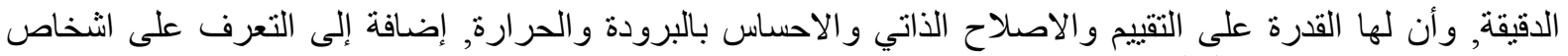

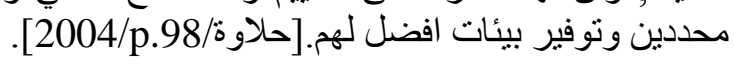

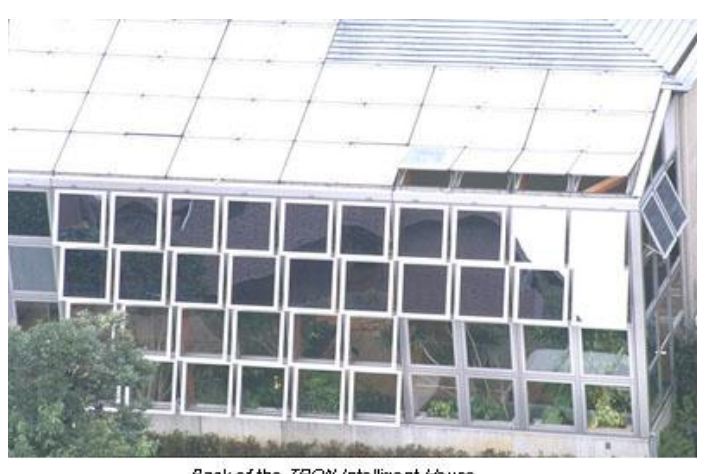

الفناء المغطى بوحدات من الزجاج ينم التحكم فيها الكترونيا

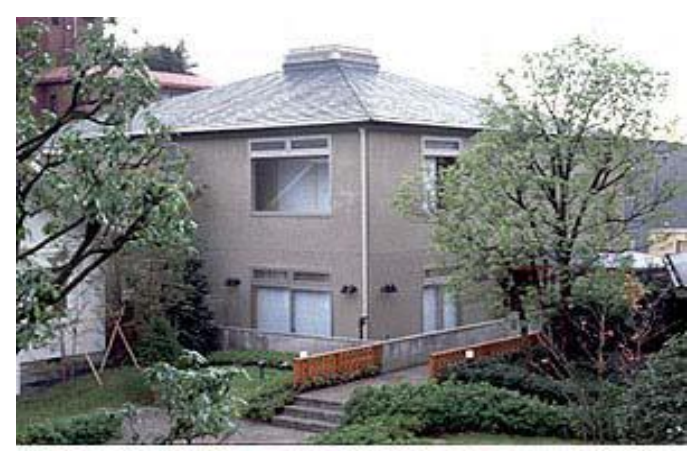

Front of the TRON intelligent House

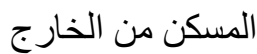

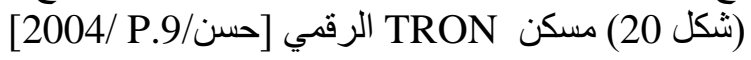

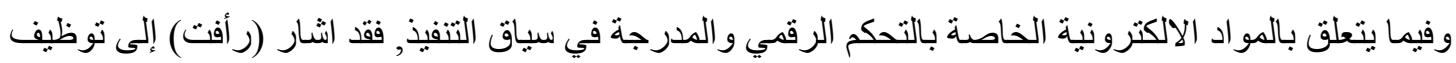

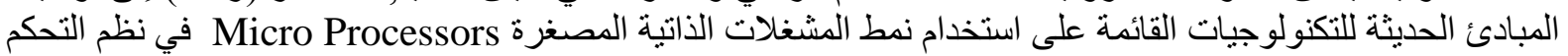

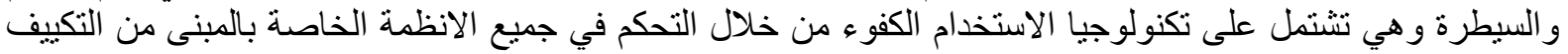

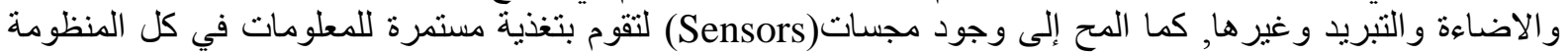

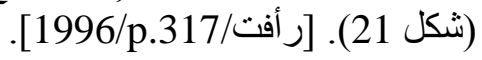




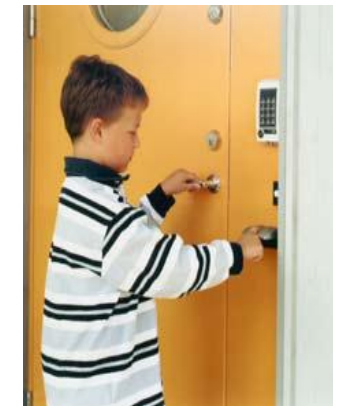

طريقة فتح الباب بالبصم

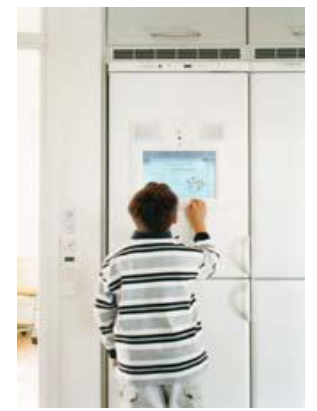

شانشة التحكم الداخلية

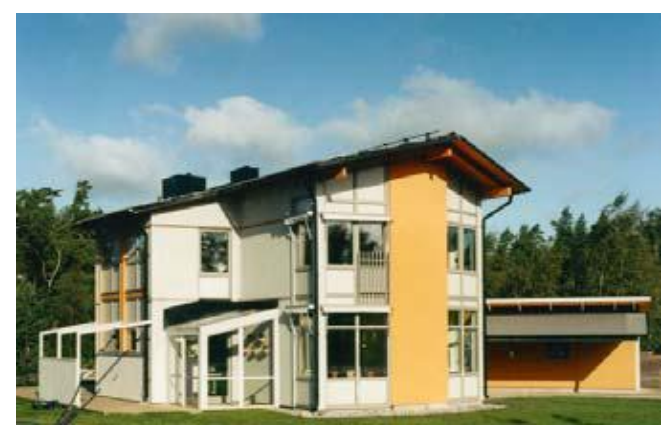

المسكن من الخارج

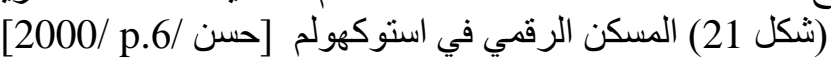

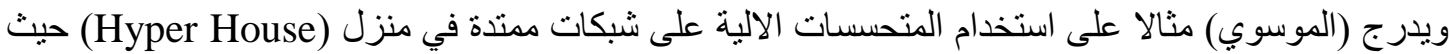

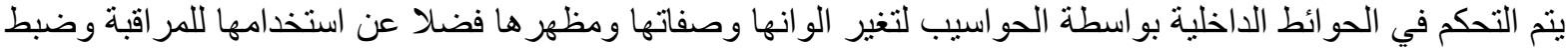

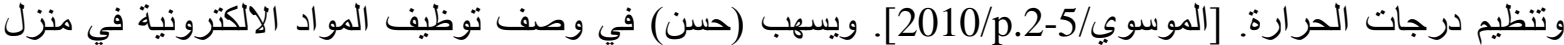

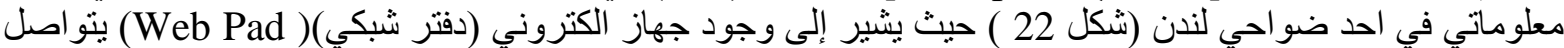

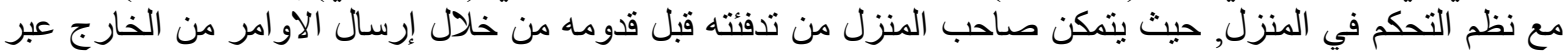

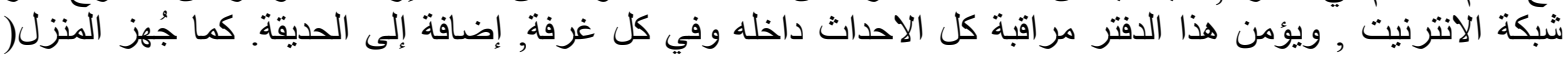

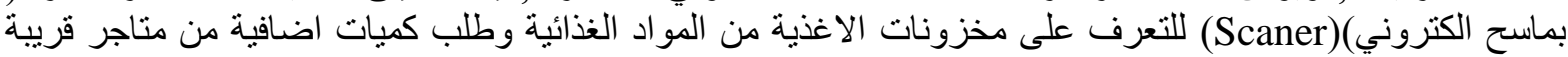

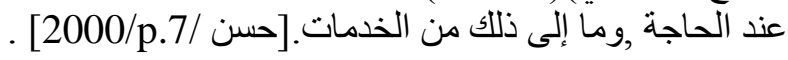
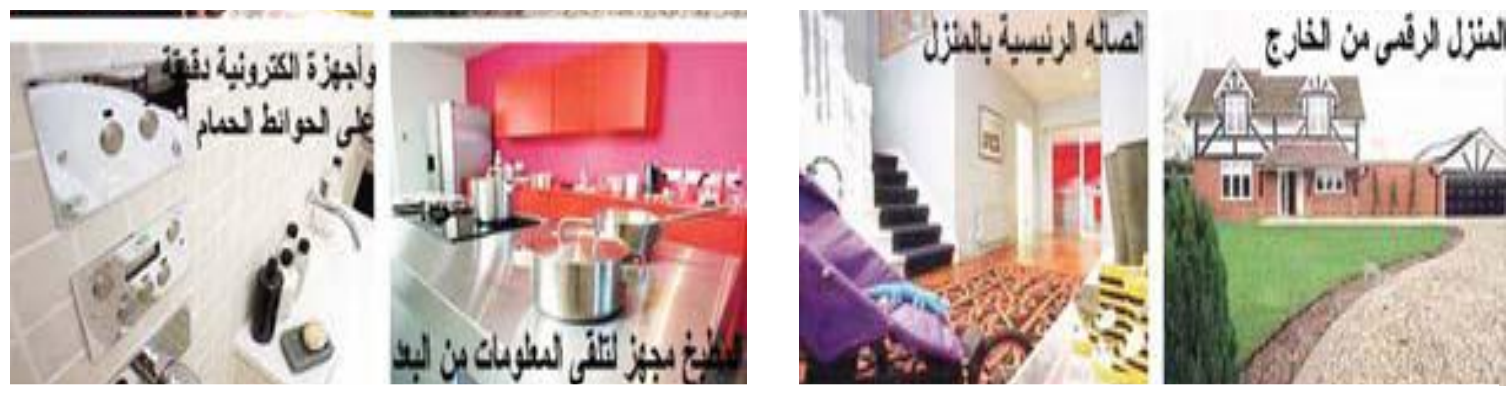

(شكل 22) المسكن الرقمي في و اتفورد بلندن - التجهيز ات الرقمية التي تحتويها بعض فر اغات المسكن

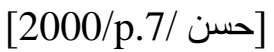

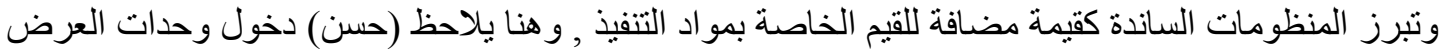

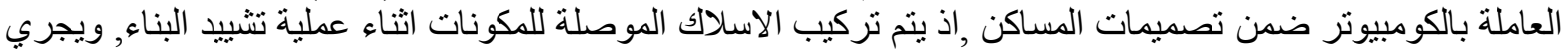

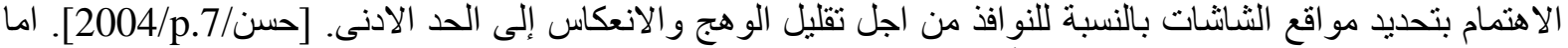

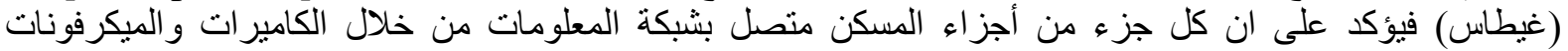
و الحاسبات وكافة الاجهزة المنزلية, حيث بالامكان استخدام اللوحات اللاسلكية المنتشرة في كل انحاء المناء المنزل لتشغيل كافة التئ

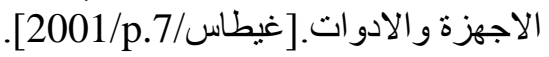

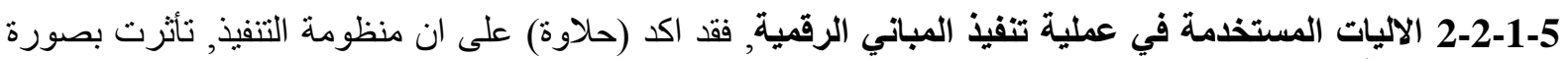

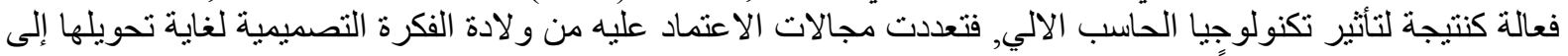

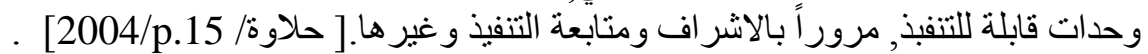
وقد لوحظ من التدقيق في الطروحات السابقة ,أن اليات التنفيذ قد ارتبطت بقيمنين ثانويتين, تمثلتا بكل من الوسائل 


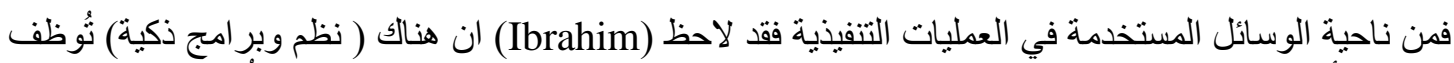

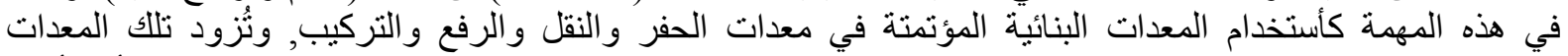

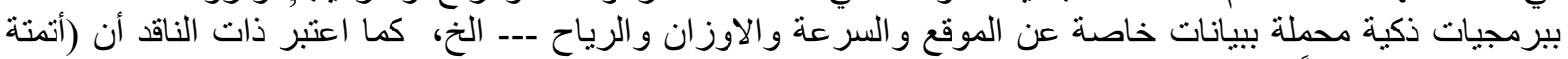

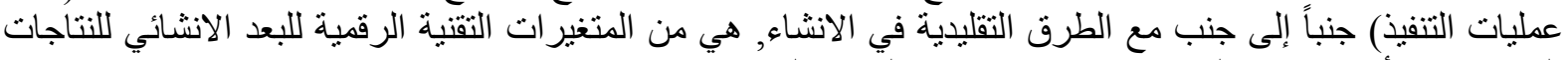

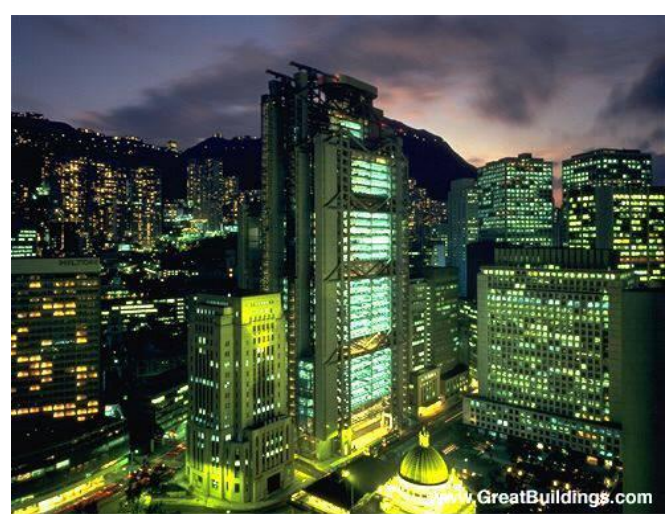

(شكل 23) مصرف شنغهاي في هو نك كونك

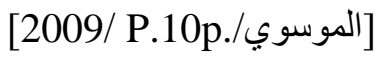

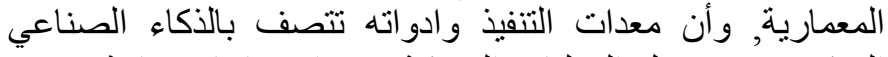
التحكمي في مجمل العمليات التنفيذية لاخراجية التهات نتاجات بنائية معقدة. .[2003/ p.18-19/Ibrahim]

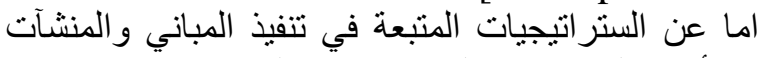

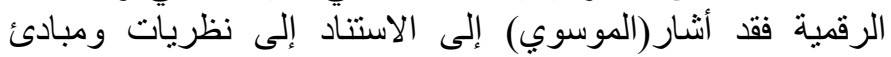

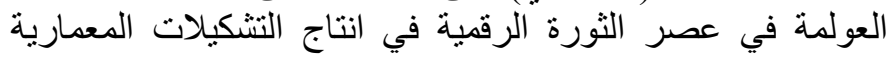

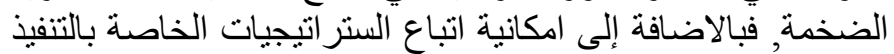

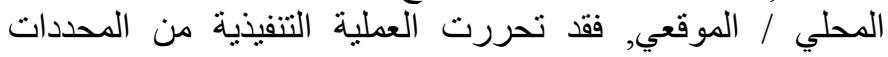

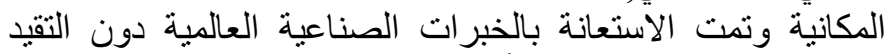

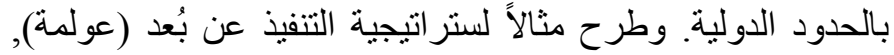

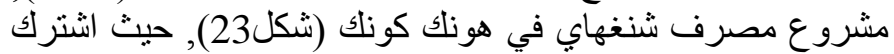

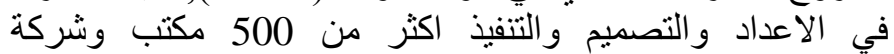

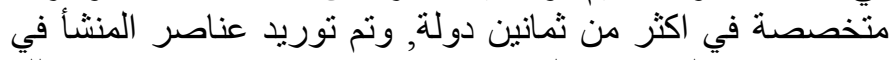

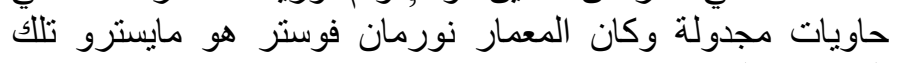
التجربة. [الموسوي/2009/p.9] دكان.

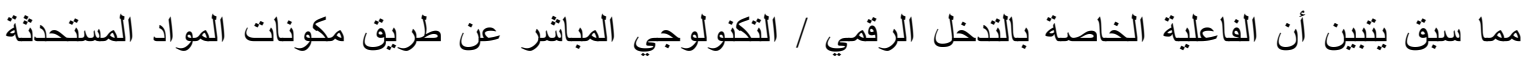

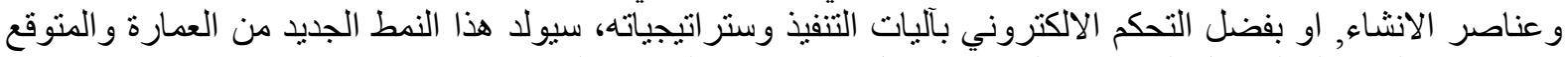

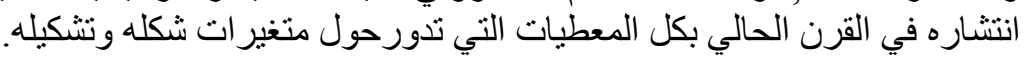

2-5 الجاتب الثاني / المتغيرات الخاصة بالانشطة الحياتية داخل المسكن الرقمي

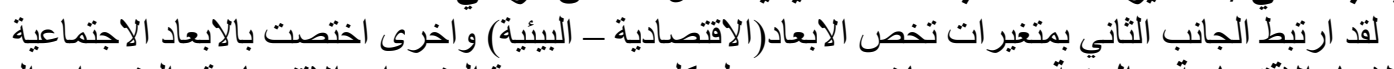

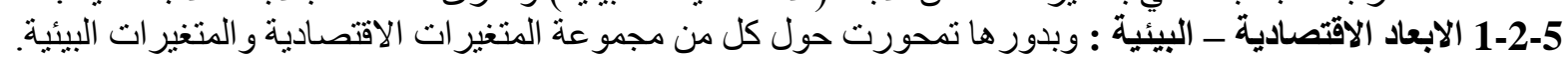

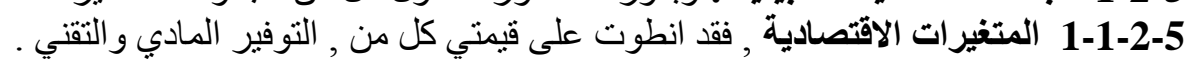

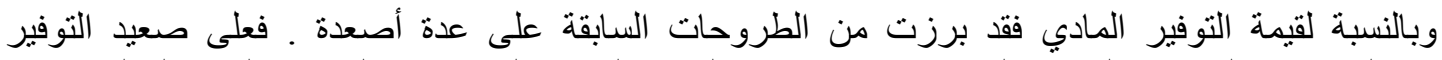

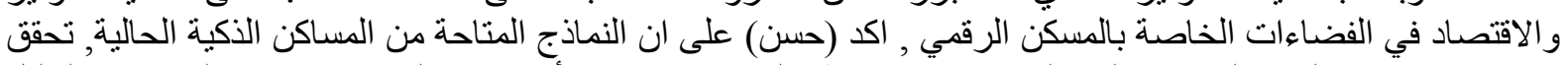

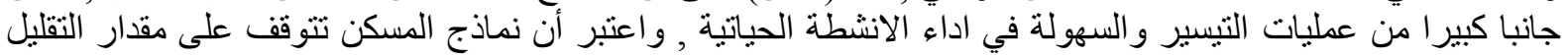

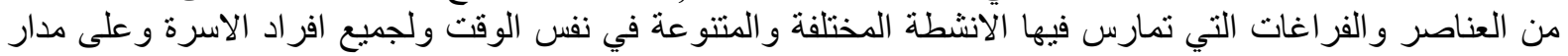

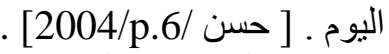

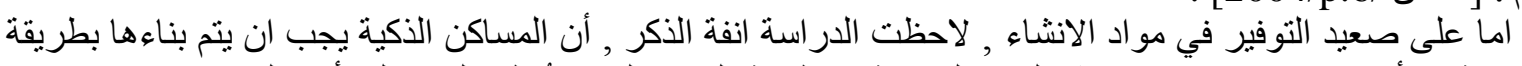

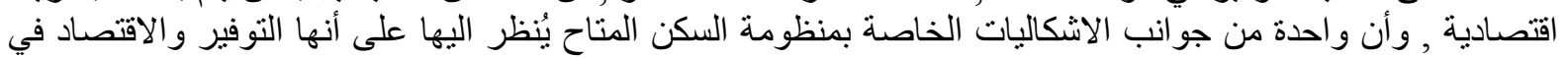

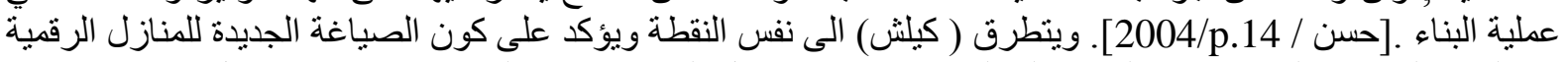

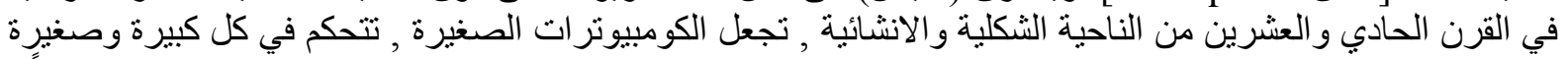

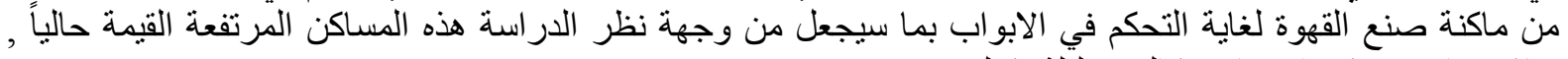

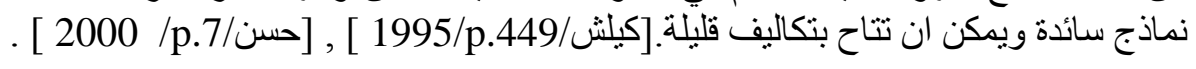

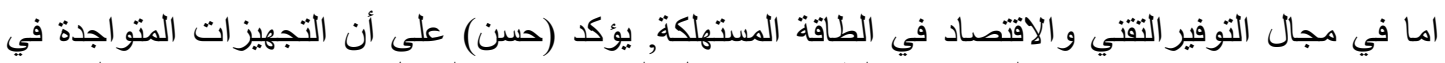

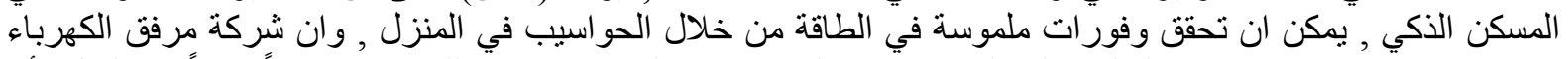

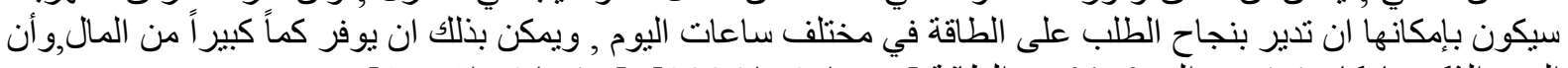

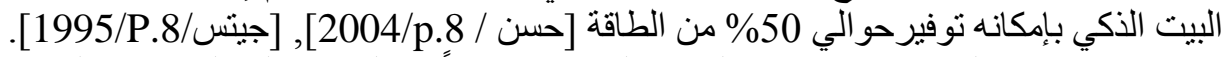

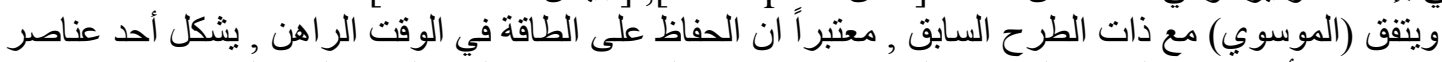

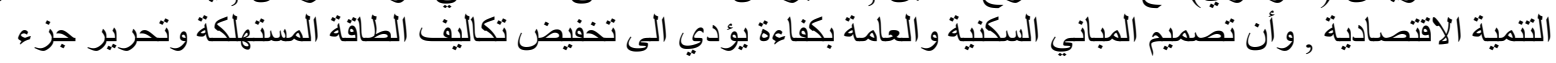




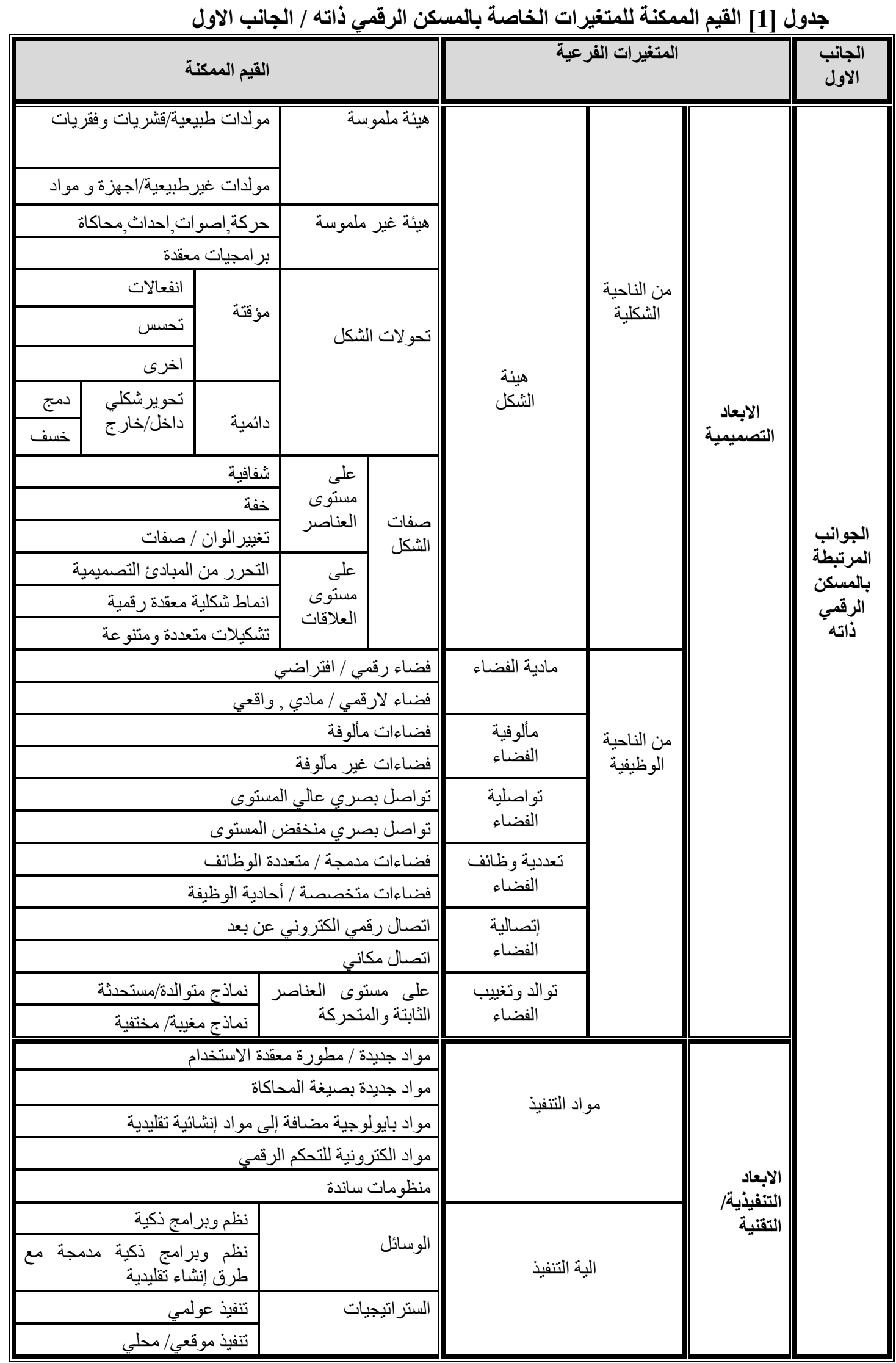




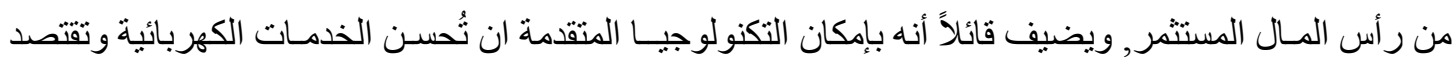

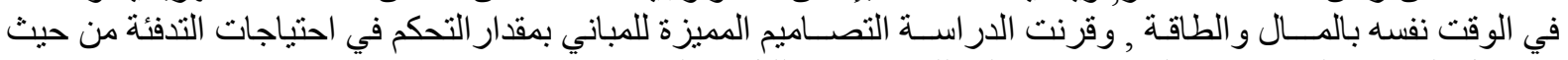

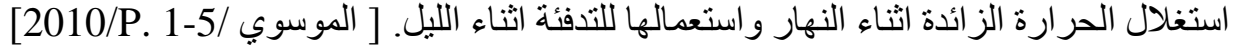

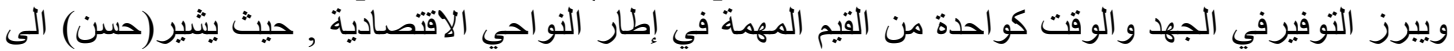

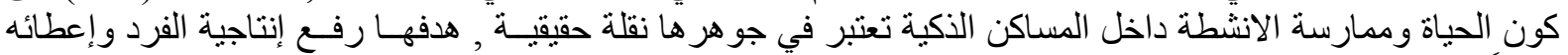

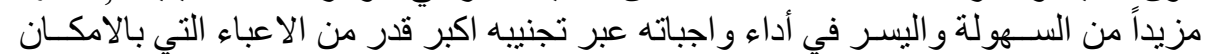
إزالتها من حياته , وبذللك يمكن توفير الكثير من الوقت واء والجهر الذي يضيع وبحسب (حسن) في ظل المساكن التقليدية

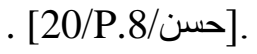

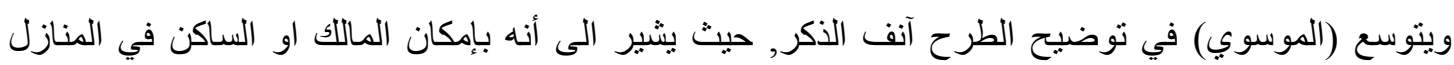

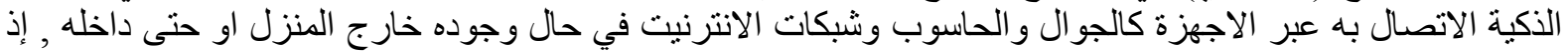

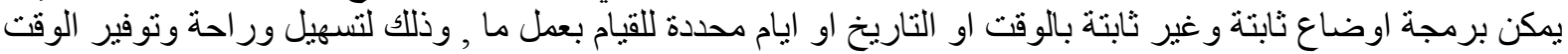

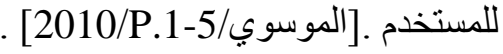

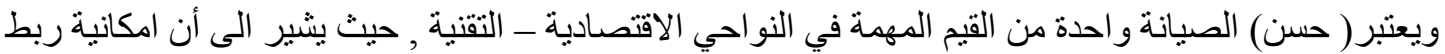

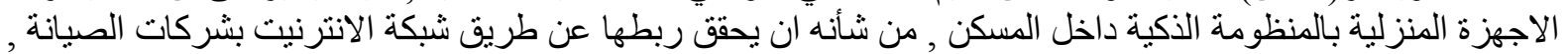

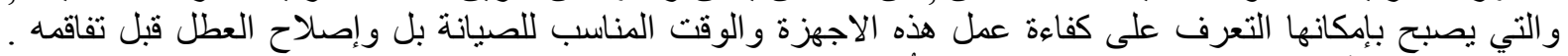

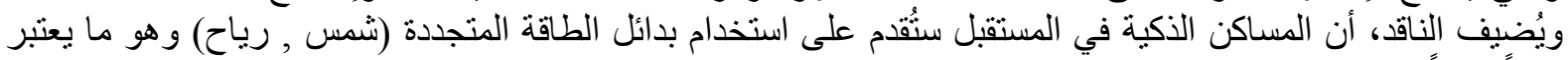

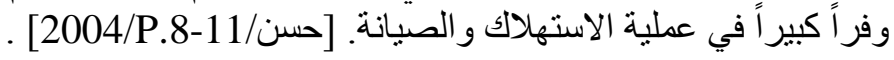

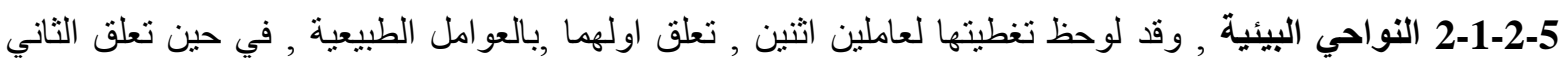
بالعو امل التقنية .

وفيما يرتبط بالعوامل الطبيعية الخاصة بالنواحي البيئية , فقد استعرض ( الموسوي) مجموعة من الحلول

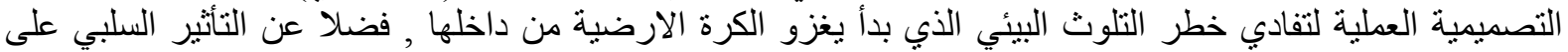

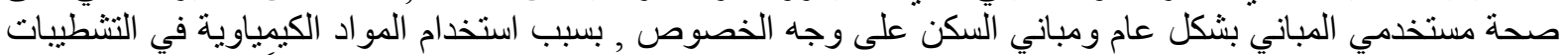

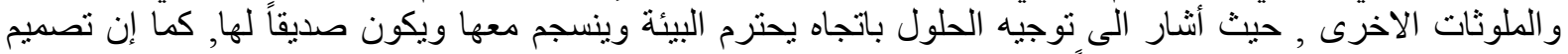

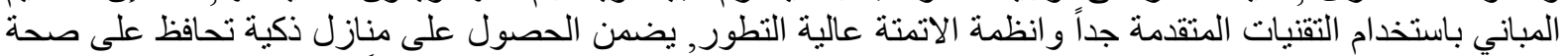

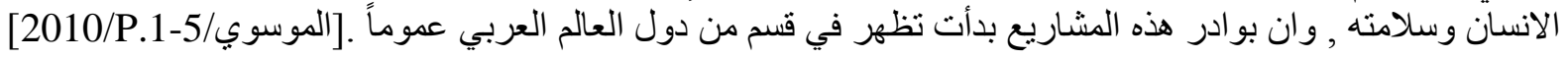

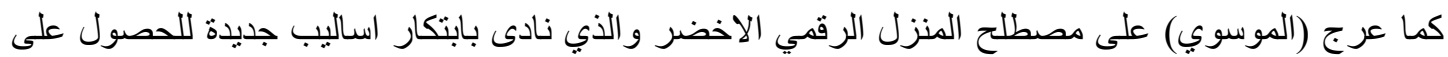

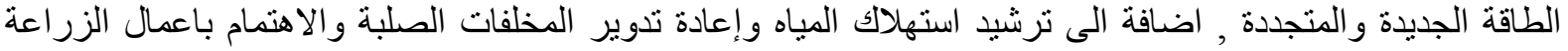

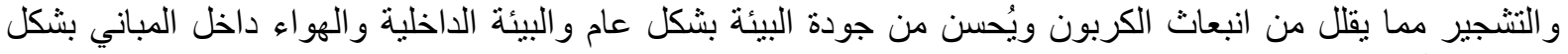

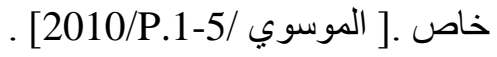

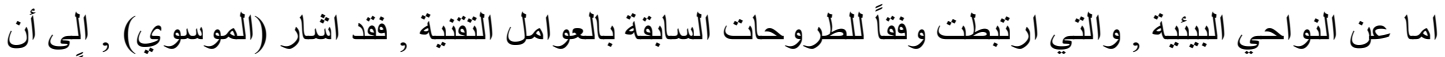

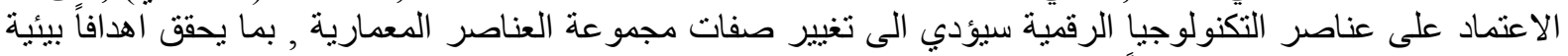

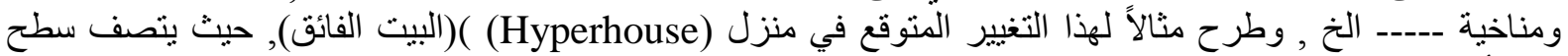

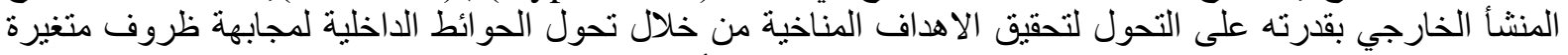

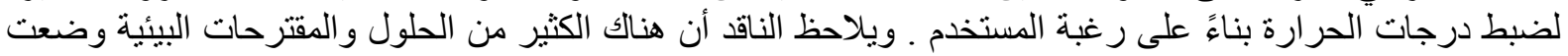

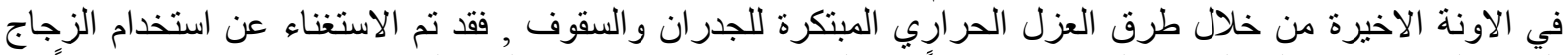

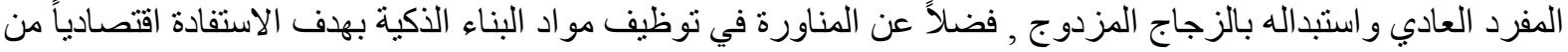

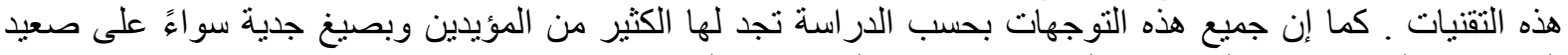

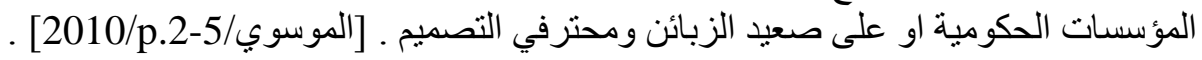




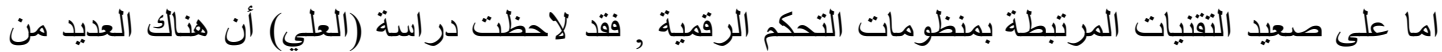

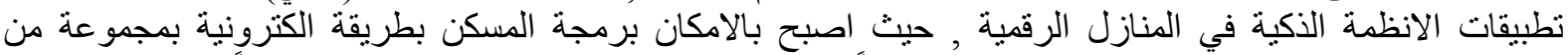

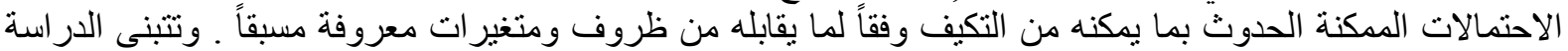

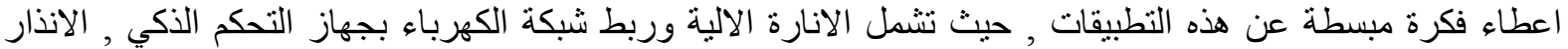

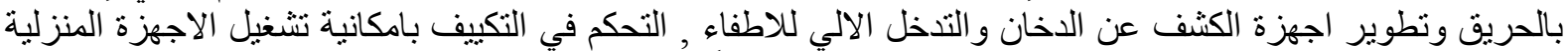

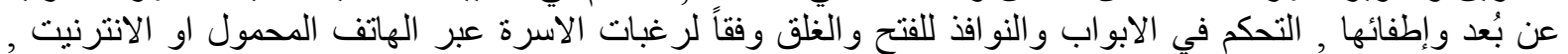

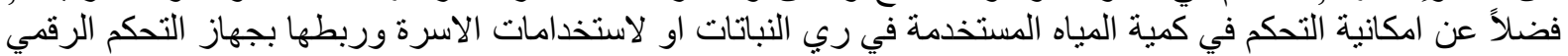

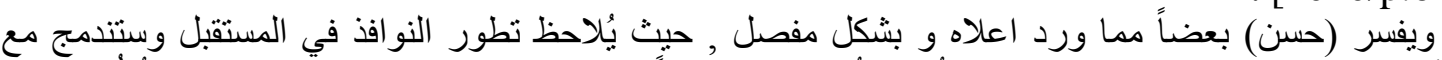

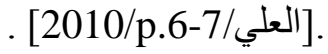

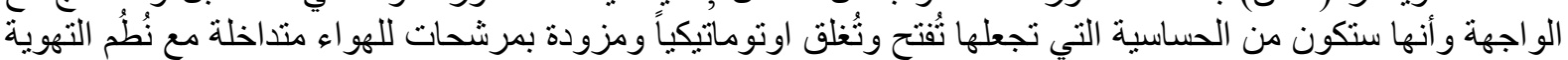

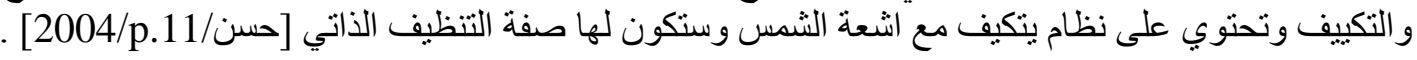

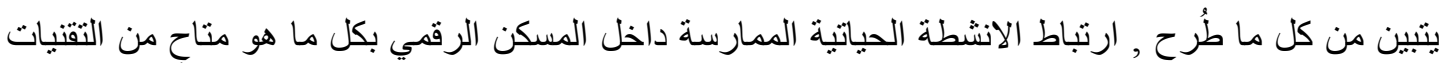

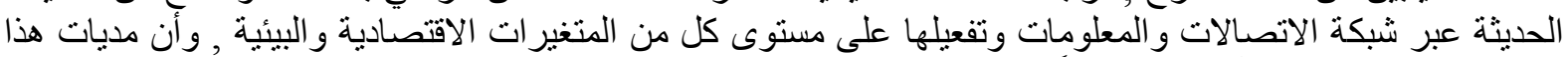

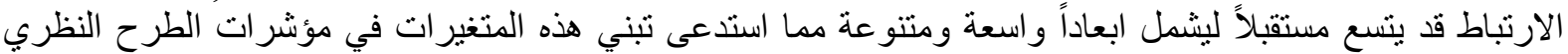

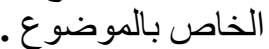

2-2-5 الابعاد الاجتماعية : وبدور ها تمحورت حول كل من المتغير ات السلوكية ومتغير ات تعلقت بالانشطة الخدمية.

1-2-2-5 الممارسات السلوكية الخاصة بالسكن الرقمي، كبعد اجتماعي , فقد القت العديد من الدر اسات السابقة الضوء

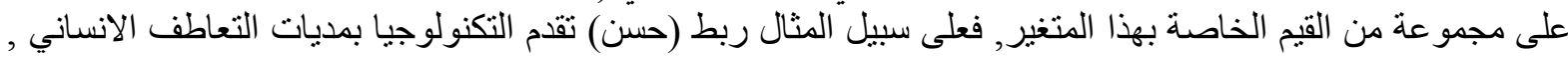

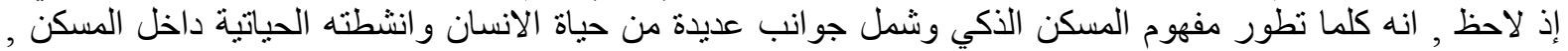

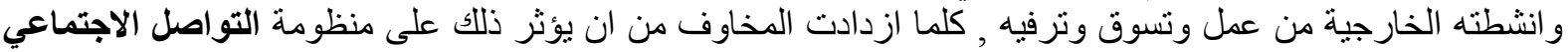

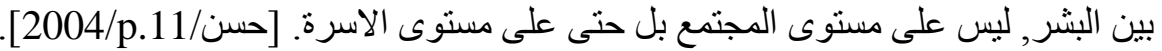

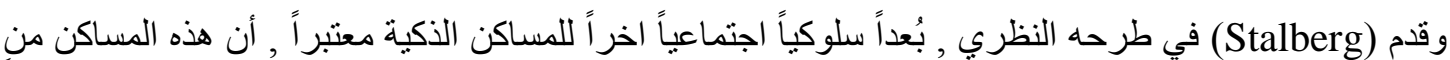

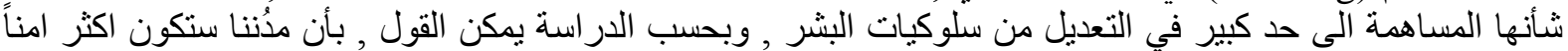

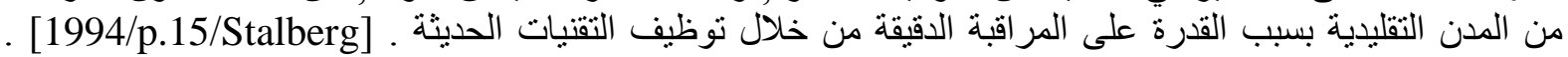
[2004/p.8/

اما عن التفكير الابداعي , كأحد القيم المرتبطة بالسلوكيات الممارسة في المسكن الرقمي , فقد اعنبر (غيطاس)

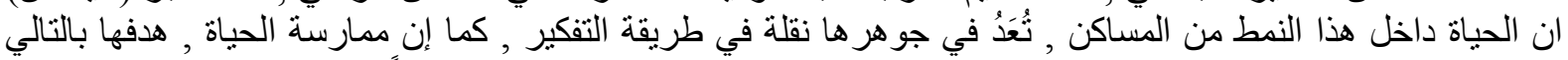

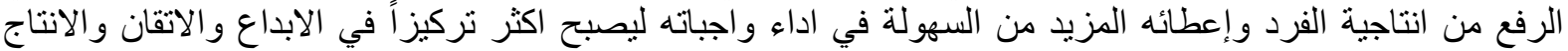

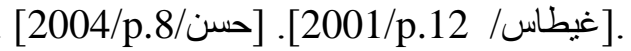

2-2-2-5 الانشطة الخدمية الخاصة بالابعاد الاجتماعية للمسكن الرقمي , فقد لوحظ من الدر اسات السابقة , اشتمالها على الإلى

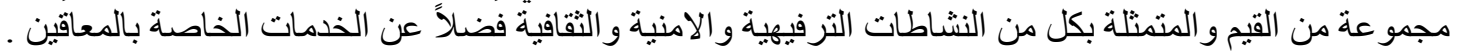

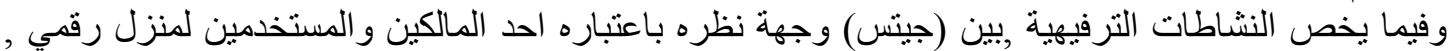

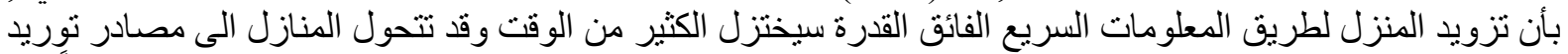

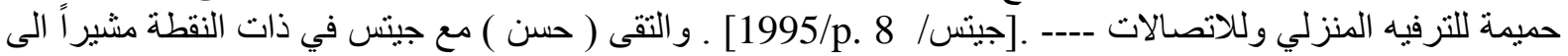

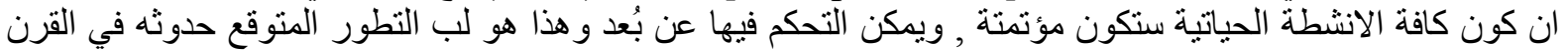

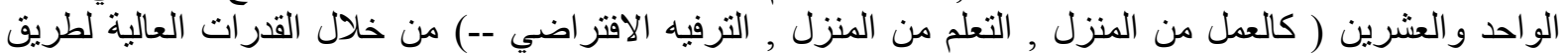

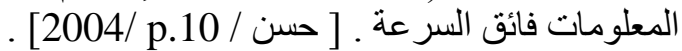

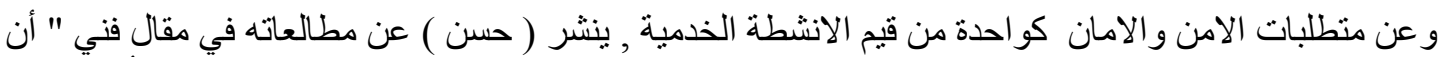

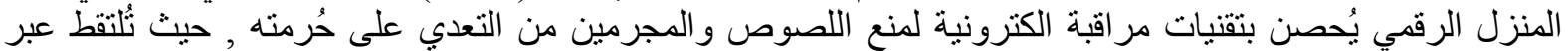

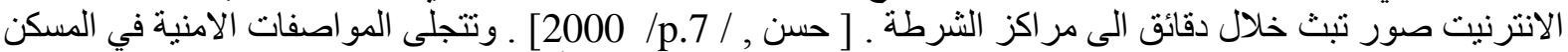
الرقمي بحسب ( Jedamzik) بإمكانية حماية المنزل من السرقات , حيث ثُنبه بعض الانظمة الالكترونية الساكن عند الأند 
خروجه بأن احد الابو اب الخارجية او النوافذ ماز ال مفتوحاً , في حين انظمة اخرى بإمكانها ان تجعل المنزل يتصل

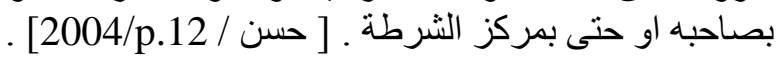

اما النشاط الخدمي الثقافي فيبرز في طروحات ( كاكو ) كقيمة مهمة معتبراً , الثورة المعلوماتية واحدة من اكبر الثبر

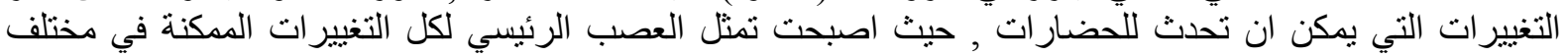

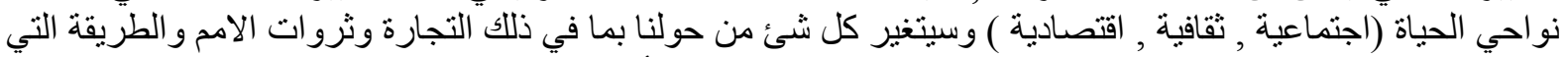

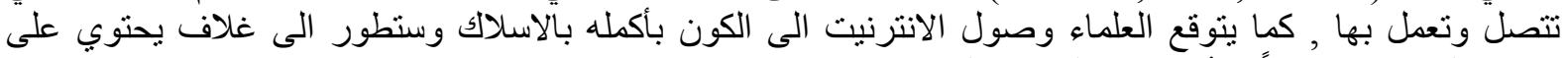

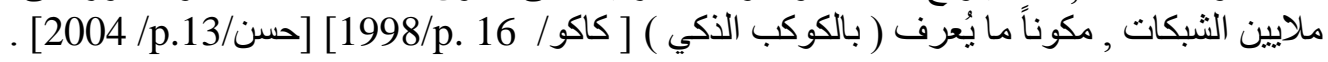

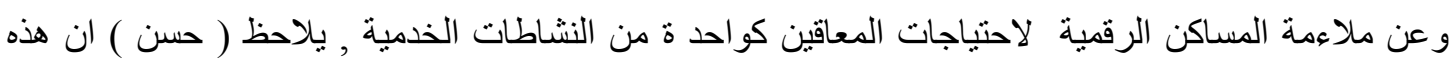

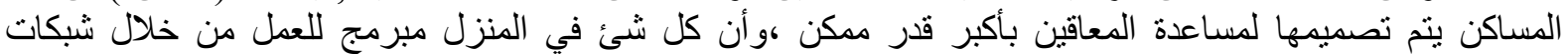

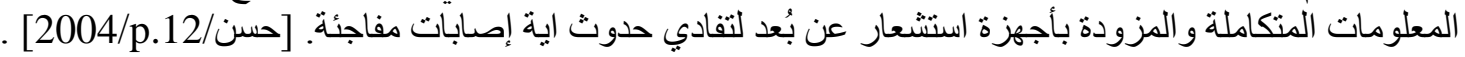

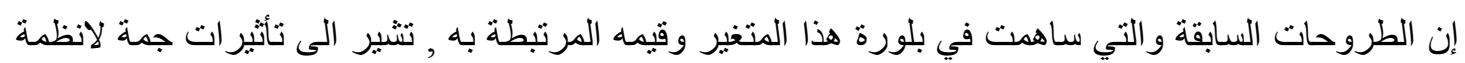

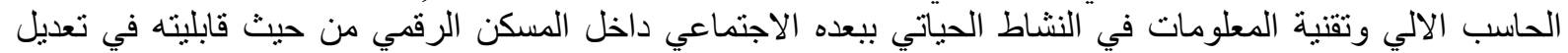
سلوكيات المستخدمين او القدرة على تلبية احتياجاتهم.

جدول [2] القيم الممكنة للمتغيرات الخاصة بالانشطة الحياتية / الجاتب الثاني

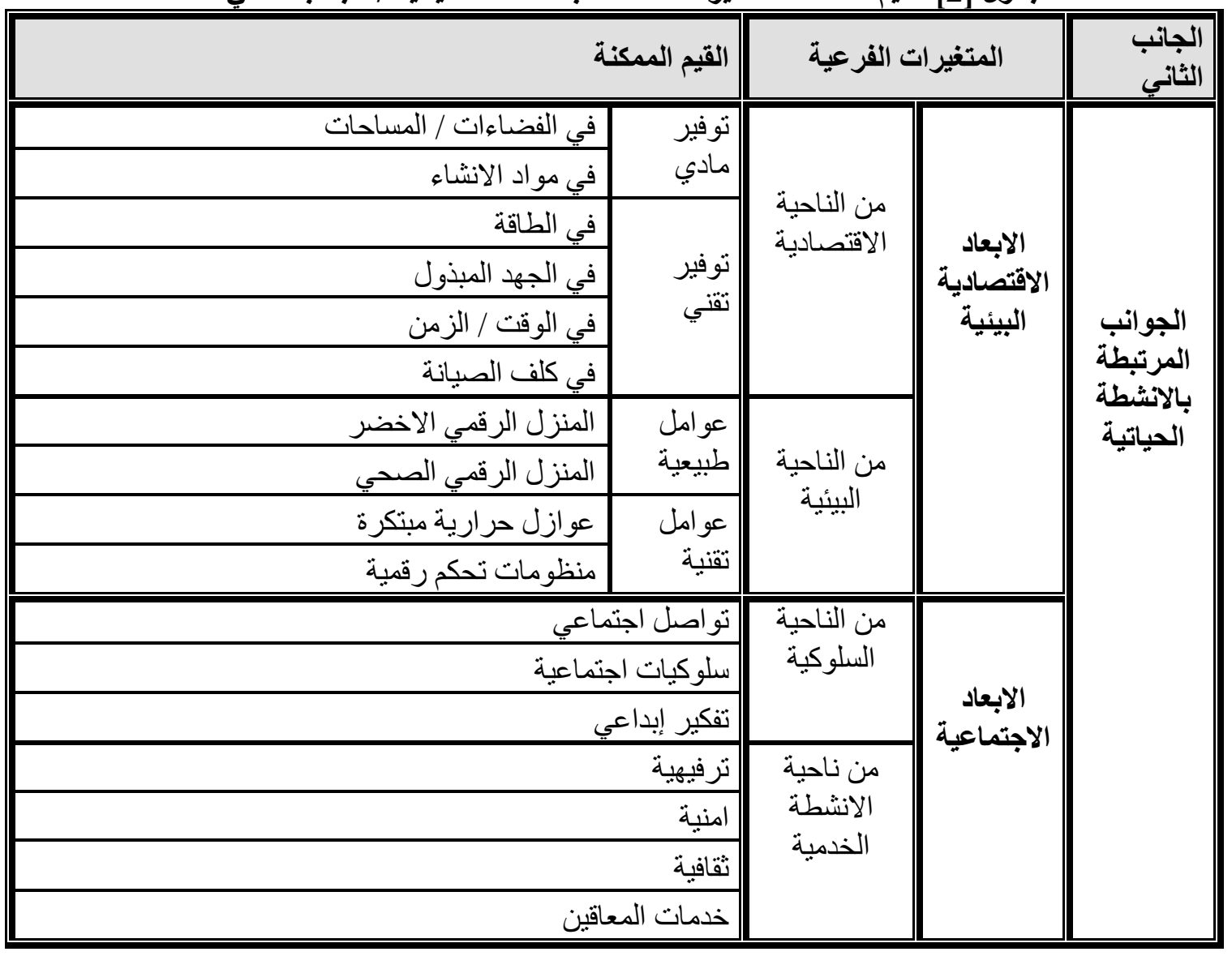




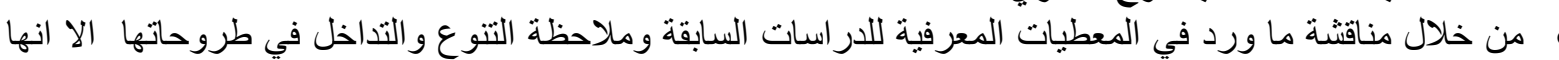

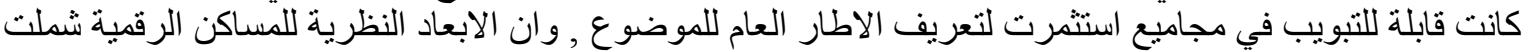

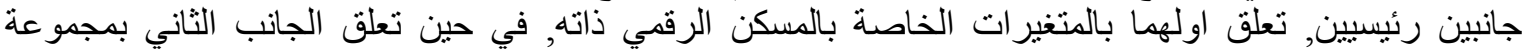
المتغيرات الخاصة بالانشطة الحياتية الممارسة فيها.

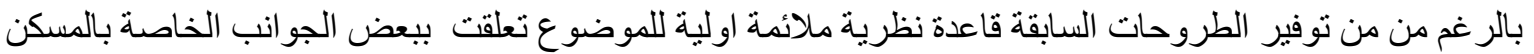

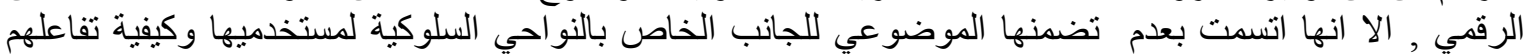

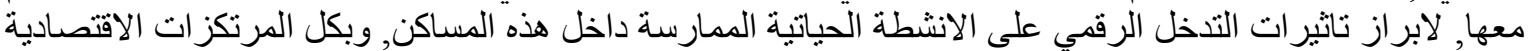
, البيئية , و الاجتماعية..الخ.

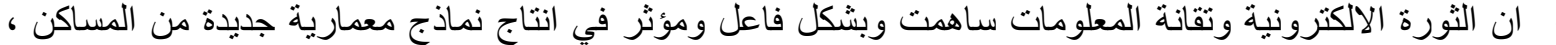

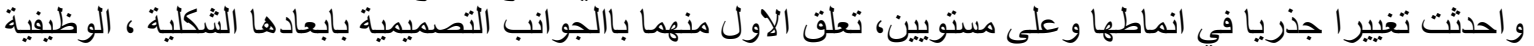
، في حين تعلق المستوى الثاني بالجو انب الخاصة بالانشطة الحياتية، حيث امكن تفصيليا استتناج ما يلي:

\section{من ناحية الجوانب المرتبطة بالابعاد التصميمية والتنفيذية:}

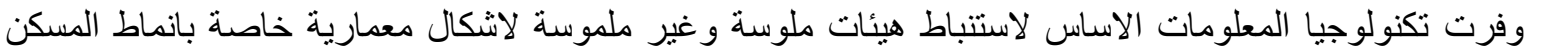

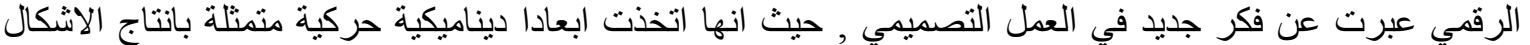

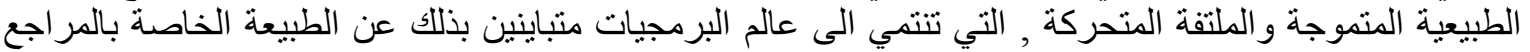

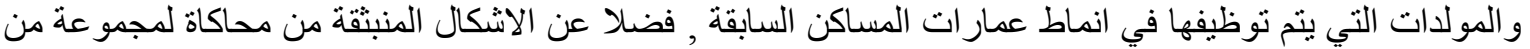

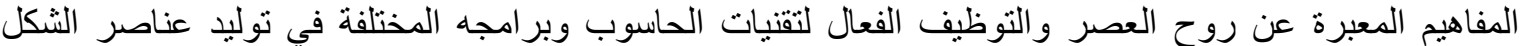

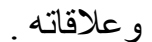

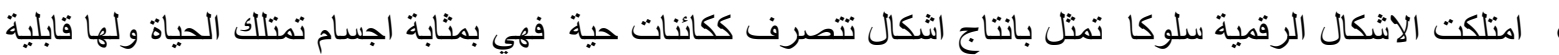

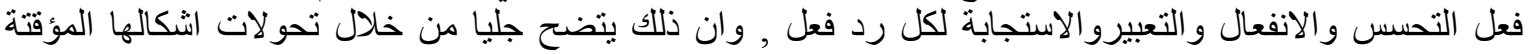

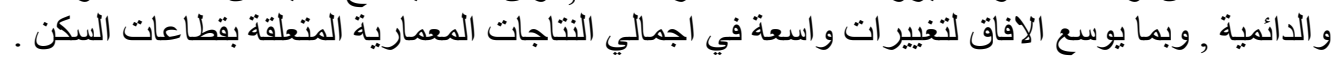

اتصفت المساكن الرقمية بصفات شكلية على مستوى كل من عناصر الثكل و العلاقات الخاصة بقو اعد التشكيل حيث

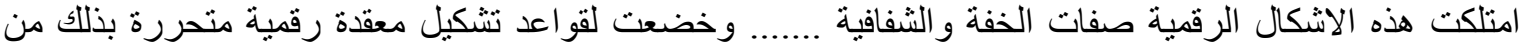
هيمنة الاشكال البسيطة و التقليدية ، التي لازمت لوقت طويل التيل النتاج الانماط المتداولة من اشكال المساكن .

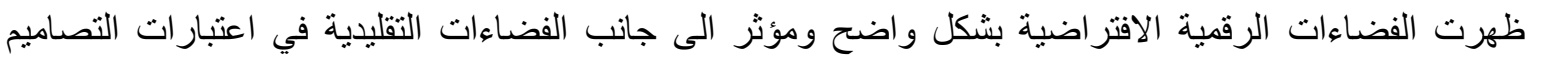

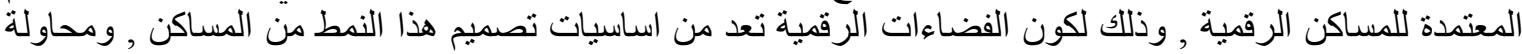

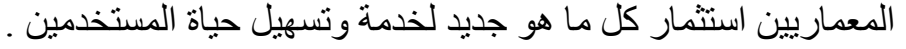

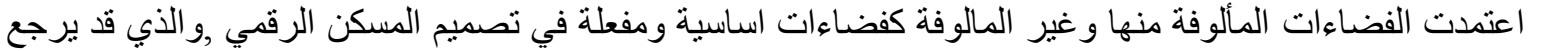

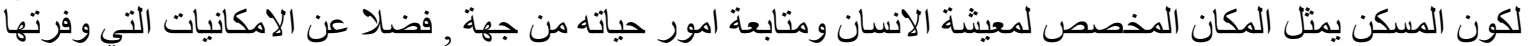

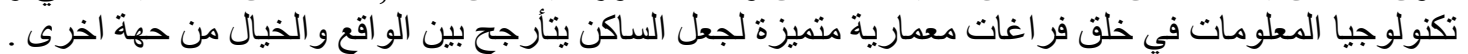

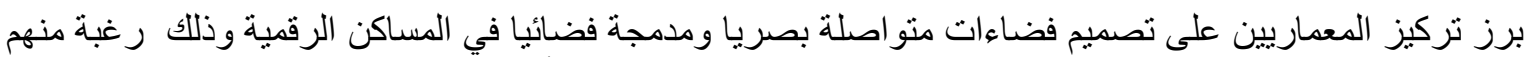

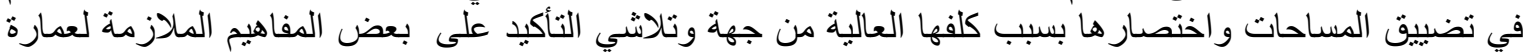

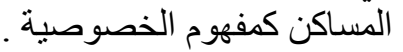


هدوث تغييرات في التشكيلات الوظيفية للاستخدامات السكنية , حيث تعددت وظائف الفضاء في المساكن الرقمية و تفعلت امكانية الدمج للوظائف المختلفة وممارستها في حيز و احد , وذللك بسبب تغير نوع الاحتياجات ومكان ونو عية الرية

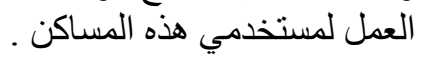

مثلت الفضاءات ذات الاتصال المكاني الى جانب نظيرتها ذات الاتصال الرقمي , ذات التات الاهمية في تصميم المساكن

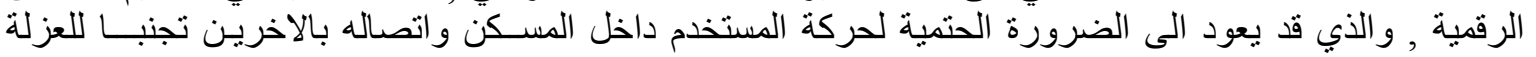

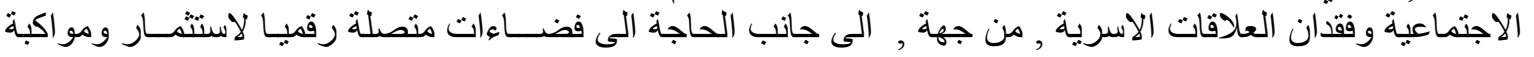

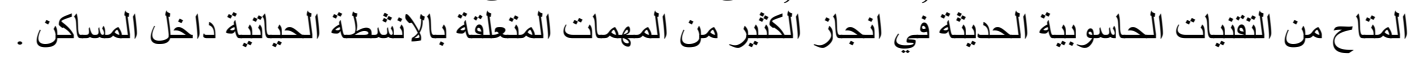

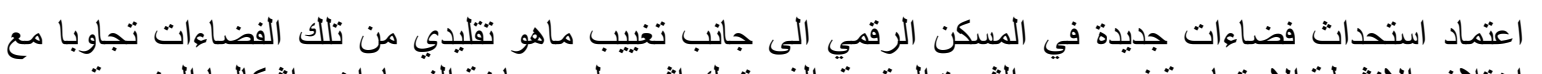
اختلاف الانشطة الاجتماعية في عصر الثورة الرقمية ,الذي ترك الثراء الثره على صياغة الفضاءات و اثنكالها الهندسية .

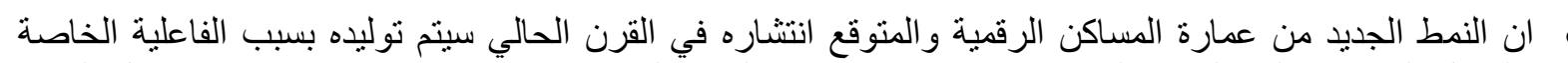

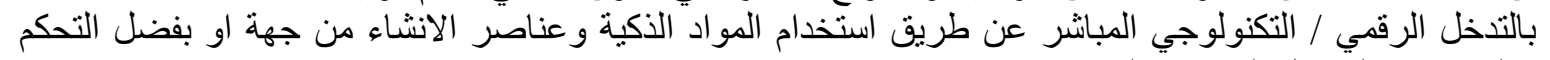
الالكتروني بالوسائل الخاصة بالتبنفيذ وستر التيجياته من جهة ثنانية.

\section{من ناحية الجواتب المرتبطة بالاتشطة الحياتية :}

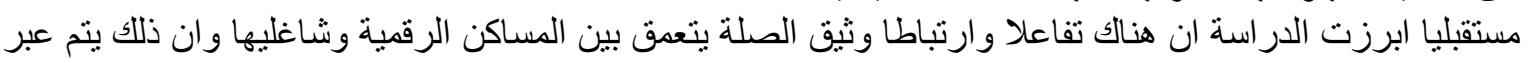

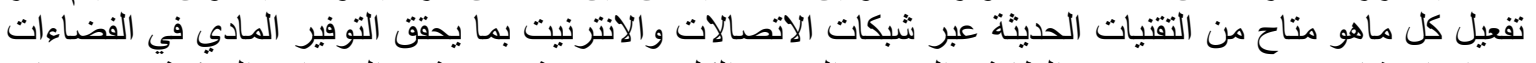

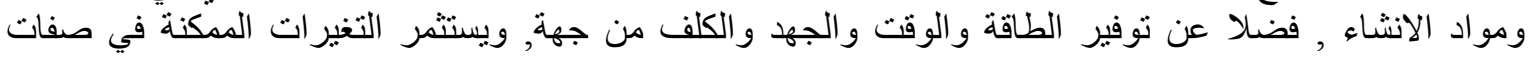
العناصر التصميمية بو اسطة التحكم الرقمي لتحقيق الاهدية واف البيأية و المناخية واستغلال مصادر الطاقة البديلة من جهة

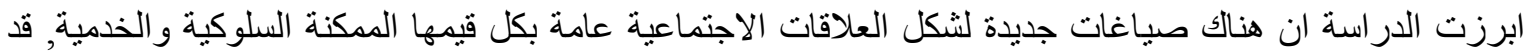

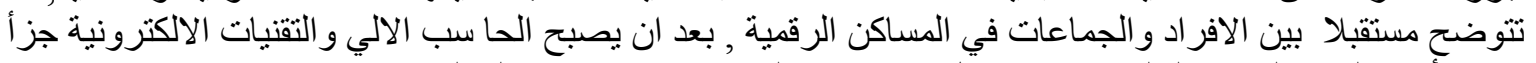

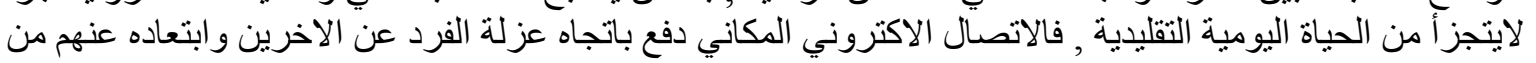

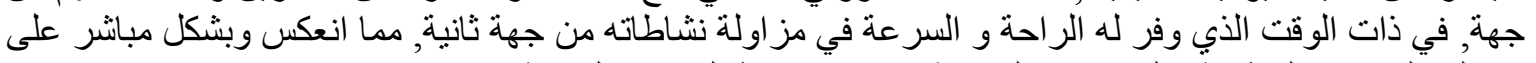

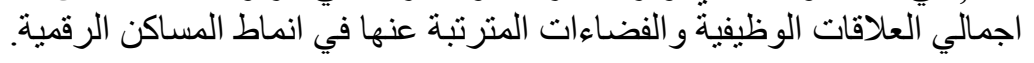

ان انوظيف التقنيات الحديثة في تصميم المساكن الرقمية قد يساهم الى حد كبير في التعديل من السلوك الكانس الانساني ويفسح

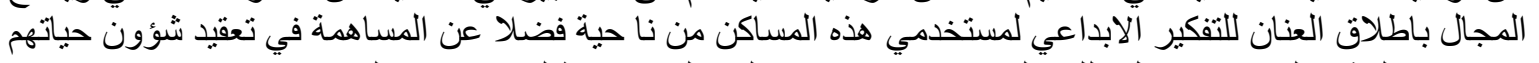

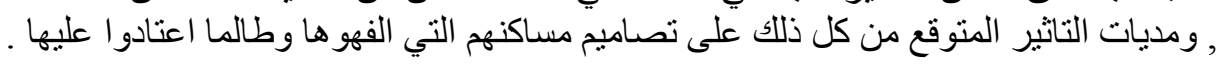

• اعتماد التدخل الرقمي في انجاز الانشطة الخدمية لثاغلي المساكن الرقمية من النواحي الترفيهية والامنية والثقافية

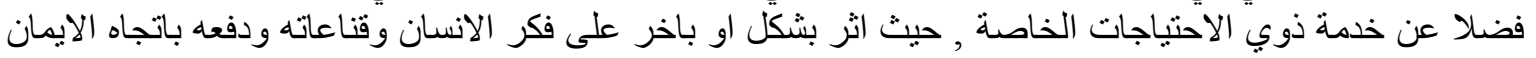

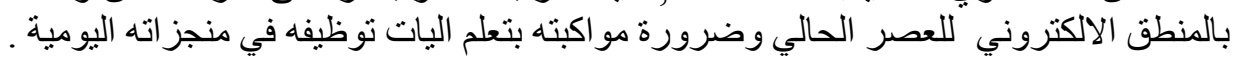

2-6 20 الاستنتاجات العامة برز التعقيد كصفة غالبة للانماط الثكلية الخاصة بالمساكن الرقمية وعلى مستوى كل من هيئات الثكل و التحو لات

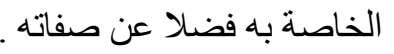

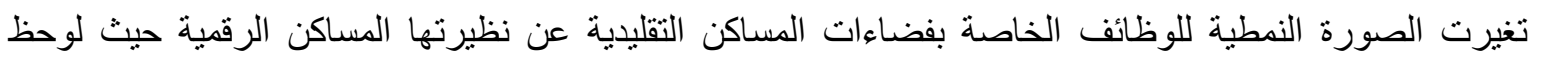

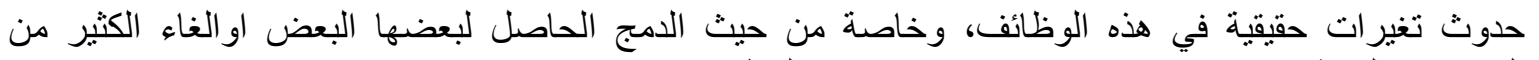

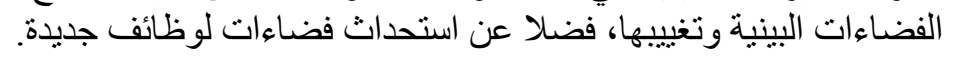

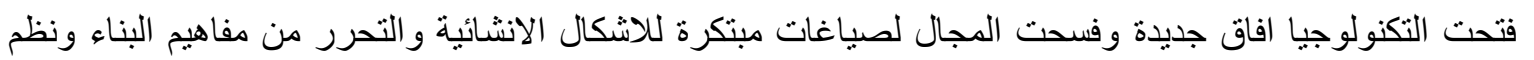

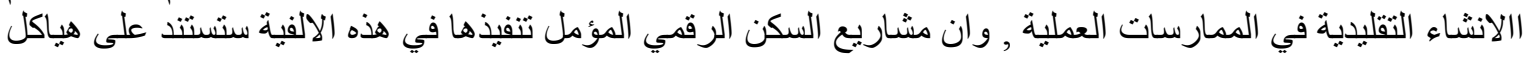


انشائية جديدة ومبتكرة وتشكيلات غير مسبوقة الاستخدام اشبه بالخيال, وان ذللك سبتفعل الكترونيا من خلال التكامل

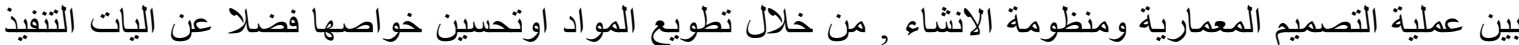
المؤتمة المستخدمة في انشائها وتثكيلها.

استدلت الدر اسة الى وجود كم من التأثير ات الخاصة بانظمة الحاسب الالي وتقنية المعلومات في النشاط الحياتي ببعديه

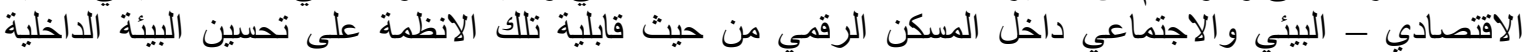

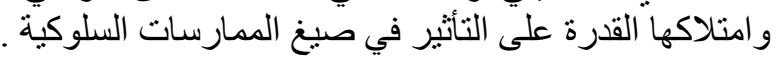

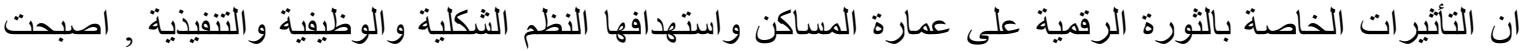

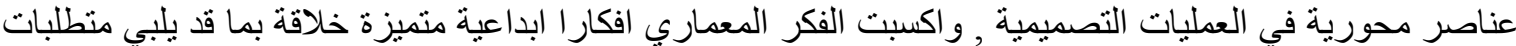
الاعمال التصميمية الناتجة , و المتطلبات الخاصة بمستخدمي تلك المساكن فضلا عن قابليلتها التعبيرية عن الحقبة

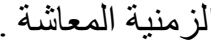

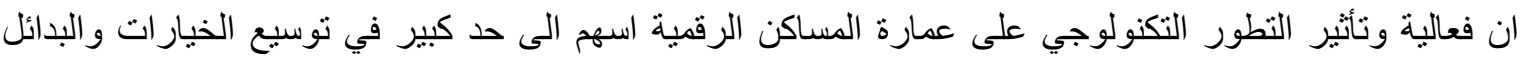

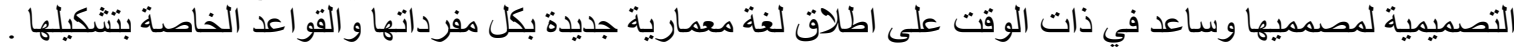

هابتعدت انماط المساكن الرقمية الى حد ما عن هوية واصالة وروح المكان المصممة فيه ، كون التوجهات الفكرية

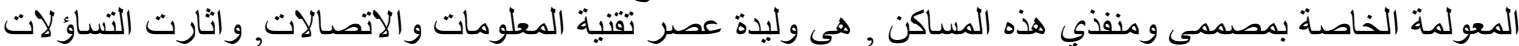

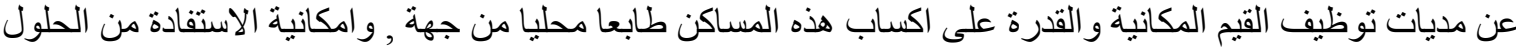

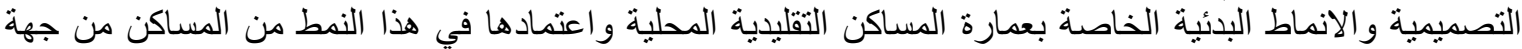

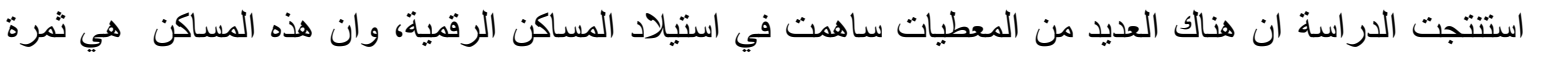

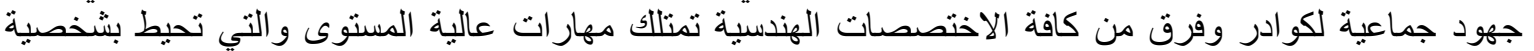

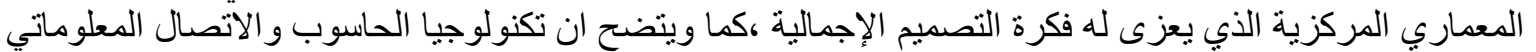

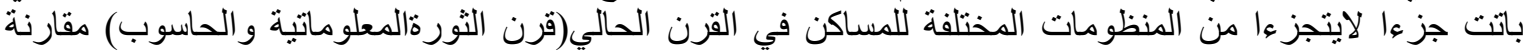

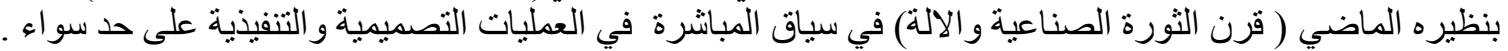

3-6 - 3 التوصيات

وبشكل عام فإنه يمكن تقديم التوصيات التالية:

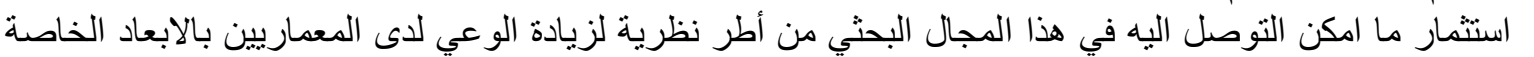

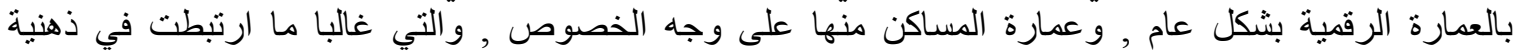

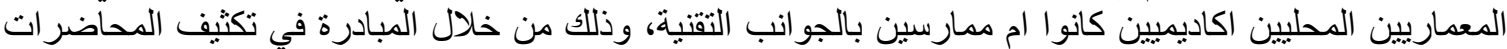

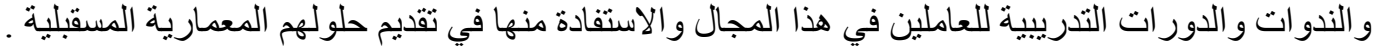

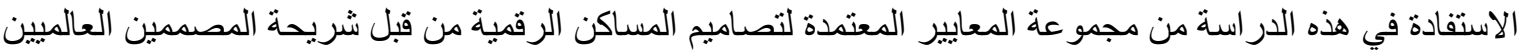

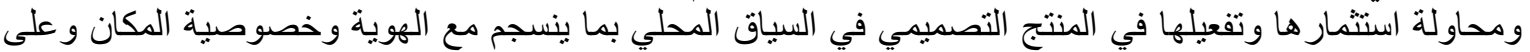

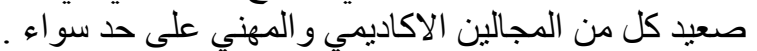

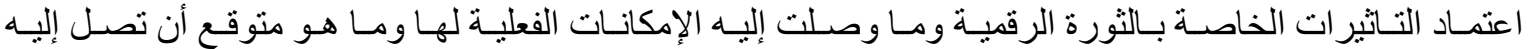

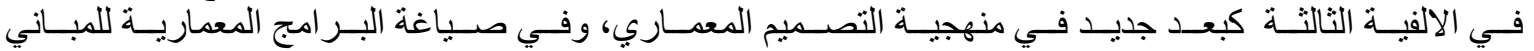

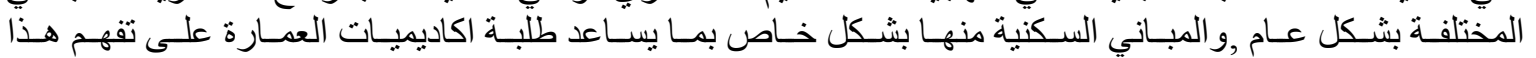

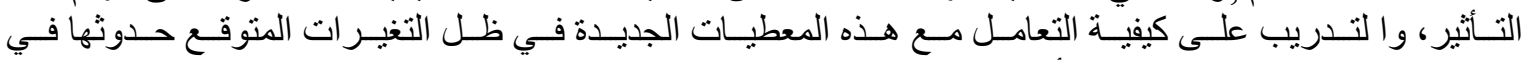

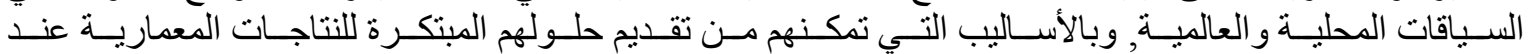
ممارسة العمل التصميمي اكاديميا ومهنيا. 


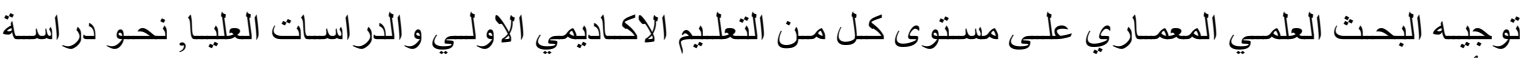

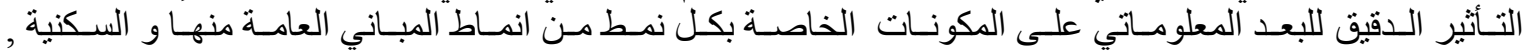

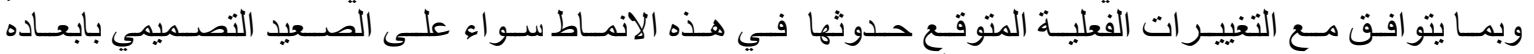

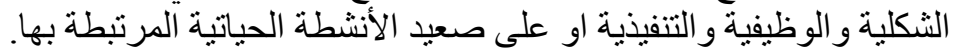

\section{المصادر العربية والاجنبية}

1- البجاري ، احمد لؤي ، " الاستدامة في العمارة الداخلية - اثر التكنولوجيا الرقمية في التشكلات التتبؤئية

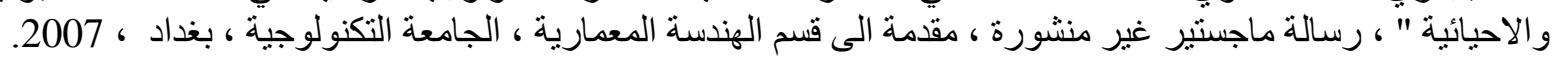
2- ثابت ، ن ـ م ، " استخدام المخلفات كمو اد بناء بديلة للمواد التقليدية " ، مؤتمر الاز هر الدولي الثنامن ، كلية الهندسة ،

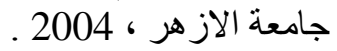
3- جيتس، بيل، ترجمة عبد العبد السلام رضوان ، " المعلوماتية بعد الانترنيت " ، طريق المستقبل ، سلسلة عالم المعرفة ،

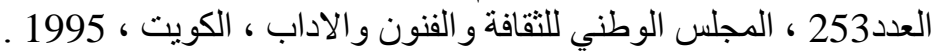

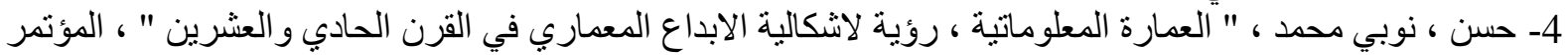

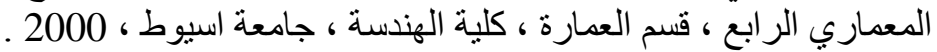

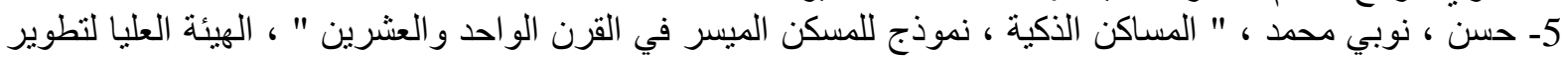

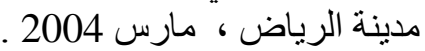

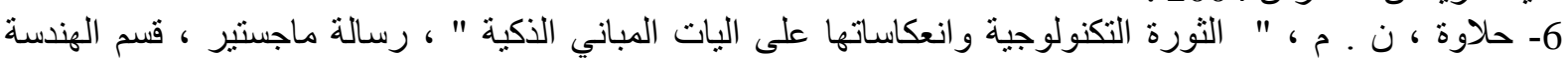

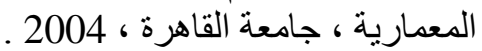

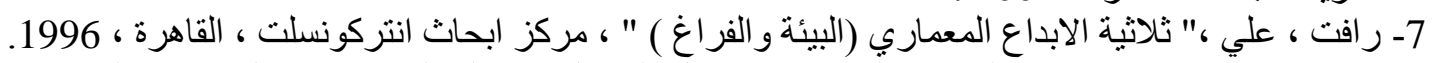

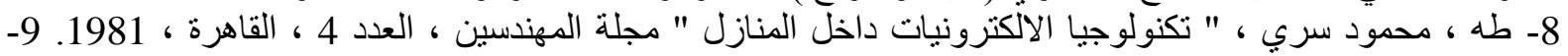

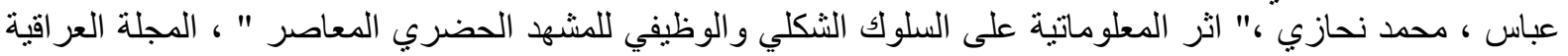

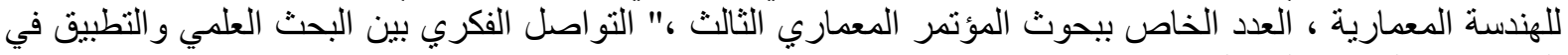

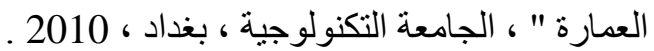

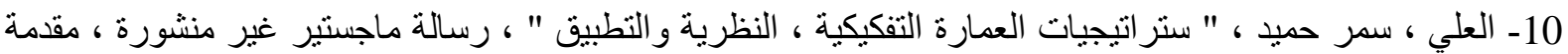

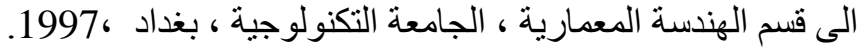
11- العلي ، ناصر ،" البيوة العية الذكبة طفرة معمارية مقبلة على مفهوم جديد للمسكن " ، الصحيفة الاقتصادية الالكترونية

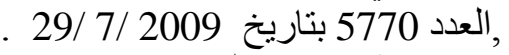
12- غيطاس ، جمال محمد " مشاهد من الحياة الرقمية ـ ـ اول تجربة للحياة داخل المنزل الرقمي " ، جريدة الاهر ام

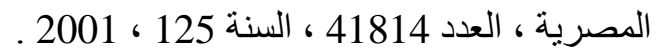
13- كاكو ، ميتشو ، ترجمة سعد الدين خرفان ، الدون ، " رؤى مستقبلية : كيف سيغير العلم عالمنا وحياتك ؟ " ، سلسلة عالم

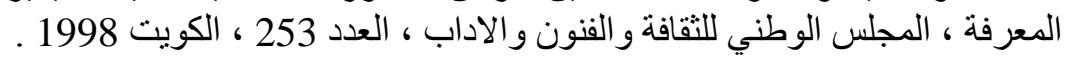

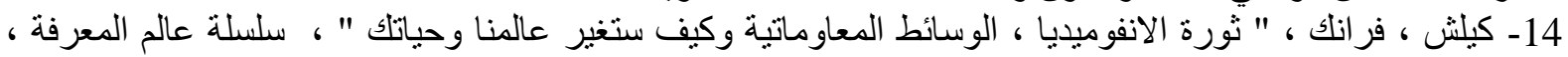

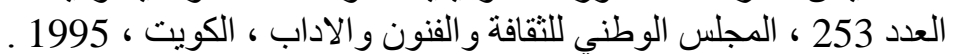

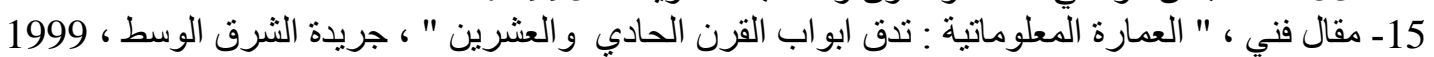

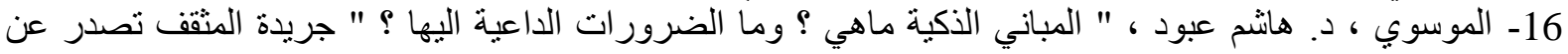

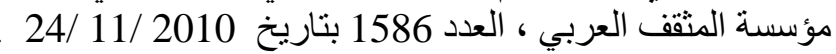

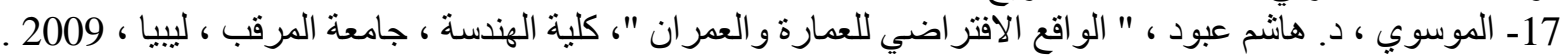

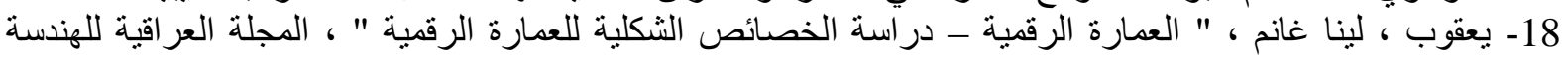

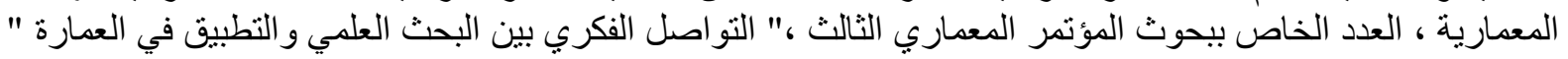

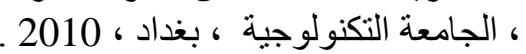

19- Castle, H. ;" Editoria" in Digital Citiets;Architectral Design magazine / Vol 79; No 4; July ;/August; 2009.

20- Chiardia , A. ;" Spatial Design Economies"; in Digital Citiets;Architectral Design magazine / Vol 79 ;No 4; July ;/August; 2009.

21- Gao , W. P. , " Tectonics", National Graduate Institute of Architecture , Chiao - Tung University, Taiwan 2003 , Roc, 2003. 
22- Ibrahim , A. , " New Architecture Forms in Digital Age " , Master Theses, Department of Architecture, Faculty of Fine Art, Alexandria University , 2003.

23- Leach ,N. ; "Digital "; in Digital Citiets;Architectral Design magazine / "Vol 79;No 4; July ;/August; 2009.

24- Lynch , K. , " A Theory of Good City Form " , Mit Press , Massachusetts , by Massachussets Institute of Tecnology, New York, 1981.

25- Nicholas N. , " Being Digital "Vintage Books , USA, 1995

26- Riewoldt , O. , " Intelligent spaces, Architecture for the information Age ", Laurence King , Hong Kong, 1997.

27- Roche ,F. ;"Extract of Neighbourhood Protocols"; in Digital Citiets; Architectral Design magazine / Vol 79 ;No 4; July ;/August; 2009

28- Verebes, T. ;" Experiments in Associative Urbanism "; in Digital Citiets ; Architectral Design magazine / Vol 79 ;No 4; July ;/August; 2009.

29- Yeang, Ken , " The skyscraper , bioclimatically considered " , Great Britain , 1996 , by Academy Edition LTD .

تم اجراء البحث فى كلية ألهندسة = جامعة ألموصل 